\title{
AN ECONOMIC ANALYSIS OF CHILDREN'S BEHAVIOR AND ACADEMIC EXPERIENCES IN CANADIAN SCHOOLS
}

\author{
By
}

\section{Wen Ci}

A thesis submitted to

The Faculty of Graduate and Postdoctoral Affairs in partial fulfillment

of the requirements for the degree of

Doctor of Philosophy

Department of Economics

Carleton University

Ottawa, Ontario

CCopyright 2013. Wen $\mathrm{Ci}$ 


\section{Dedication}

To My Mother: Jinfang Tang 


\begin{abstract}
Using a confidential Canadian dataset of children and youth (National Longitudinal Survey of Children and Youth), I have provided empirical evidence of the school performance, bullying behavior, and language immersion of children in four chapters of the $\mathrm{Ph} . \mathrm{D}$. thesis.
\end{abstract}

In the first chapter, the academic performance of children of immigrants is compared with that of their classmates of Canadian-born parents. The comparison starts when children are in kindergarten and continues until they grow up to become adolescents.

In the second chapter, the bullying behavior of children is explored. This chapter focuses on the identification of causality between parental control and children's bullying behavior, which is generally under-investigated in the existing literature. First, we build a theoretical model to capture the strategic dependence of children's bullying behavior and the corresponding parental control. Then, we employ conditional fixed effects logistic estimation to test the theoretical conclusions. The empirical results support our hypothesis that stricter disciplinary measures taken by parents are more effective in deterring the child from bullying when all the other factors are held constant. The causality is carefully justified by making great efforts to account for all possible identification issues.

Chapter 3 studies the children's bullying behavior in a dynamic scenario by answering the question of when is the best time to stop bullying. Results from the semi-parametric propensity score matching suggest that early bullying detection and intervention contributes to a positive suppression effect on it.

In the last chapter, we provide empirical evidence on who are in French immersion programs and who are more likely to drop out of French immersion. Results from the two-stage 
least-squares estimation indicate that children with higher reading ability are more likely to enter French immersion programs. Both simple logistic estimation and duration analysis produce similar conclusions on French immersion attrition, implying that children who have higher hyperactivity scores tend to drop out of the program if they have a female teacher. Two explanations are provided: 1) hyperactive children might relate better to male teachers; and 2) female teachers may be less tolerant to children with behavioral problems. 


\section{Acknowledgements}

I would like to thank Christopher Worswick for supervision of this Ph.D. thesis; Catherine Deri Armstrong, Marel Voia, Lynda Khalaf for providing useful comments in the previous thesis workshops; Frances Woolley, Ba Chu, José C. Galdo for participating in the brown bag Ph.D. session and giving valuable feedbacks to my papers at Carleton University; Kim Huynh for helpful suggestions during the Bank of Canada-Carleton Symposium, 2012; Linhui Zhang, Courtney Ward, Derek Pyne, and Brian Krauth for comments at 2012 Calgary CEA meeting; Michael Haan, Ted McDonald, Weiqiu Yu, and Michael Farnworth for providing useful comments during the workshop at the University of New Brunswick; Jean-Michel Billette, Zacharie Tsala Dimbuene and Nan Zhou of Statistics Canada for vetting the results. Special thanks to my husband Andy Wang for editing this thesis. 


\section{Table of Contents}

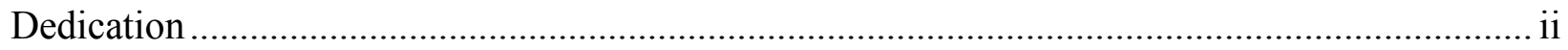

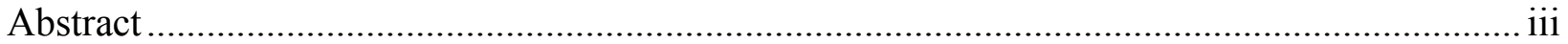

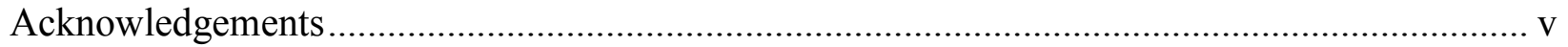

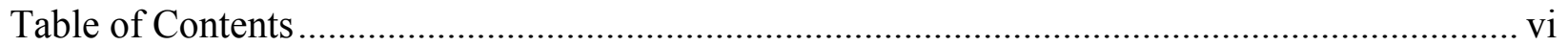

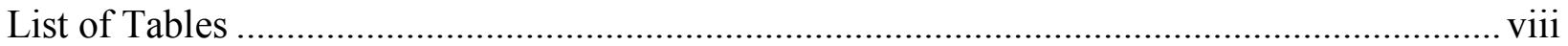

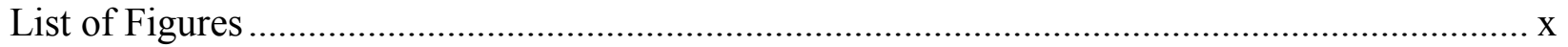

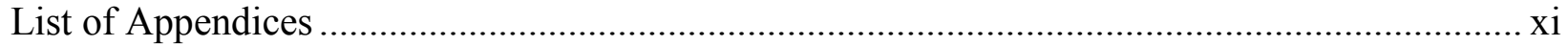

Chapter 1 The Assimilation of Children of Immigrants in Canadian Schools: up to 14 years of Longitudinal Tracking from Kindergarten to High School .................................................... 1

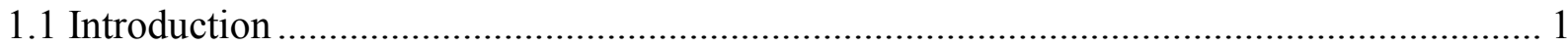

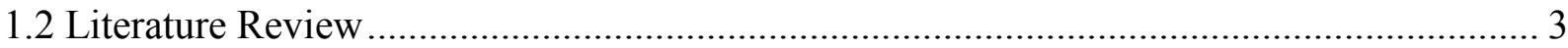

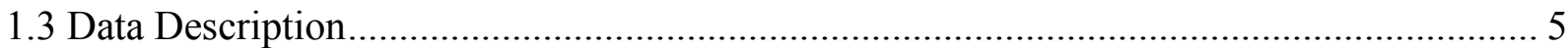

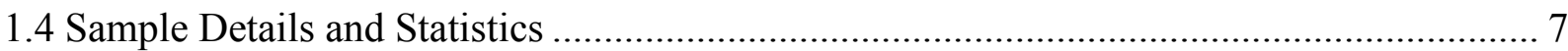

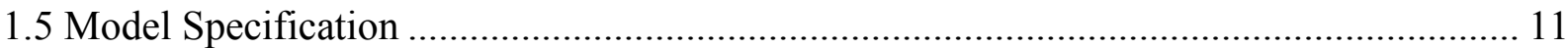

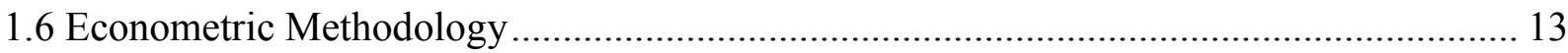

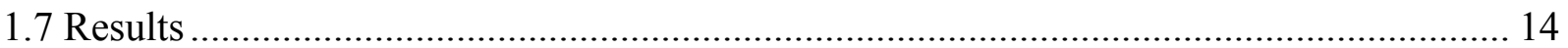

1.7.1 Longitudinal Regression Results ....................................................................... 14

1.7.2 Cross-sectional Regression Results .................................................................... 19

1.8 Assimilation process of the school performance of children of immigrants..................... 23

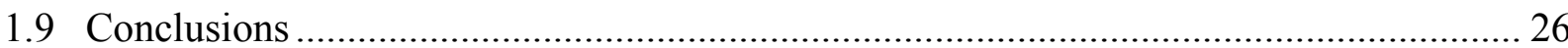

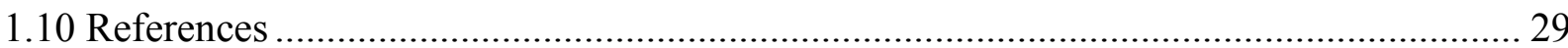

Chapter 2 Is there a 'Tiger Mother' effect on Bullying? Theory and Evidence for Canada ... 33

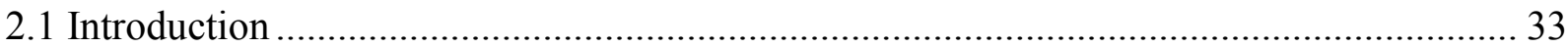

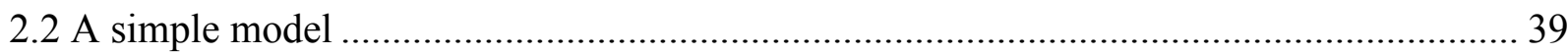

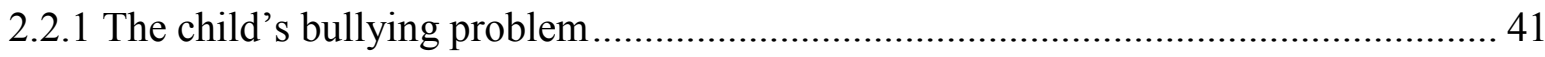

2.2.2 The parent's control problem........................................................................ 42

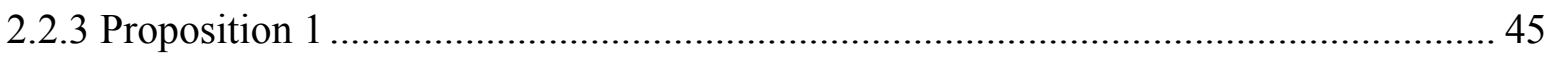

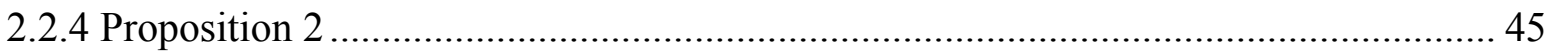

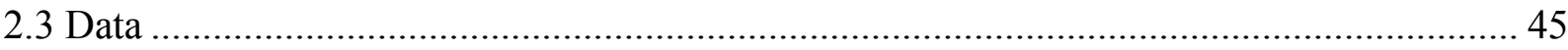

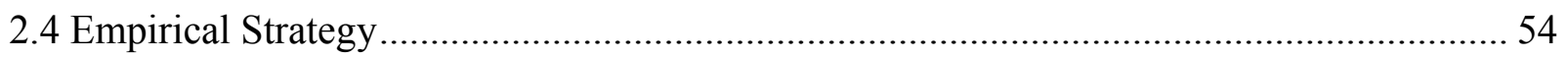

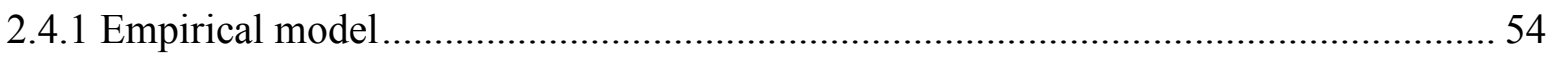

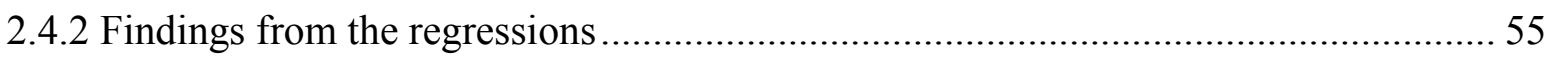

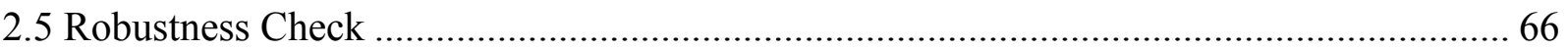




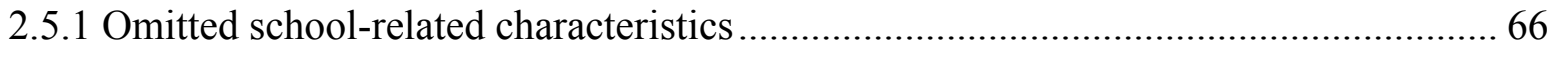

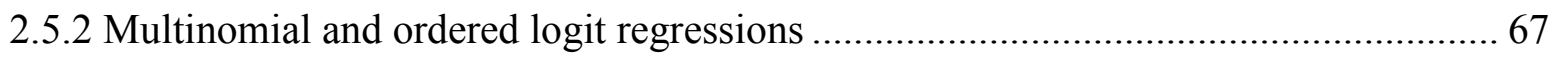

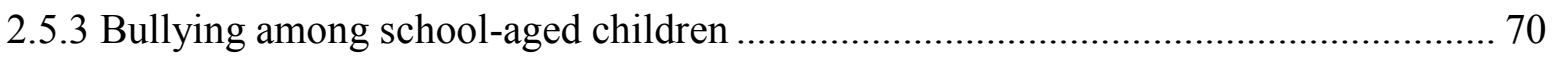

2.5.4 Estimation with all the relevant controls and the fixed effects sample selection bias. 72

2.5.5 A note on the instrumental variable estimation ........................................................ 77

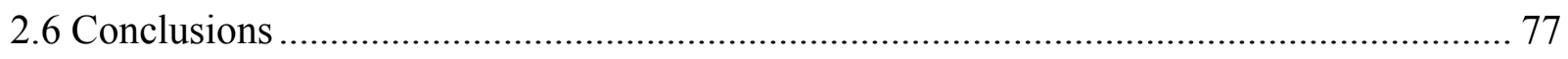

2.7 Reference

Chapter 3 Timing Matters in Stopping Bullying among Children: an Empirical Study Using a

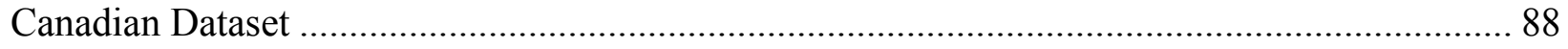

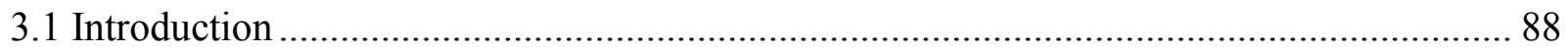

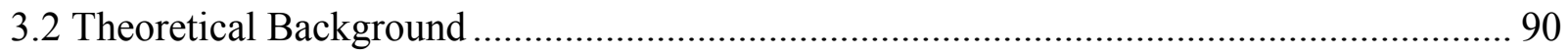

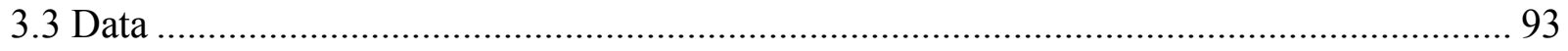

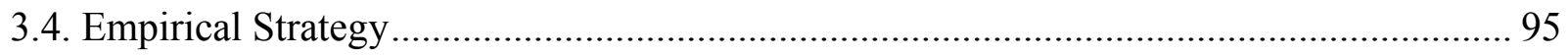

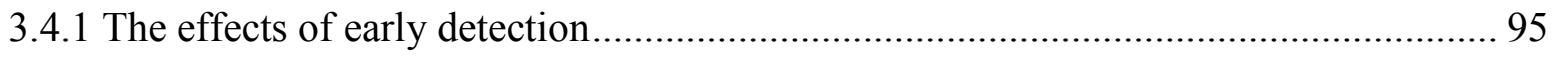

3.4.2 Results from the propensity score matching evaluation ............................................ 103

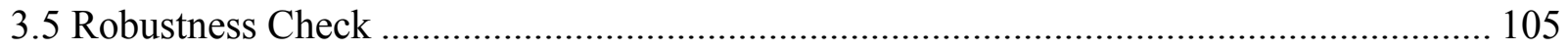

3.5.1 Sensitivity analysis of hidden bias in the matching .............................................. 105

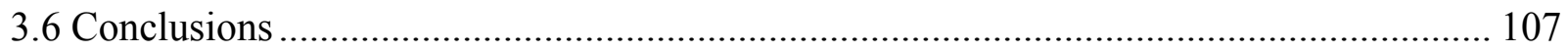

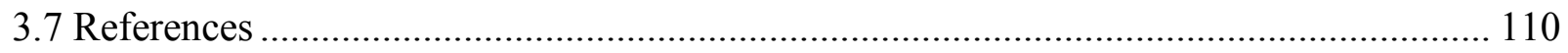

Chapter 4 Who Entered and Who Left? School Program Streaming and Attrition: Evidence from French Immersion Programs ................................................................................. 115

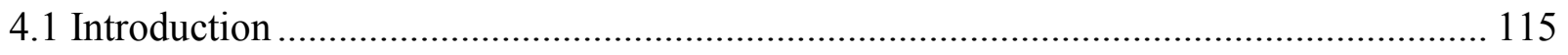

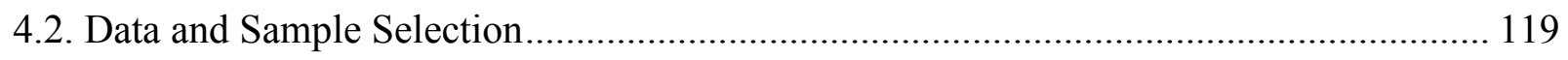

4.3 Preliminary evidence on Streaming by School Program Type ……………………....... 122

4.4. Estimation of Models of French Immersion Enrollment ................................................. 129

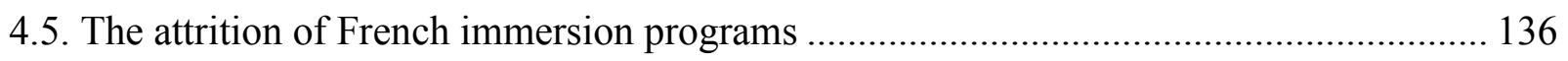

4.6. Sensitivity analysis of the change of the teacher's gender............................................ 145

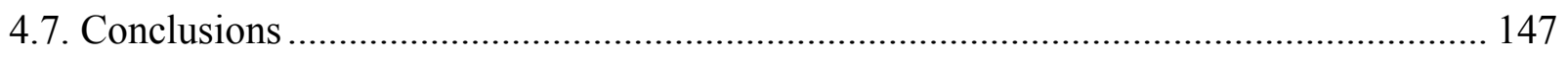

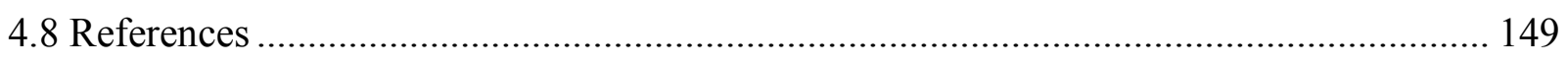

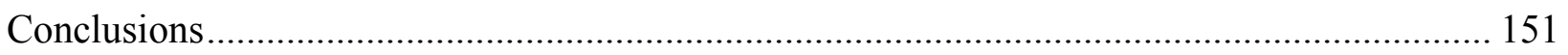




\section{List of Tables}

Table 1- Age ranges and available survey cycles for each test................................................... 6

Table 2 - Test Performance by PMK's Immigrant Status and Mother-tongue............................... 10

Table 3 - Two-stage estimation results of the reading and mathematics tests scores ................... 17

Table 4 - Estimation results for vocabulary, cognitive, literacy and numeracy scores ................. 21

Table 5 - The longitudinal attrition of the sample of PMK-reported bullying variable ............... 49

Table 6 - Summary statistics of age distributions of the PMK-reported sample .......................... 50

Table 7 - Descriptive statistics of parenting scores..................................................................... 51

Table 8 - Descriptive Statistics of other covariates.................................................................. 52

Table 9 - The estimated coefficients of regressions of PMK- reported child bullies.................... 62

Table 10 - The estimated coefficients of regressions of child bullies for girls and boys

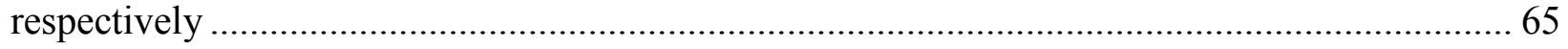

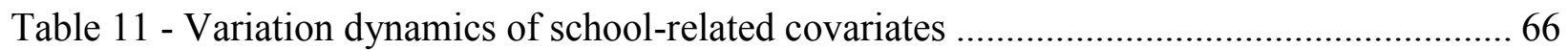

Table 12 - The estimated coefficients of multinomial logit and ordered Logit regressions of

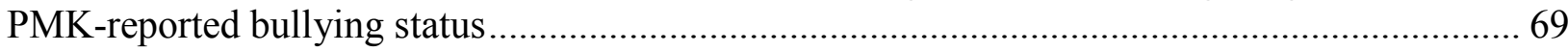

Table 13 - The estimated coefficients of regressions of PMK- reported school-aged child bullies

Table 14 - The estimated coefficients of regressions with all the possible determinants on

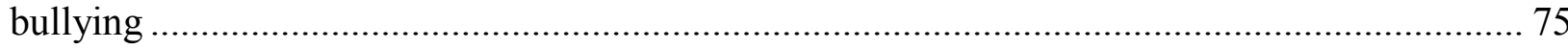

Table 15 - Descriptive statistics of bullying broken down by ages on the PMK-reported sample

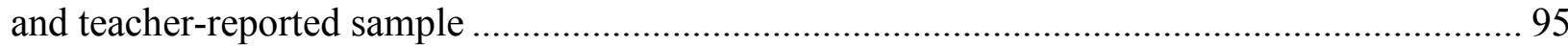

Table 16 - Covariates used to generate the propensity scores before matching ........................ 102

Table 17 - Average treatment effects of early detection of bullying on the outcome of bullying suppression with common support.

Table 18 - Rosenbaum Bounds test for the average treatment effects on the treated of the early

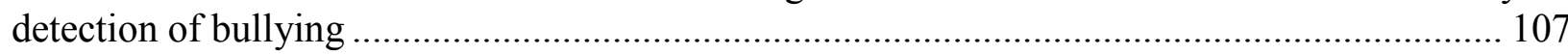

Table 19 - Cross tabulation of French immersion children by teachers and PMKs.................... 121

Table 20 - Sample means of demographic variables by school program type........................... 123

Table 21 - Sample means of parents' linguistic background by school program type .............. 124

Table 22 - Sample means of parental income, receipt of employment insurance income and social welfare assistance by school program type ………….................................................... 126

Table 23 - Sample means of test scores, behavior scores, and school achievement expectations by school program type.

Table 24 - Estimated marginal effects of Reduced Form and Instrumental Variable Models of French Immersion Enrollment. 
Table 25 - Dynamics of enrollment in French immersion programs from Cycle 3 to Cycle 4 broken down by ages ................................................................................................... 139

Table 26 - Estimation results of decisions of dropping out of French immersion programs ..... 144

Table 27 - Sensitivity analysis of the cox duration estimates to the choice of the gender of the teacher 


\section{List of Figures}

Figure 1 - The age composition of the sample of each cohort in the math test .............................. 8

Figure 2 - Test Score Differences: NEF Children Relative to the Children of Canadian-born

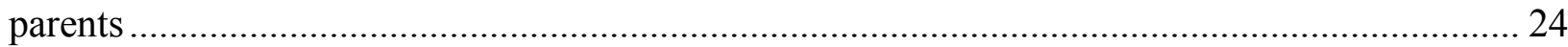

Figure 3 - Test Score Differences: EF Children Relative to the Children of Canadian-born

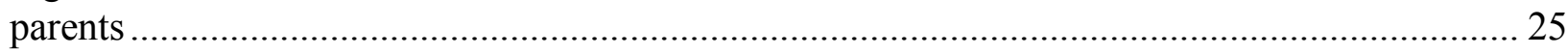

Figure 4 - The age dynamics of the PMK bullying sample ……………….............................. 48 


\section{List of Appendices}

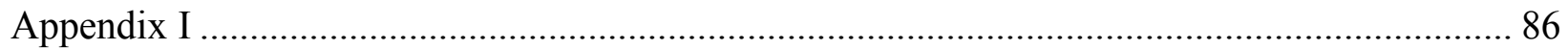

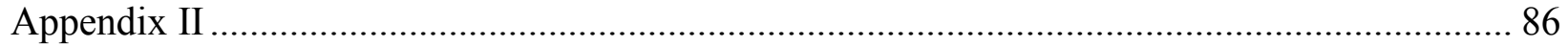

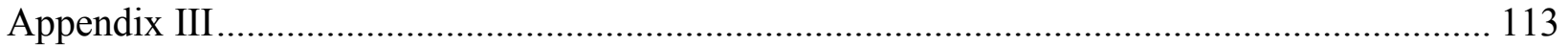




\section{Chapter 1 The Assimilation of Children of Immigrants in Canadian Schools: up to 14 years of Longitudinal Tracking from Kindergarten to High School}

\subsection{Introduction}

As a major immigrant-receiving country, Canada has a diverse population. Each year a large fraction of children enter Canadian elementary schools having been raised in families with a neither English nor French linguistic background. How these children succeed in their new school environment is an important part of an immigrant family's assimilation process to their new country.

In this paper, we use Canadian data (National longitudinal survey of children and youth) to conduct the comparison of the school performance of children with an immigrant parent to those of Canadian-born parents. Although most immigrants had some training in at least one of the official languages (English and French) before entry to Canada, there is still a distance in the language proficiency between the immigrants and domestic- born people ${ }^{1}$. Therefore, the children of immigrants who were either born outside of Canada or within Canada will be affected by their parents' lower fluency levels in Canada's official languages. Research has shown that the school attainment of children will be related to their family characteristics ${ }^{2}$, thus the school performance of the children of immigrants is expected to vary according to these family characteristics.

\footnotetext{
${ }^{1}$ Chiswick, Lee and Miller (2006); Chiswick and Miller(1994); Dustmann and Fabbri (2003).

${ }^{2}$ See, for examples, Sweetman (2002).
} 
Worswick (2004) was one of the first studies to compare the school performance of the children of immigrants to the performance of the children of Canadian-born parents. He found that children with an Allophone immigrant parent had lower scores in vocabulary test under age six relative to those with a native-born parent. By age 14, the difference in the reading and mathematics between the children of immigrants and those of Canadian-born parents disappeared. However, due to the limited number of survey years that are available at that time, that study was only able to carry out a partial assessment of the performance of these children in Canadian schools ( up to age 15). However, the difference in the academic achievement between children of immigrants and those with Canadian-born parents may possibly change during high school and may even be reversed compared to the case when the children were young, so the previous work by Worswick (2004) may fail to capture the full assimilation process.

Compared to the early work, this paper contributes in the following perspectives: 1) Five more data waves are available and instead of age 15 (as in Worswick, 2004), we are able to track the children to age 21 , which benefits both the cross-sectional and longitudinal analysis; 2) In addition to the original vocabulary, reading and mathematics test scores, three more test scores which are designed to evaluate the cognitive, literacy and numeracy abilities of adolescents are now available making it possible to draw a more thorough picture of the assimilation of the education achievements as the children mature into adulthood; 3) Cohort analysis is carried out on the mathematics test scores. 


\subsection{Literature Review}

Much of the immigration literature relates to the performance of immigrants in the new labor market using the native born as the comparison group ${ }^{3}$ and relatively little research on the educational and earnings achievements of their children has been carried out ${ }^{4}$. Recently, Liebig and Widmaier (2010) use an international comparison of the labour market performance of the children of immigrants in OECD countries and EU countries and find lower performance of Program for International Student Assessment (PISA) for the children of immigrants in most European OECD countries ${ }^{5}$. Damas de Matos (2010) finds that family characteristics play a significant role in explaining the relative school attainments of children of immigrants from Turkey, Morocco and ex-Yugoslavia. In Britain, Dustmann and Theodoropoulos (2010) find higher educational achievements, but lower employment probabilities, for children of immigrants who were born in Britain. Domingues Dos Santos and Wolff (2011) show that the educational attainments of the children of immigrants are related to their family background for the case of France.Using US data from the Early Childhood Longitudinal Survey—Kindergarten Cohort, Lahaie (2008) shows that early parents' participation plays a significant role in the improvement of English proficiency and math skills of children of immigrants. Cortes (2006) finds for the US, that the more years since immigration, the better the school performance attained by the first and second- generation immigrant children.

\footnotetext{
${ }^{3}$ Recent studies include: Aydemir and Skuterud (2005); Chiswick and Miller (2009); Dustmann and Fabbri (2003); Ferrer and Riddell (2004); Frenette and Morissette (2005); Green and Worswick (2012); Hum and Simpson (2004); Li (2003); Li (2000).

${ }^{4}$ Earlier research about the children of immigrants includes: Cummins (1992); Currie and Thomas (1990); Richmond and Mendoza (1990); Rumbaut (1997); Sweetman (2002); Wagner (1998).

${ }^{5}$ Similar research was also carried out by Health (2010); Schröder (2010).
} 
In Canada, Bonikowska and Hou (2011) indicate that the recent cohorts of children of immigrants who immigrated to Canada at age 12 or younger achieve higher success in education than those Canadian-born children by age 25 to 34 . Also, the recent cohorts of "childhood immigrants" have earnings which are either similar to or higher than those of the native born. McDonald and Worswick (2011) show that the probability of immigrant children completing an apprenticeship depends on whether their immigrant parents have obtained an apprenticeship credential. Aydemir, Chen, and Corak (2009) find that the second generation of immigrants only weakly carries the characteristics of their first generation in terms of level of earnings meaning that the children of immigrants can adjust to the Canadian school system and labor market very well. Finnie and Mueller (2009) show that rates of participation in post-secondary education are higher for first and second generation immigrants relative to the Canadian-born population. Abada, Hou and Ram (2008) report that university completion rates are higher among the children of immigrants from most source region groups in Canada, and this is especially true for those children of Chinese and Indian immigrants.

Also, a number of studies exist on the topic of assimilation as well as work performance of children of immigrants on the labor markets ${ }^{6}$. However, this study is distinguished from the existing research in terms of the following perspectives: (1) Unique Canadian NLSCY data allows us to track the same group of children over a very wide age range from 4 to 21 , (2) a variety of econometric methodologies are employed to account for the different model specifications (such as longitudinal research methods), and (3) various school performance

\footnotetext{
${ }^{6}$ Recent work includes Hum and Simpson (2007); Kroneberg (2008); Meurs, Pailhe and Simon (2006); Portes and Fernadez-Kelly (2008); Rumbaut (2008).
} 
indicators are available at different stages of life allowing for a thorough picture of the assimilation process of children of immigrants in Canadian schools.

\subsection{Data Description}

The analysis is based on confidential data from the master files of the National Longitudinal Survey of Children and Youth (NLSCY) of Statistics Canada. ${ }^{7}$ The eight cycles (1994/95, 1996/97, 1998/99, 2000/2001, 2002/2003, 2004/2005, 2006/2007, 2007/2008) are used in this analysis. We employ six school performance test scores as dependent variables: 1) the Peabody Picture Vocabulary test - revised (PPVT-R) score, 2) the mathematics computation test score, 3) the reading comprehension test score, 4) the literacy assessment score, 5) the numeracy assessment score, and 6) the cognitive measure score. The longitudinal weights are employed in the corresponding regressions and enable the longitudinal comparison of the school performance of the same group of children at different ages.

Table 1 below lists the age ranges of each test and the survey cycles in which each test was administered. The PPVT-R is available only in the first three cycles and was administered to children aged four and five and those aged six who had not yet been in grade two. The test evaluates the child's competency to recognize vocabulary. In cycle two, the reading comprehension test was introduced to evaluate the reading abilities of children in grade two and above. However, the reading test is only available in cycle two and cycle three: 1996/97 and 1998/99. The vocabulary and reading tests are the only two tests which have not been updated since the paper by Worswick (2004). All the other tests listed in Table 1 illustrated below are either newly updated or newly added after cycle three. The mathematics computation test is the only test which is administered to children through all eight cycles. Children in grade two and

\footnotetext{
${ }^{7}$ The data were accessed by the Author at the Carleton-Ottawa-Outaouais Research Data Centre.
} 
above (aged seven to 15) were able to take the mathematics test. The cognitive test was administered to youths aged 16 and 17 but was only introduced in cycle five and, after cycle six, it was no longer consistent with the previous versions. The literacy assessment which was designed to evaluate the youths' literacy abilities were performed on the youths aged 18 and 19 in cycles six, seven and eight. Also, in cycles six, seven and eight, the numeracy assessment was administered to youths aged 20 and 21.

Table 1 - Age ranges and available survey cycles for each test

\begin{tabular}{ccc}
\hline Test & Age range & Available cycles \\
\hline Vocabulary (PPVT-R) & $4-6$ & $1-3$ \\
Reading & $7-15$ & $2-3$ \\
Mathematics & $7-15$ & $1-8$ \\
Cognitive & $16-17$ & $5-6$ \\
Literacy & $18-19$ & $6-8$ \\
Numeracy & $20-21$ & $6-8$ \\
\hline
\end{tabular}

In the NLSCY data, the information on the child and his/her family background is reported by his/her PMK, the person who is most knowledgeable about the child. In each cycle the PMK is the child's mother for approximately 90 percent of children (including biological mother, step mother, adoptive mother or foster mother). Thus, in this analysis, we can safely treat the PMK as the child's mother.

To better account for the differences among children, we divide them into different groups not only by their PMK's immigration status but also by their PMK's mother-tongue language (following the approach of Worswick, 2004). Thus, the analysis is carried out for three groups of children: 1) children with a Canadian-born PMK (CB), 2) children with either an 
Anglophone or Francophone immigrant $\mathrm{PMK}^{8}(\mathrm{EF})$ and 3) children with an Allophone immigrant $\mathrm{PMK}^{9}(\mathrm{NEF})$. As the same group of children are tracked across cycles in the NLSCY, we should expect that the PMK of the child who responds to the survey to change across cycles. However, the actual number of children whose PMK's immigrant status changes over years of the survey is not substantial and unlikely to affect our results with the change being around 0.4 percent from cycle one to cycle two, 0.3 percent from cycle two to cycle three, 0.09 percent from cycle three to cycle four, and 0.2 percent from cycle four to cycle five. Additionally, after cycle five of the NLSCY, much of the information on the PMK of youths who are older than 16 years old is no longer collected in the data; consequently, we employ the child's most recent previous information on the PMK in our analysis.

The NLSCY sample frame does not contain a large number of children who were actually born outside of Canada ${ }^{10}$. We focus on all children whose PMK was an immigrant and refer to this group of children as the children of immigrant parents (whether or not the child was born in Canada).

\subsection{Sample Details and Statistics}

Due to the limited cycles in which each test is available and age restrictions, the vocabulary test, literacy assessment, numeracy assessment and cognitive measurement were mainly administered to the cross-sectional children ${ }^{11}$ over the eligible age ranges. However, the samples of the

\footnotetext{
${ }^{8}$ An Anglophone parent is defined as a PMK whose mother tongue is English. A Francophone parent is defined as a PMK whose mother tongue is French.

${ }^{9}$ An allophone parent is defined as a PMK whose mother tongue is neither English nor French.

${ }^{10}$ In all the regression models, approximately 87 percent children of immigrants were born in Canada (second generation of immigrants), while only roughly 13 percent are the first generation of immigrants who were born outside of Canada. (This calculation is based on the average of the percentages in all eight cycles).

${ }^{11}$ Cross-sectional children are those who exist in the sample for only one cycle.
} 
mathematics test and the reading test contain the longitudinal children ${ }^{12}$ who were tracked in the following cycles within the age range. The youths in the samples of the literacy assessment, the numeracy assessment and the cognitive measurement are part of those who appeared in the samples of the vocabulary test, mathematics test and the reading test.

Figure 1 below reveals the age composition of the math test scores in each cohort. There are new entrants entering in the math test in cycles one, two, three and four, and there are children leaving the test in cycles five, six, seven and eight. Cohort analysis is necessary in this situation due to the changing composition of the pooled sample of children with math test scores. Children who first took the math test in cycle one are defined to be in cohort one, those who first took the math test in cycle two are in cohort two, and etc.

\section{Figure 1 - The age composition of the sample of each cohort in the math test}

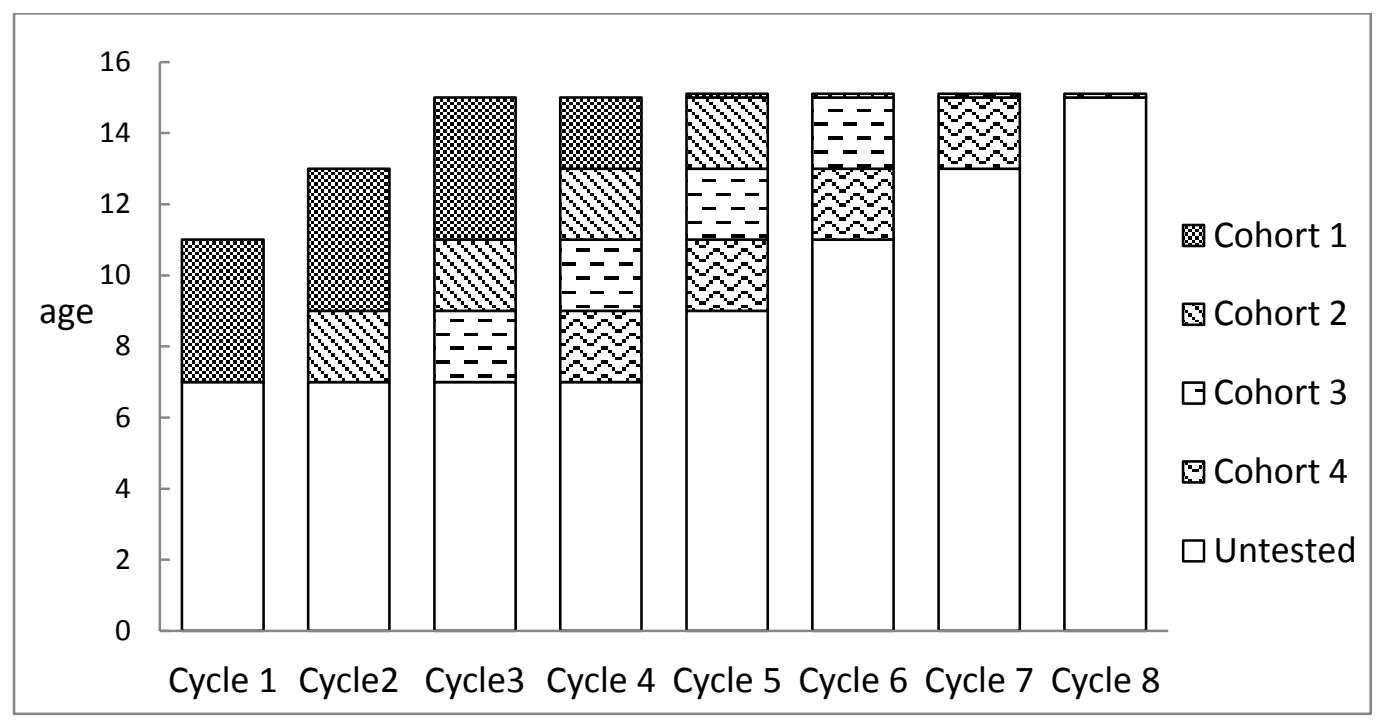

\footnotetext{
${ }^{12}$ Longitudinal children are the children who appeared in the sample and then were tracked through at least one of the following cycles.
} 
Table 2 below presents sample means, standard deviations, and sample sizes of the test scores by their PMK's immigrant status and mother tongue language. The vocabulary test scores of the children of immigrant parents are significantly lower by roughly 40 percent of one standard deviation (17.43) than those of children of Canadian-born parents. This result is similar to what was found by Worswick (2004). Children with an Anglophone or Francophone immigrant parent (EF children) have average vocabulary test scores that do not significantly differ from the mean scores for children of Canadian-born parents (CB children), while the vocabulary scores of children with an Allophone immigrant parent (NEF children) are significantly lower than those of children of native-born parents by approximately seventy percent of one standard deviation (16.79) of the test score. However, compared to the children whose PMK was born in Canada, higher mean scores in the reading test were found to be significant at one percent level for EF children and NEF children have similar average reading scores.

According to the mean score comparisons, both EF children and NEF children performed better in the mathematics test than did the children of Canadian-born parents in cohorts one, three and four. No significant difference was found between the math scores of the two groups of children of immigrants in cohort two and those in the $\mathrm{CB}$ comparison group.

The EF children do not have the significantly different performance from the CB children on the literacy assessment, numeracy assessment or cognitive assessment, while the NEF children do have significantly higher performance (at the ten percent level) than do the children of Canadian-born parents on the cognitive assessment and numeracy assessment. For the case of the literacy assessment, the scores of NEF children are not significantly different relative to the scores of children of native-born parents. 
Table 2 - Test Performance by PMK's Immigrant Status and Mother-tongue

\begin{tabular}{|c|c|c|c|c|}
\hline $\begin{array}{l}\text { Status } \\
\text { Categories } \\
\text { of Children }\end{array}$ & $\begin{array}{c}\text { Children of } \\
\text { Canadian- } \\
\text { born } \\
\text { Parent(CB) }\end{array}$ & $\begin{array}{c}\text { Children of } \\
\text { immigrant } \\
\text { parent }\end{array}$ & $\begin{array}{c}\text { Children of } \\
\text { Anglophone or } \\
\text { Francophone } \\
\text { immigrant } \\
\text { Parent(EF) }\end{array}$ & $\begin{array}{c}\text { Children of } \\
\text { Allophone } \\
\text { Immigrant } \\
\text { Parent (NEF) }\end{array}$ \\
\hline Vocabulary & $\begin{array}{l}100.32 \\
(14.76) \\
{[14071]}\end{array}$ & $\begin{array}{c}92.94 * * * \\
(17.43) \\
{[1417]}\end{array}$ & $\begin{array}{c}99.79 \\
(16.06) \\
{[616]}\end{array}$ & $\begin{array}{c}88.34 * * * \\
(16.79) \\
{[801]}\end{array}$ \\
\hline Reading & $\begin{array}{c}99.93 \\
(14.79) \\
{[9728]}\end{array}$ & $\begin{array}{c}100.36^{* *} \\
(16.01) \\
{[811]}\end{array}$ & $\begin{array}{c}104.16^{* * *} \\
(15.29) \\
{[389]}\end{array}$ & $\begin{array}{c}97.42 \\
(15.95) \\
{[422]}\end{array}$ \\
\hline $\begin{array}{l}\text { Mathematics } \\
\text { Cohort } 1\end{array}$ & $\begin{array}{c}99.75 \\
(14.82) \\
{[10373]}\end{array}$ & $\begin{array}{c}101.03 * * * \\
(15.98) \\
{[869]}\end{array}$ & $\begin{array}{c}101.49 * \\
(15.84) \\
{[464]}\end{array}$ & $\begin{array}{c}100.13^{* * *} \\
(15.18) \\
{[408]}\end{array}$ \\
\hline $\begin{array}{c}\text { Mathematics } \\
\text { Cohort } 2\end{array}$ & $\begin{array}{c}99.79 \\
(14.86) \\
{[6935]}\end{array}$ & $\begin{array}{c}100.98 \\
(16.45) \\
{[497]} \\
\end{array}$ & $\begin{array}{c}102.41 \\
(17.33) \\
{[247]} \\
\end{array}$ & $\begin{array}{c}100.05 \\
(14.86) \\
{[286]}\end{array}$ \\
\hline $\begin{array}{l}\text { Mathematics } \\
\text { Cohort } 3\end{array}$ & $\begin{array}{c}99.90 \\
(14.81) \\
{[6718]}\end{array}$ & $\begin{array}{c}101.90 * * * \\
(15.61) \\
{[527]}\end{array}$ & $\begin{array}{c}102.80 * * \\
(16.06) \\
{[265]}\end{array}$ & $\begin{array}{c}101.77 * * \\
(15.78) \\
{[251]} \\
\end{array}$ \\
\hline $\begin{array}{l}\text { Mathematics } \\
\text { Cohort } 4\end{array}$ & $\begin{array}{c}99.71 \\
(14.98) \\
{[10465]}\end{array}$ & $\begin{array}{c}101.67 * * * \\
(14.93) \\
{[911]}\end{array}$ & $\begin{array}{c}101.06 * * * \\
(15.21) \\
{[374]}\end{array}$ & $\begin{array}{c}103.41 * * * \\
(14.85) \\
{[446]}\end{array}$ \\
\hline $\begin{array}{c}\text { Cognitive } \\
\text { Assessment }\end{array}$ & $\begin{array}{c}99.41 \\
(14.84) \\
{[2214]}\end{array}$ & $\begin{array}{c}103.37 * * \\
(15.49) \\
{[170]}\end{array}$ & $\begin{array}{c}102.65 \\
(16.04) \\
{[102]}\end{array}$ & $\begin{array}{c}104.58 * \\
(14.57) \\
{[68]}\end{array}$ \\
\hline $\begin{array}{c}\text { Literacy } \\
\text { Assessment }\end{array}$ & $\begin{array}{l}100.07 \\
(14.80) \\
{[1893]}\end{array}$ & $\begin{array}{c}99.49 \\
(15.89) \\
{[135]}\end{array}$ & $\begin{array}{c}100.66 \\
(16.43) \\
{[81]}\end{array}$ & $\begin{array}{c}97.97 \\
(15.18) \\
{[54]}\end{array}$ \\
\hline $\begin{array}{l}\text { Numeracy } \\
\text { Assessment }\end{array}$ & $\begin{array}{c}99.99 \\
(14.84) \\
{[1676]}\end{array}$ & $\begin{array}{c}100.06 \\
(16.52) \\
{[119]}\end{array}$ & $\begin{array}{c}98.11 \\
(18.19) \\
{[69]}\end{array}$ & $\begin{array}{c}102.96 * \\
(13.32) \\
{[50]}\end{array}$ \\
\hline \multicolumn{5}{|c|}{$\begin{array}{l}\text { Notes. } \\
\text { 1. All the test scores have been adjusted to have the same mean (100) and the same } \\
\text { standard deviation (15) as those of the vocabulary test scores. } \\
\text { 2. The significance tests of the difference in the sample means between the group of } \\
\text { children of immigrants and the comparison group of children of native-born parents were } \\
\text { employed with } * \text { representing ten percent significance level, ** representing five percent } \\
\text { significance level and } * * * \text { representing one percent significance level. } \\
\text { 3. The Longitudinal weights were used in calculating means and facilitating significance } \\
\text { tests on all the tests. } \\
\text { 4. Standard deviations and sample sizes are included in parentheses and square brackets. }\end{array}$} \\
\hline
\end{tabular}




\subsection{Model Specification}

Next, the focus turns to multivariate analysis to see whether the observed differences in test scores can be explained by the observable characteristics of the children and their families. The model employed in this analysis is mainly based on the one used by Worswick (2004) (equation (1)).

$$
\begin{aligned}
Y_{i t c_{j}}= & \boldsymbol{X}_{i t c_{j}} \alpha_{c_{j}}+E F_{i c_{j}} \times\left(\beta_{1 c_{j}}+\beta_{2 c_{j}} Y R S_{i t c_{j}}+\beta_{3 c_{j}} Y S M_{i t c_{j}}\right) \\
& +N E F_{i c_{j}} \times\left(\gamma_{1 c_{j}}+\gamma_{2 c_{j}} Y R S_{i t c_{j}}+\gamma_{3 c_{j}} Y S M_{i t c_{j}}\right)+\varepsilon_{i t c_{j}}
\end{aligned}
$$

in which, $Y_{i t c j}$ represents the test score or assessment score of child (or youth) i of cohort $c_{j}$ in period $\mathrm{t}^{13}$, which is one of the following academic indicators: the PPVT-R test score, the reading test score, the mathematics test score, the literacy assessment score of youths, the cognitive assessment score of youths, and the numeracy measurement score for youths. At different stages of the education process, different indicators of school performance are employed to measure the child's academic achievements. The term $c_{j}$ represents the four cohorts for the mathematics test scores. $\boldsymbol{X}_{\boldsymbol{i}}$ is a vector of the demographic information on the child and his/her PMK. The indicator variable $E F_{i}$ equals one for children whose immigrant PMK's native language is either English or French. The indicator variable $N E F_{i}$ equals one for children whose PMK is an immigrant with a mother tongue that is neither English nor French. The variable $Y R S_{i t}$ is equal to the child's age minus the minimum age of each test/assessment ${ }^{14}$. The variable $Y S M_{i t}$ is the

\footnotetext{
${ }^{13}$ The reading and mathematics regressions are based on the panel regression models with time $t$, however, the other four test/assessments regressions are based on the cross-sectional models without time $t$.

${ }^{14}$ This is the minimum age for which the test or assessment was administered to a child or a youth in the survey. For the vocabulary test, it is four; for the reading and mathematics tests, it is seven; for the literacy assessment, it is 18; for the numeracy assessment, it is 20 ; and for the cognitive measurement, it is 16 .
} 
number of years since migration for the child's immigrant PMK, taking the value zero for the children who have Canadian-born parents (CB).

One of the major changes made to the model compared to that in the paper by Worswick (2004) is that, using more recent cycles of the NLSCY, it is possible to introduce cohort analysis to the mathematics sample. We divide the mathematics sample into four cohorts including four groups of children who first took their mathematics test respectively in 1994, 1996, 1998 and 2000. The time span between the first and the last cohort is eight years which could be substantial to make the two groups of children differ in many perspectives. An important reason to suspect that cohort differences are important is the fact that in the mid-1990s, Canadian immigration policy for the economic class underwent the changes in the selection method from the occupation-oriented indicators to be based on more general human capital factors (educational achievement). We suspect that these changes in the criteria of selecting immigrants could be further transferred to and be reflected by the changes in the school performance of their children ${ }^{15}$.

Model (1) allows for differences in academic performance among children by their PMK's immigrant status and mother tongue languages to vary according to the age of the child (measured as YRS, the difference between the child's age and the minimum age for each test/assessment), but also allows for an immigrant assimilation dynamic as a result of the effect of years-since-migration of children's immigrant PMK. In particular, the coefficients $\beta_{1}$ and $\gamma_{1}$ reflect the level differences in academic performance respectively for the EF children and the $\mathrm{NEF}$ children relative to that of the $\mathrm{CB}$ children for the case of $Y R S_{i t}=0$ and $Y S M_{i t}=0$. The assimilation process of the academic performance of the children with immigrant parents can be

\footnotetext{
${ }^{15}$ Beach, Green and Worswick (2006).
} 
explained as the result of the increase of the variables $Y R S_{i t}$ and $Y S M_{i t}$ and the resulting effects on the dependent variable.

\subsection{Econometric Methodology}

The true effect of the immigrant status of parents on the school performance of children could be easily confounded by unobserved characteristics of children, which have impacts on their academic performance and fall into the error term. For example, the cultural differences between immigrant and non-immigrant families could potentially affect children's school outcomes. A family which emphasizes the academic achievement of the children will put more effort into suppoting the school work of children, which might contribute to higher scores of children in all the tests. However, it is generally hard to control for these cultural differences in our model. Therefore, the endogeneity associated with the parental immigrant status will blur its true causal effect on the children's school performance. Under this context, the longitudinal analysis if feasible is a better methodology to reduce the endogeneity problem. However, the composition of the sample for each test score is changing through years so that we need to employ different econometric methodologies to conduct the analyses on different test scores. The tight age ranges for the vocabulary test, literacy assessment, numeracy assessment and cognitive measurement ${ }^{16}$ combined with the small number of waves (of two or three cycles) in which the tests were reported make longitudinal regression analysis infeasible for these tests and assessments. For example, the youngest children included in the sample of cognitive measurement in cycle four (2000/2001) are age 16 and then in cycle five, these children turned age 18 which is not within

\footnotetext{
${ }^{16}$ The vocabulary test was administered to children aged four, five and six who are not in grade two yet, the cognitive measurement was for youths aged 16 and 17, the literacy assessment was for youths aged 18 and 19, and the numeracy assessment was for youths aged 20 and 21.
} 
the age range of the cognitive measurement. Consequently, the reading and mathematics tests which were given to children aged from seven to 15 allow for longitudinal regression analysis.

For the reading test, the fixed effects estimation method is strongly supported by the results of Hausman tests and is, therefore, employed. Here, $\varepsilon_{i t}=\alpha_{i}+e_{i t}$, where $e_{i t}$ is assumed to be a random error. In order to yield estimates not only for the time variant variables but also for the variables that do not change over time such as the immigrant status variables, a two-stage fixed effects estimation is employed (see, for example, Cobb-Clark, Connolly and Worswick, 2005). On the first stage, the coefficients on the time-varying variables are identified by running the normal fixed effects regression. On the second stage, the predicted residual from the first stage fixed effects estimation is regressed on the remaining time-invariant variables to produce the estimates on these time-invariant controls. Following the results of Hausman tests, random effects regressions are applied to each of the four cohort's mathematics regression model. Specifically, the error term $\varepsilon_{i t c_{j}}$ is tested not to be systematically correlated with the controlled covariates in the mathematics model and thus the random effects models are used.

\subsection{Results}

\subsubsection{Longitudinal Regression Results}

The results of the two-stage fixed effects and random effects estimations employed on the reading tests scores and the mathematics tests scores are presented in Table 3 below. Column (1) contains the fixed effects estimates for the reading test score model. Columns (2)-(5) contain the 
random effects estimates for the mathematics test score models of the children from each $\operatorname{cohort}^{17}$.

Based on the estimates of column (1), the EF children have roughly three points higher reading scores than the $\mathrm{CB}$ children for the case of their PMK having just arrived in Canada and the child being seven years old. However, for the equivalent case, the NEF children have four points lower reading scores than the $\mathrm{CB}$ children. Although the reading scores of the children of immigrants (EF children and NEF children) are found to improve with the years since migration of their PMKs (according to the significant estimated coefficients on the variables $\mathrm{EF} \times \mathrm{YSM}$ and NEF $\times$ YSM), the effect per year is very small. The age effects (YRS) on the reading scores are not statistically significant indicating that the EF and NEF differences relative to the CB default group do not vary with time in the school system (at least over the age range of the test), ceteris paribus. The disadvantage experienced by the NEF children is not surprising given that the PMKs may have relatively weak language skills in either English or French and may choose to speak their mother tongue at home in order to ensure that their children develop fluency in that language from an early age. The advantage experienced by the EF children may reflect a positive selection through either the decision to immigrate to Canada on the part of the immigrant PMK or the decision to accept the PMK as an immigrant on the part of the immigrant selection system.

Unlike what was found in the reading test regression results above, neither EF children nor NEF children from each cohort have significantly worse mathematics performance (for the case of $\mathrm{YSM}=0$ and $\mathrm{YRS}=0$ ) relative to $\mathrm{CB}$ children. Instead, the math test scores of the children of

\footnotetext{
17 Regressions only including the immigrant status related covariates for different test scores were also carried out
} (but not reported here). Also, the regressions including the quadratic covariates of YSM and YRS were employed as well, but the change of the specification of the model does not substantially affect the coefficient estimates of other covariates and the regression results are not reported here. 
immigrants from cohort two are significantly better (at the ten percent level) than those of $\mathrm{CB}$ children by around three points for EF children and two points for NEF children. We do not see strong relationships between math scores and the PMK's YSM for either the NEF or the EF children with the exception of the EF children from cohort two. The estimated coefficient on the variable EFxYSM is -0.23 with one percent significance, which means that if the EF PMKs have spent ten years in Canada since first migration, their children's mathematics scores will decrease by roughly two points. The EF children had advantages in the mathematics when their EF PMKs first immigrated to Canada relative to their peers with native-born parent, but the advantages gradually diminished with the number of years since migration, which reveals one phenomenon of converging performance in mathematics between the two groups of children. The ten percent significant positive estimates on the variables $E F \times Y R S, N E F \times Y R S$ for the cohort one math regression $(0.38,0.48)$ as well as $\mathrm{EF} \times \mathrm{YRS}$ from the cohort two math regression $(0.35)$ provide some evidence of the children of immigrants' math scores improving as they spend more years in Canadian schools.

Overall, the children with an immigrant parent in the first two cohorts outperform children with a Canadian-born parent in the mathematics test, while children of immigrant parents in the last two cohorts achieve similar performance as their peers with native-born parents. This could be potentially explained by the changes in the immigration selection criteria from labour market indicators to human capital factors, which lead to different groups of immigrants with different characteristics admitted to Canada before and after the policy changes. It seems that under the former immigration selection scheme, children from the immigrant families achieve better mathematics performance compared to those from immigrant families immigrated to Canada under the latter policy scheme. Another possibility is that the changes in the source country 
composition of immigrants to Canada across time (within the NEF grouping of parental source countries) could be absorbed into the birth cohort effects if more recently born immigrant children in our sample have parents who were born in different source countries on average relative to the children of immigrant parents born in earlier years.

Based on the regression results in Table 3, the reading and math scores of children living in Quebec are significantly higher than those of children living in Ontario, and this is especially true for the math scores of cohort one and two with much higher scores (around five points and four points, respectively). Children living in Alberta and British Columbia also have higher scores in reading and math than those living in Ontario, ceteris paribus.

As expected, the higher the education level of the child's PMK and the PMK's spouse's education, the higher the children's reading and mathematics scores. In addition, children living in a single parent family have significantly lower performance in the mathematics test for each cohort. In addition, we find significantly higher scores in reading for female children by about two points and significantly lower scores in math from cohort four by around one point.

Table 3 - Two-stage estimation results of the reading and mathematics tests scores

\begin{tabular}{|c|c|c|c|c|c|}
\hline & Reading & $\begin{array}{c}\text { Math } \\
\text { Cohort 1 }\end{array}$ & $\begin{array}{c}\text { Math } \\
\text { Cohort 2 }\end{array}$ & $\begin{array}{c}\text { Math } \\
\text { Cohort 3 }\end{array}$ & $\begin{array}{c}\text { Math } \\
\text { Cohort 4 }\end{array}$ \\
\hline & $\begin{array}{c}(1) \\
\text { First stage } \\
\text { fixed effects }\end{array}$ & $\begin{array}{c}(2) \\
\text { Random } \\
\text { effects }\end{array}$ & $\begin{array}{c}(3) \\
\text { Random } \\
\text { effects }\end{array}$ & $\begin{array}{c}(4) \\
\text { Random } \\
\text { effects }\end{array}$ & $\begin{array}{c}(5) \\
\text { Random } \\
\text { effects }\end{array}$ \\
\hline Age & $2.73^{* * *}$ & $4.38^{* * *}$ & $4.28^{* * *}$ & $4.63 * * *$ \\
$(0.16)$ & $(0.04)$ & $(0.04)$ & $(0.04)$ & $\begin{array}{c}5.18^{* * *} \\
(0.04)\end{array}$ \\
\hline EF x YSM & $0.02 * * *$ & 0.04 & $-0.23 * * *$ & $-0.09 * *$ & -0.02 \\
& $(0.002)$ & $(0.06)$ & $(0.067)$ & $(0.05)$ & $(0.05)$ \\
\hline NEF x YSM & $0.009^{* * *}$ & 0.04 & -0.09 & -0.003 & $0.09 *$ \\
& $(0.002)$ & $(0.06)$ & $(0.07)$ & $(0.07)$ & $(0.05)$ \\
\hline EF x YRS & -0.26 & $0.38^{*}$ & $0.35 *$ & 0.14 & 0.29 \\
& $(1.19)$ & $(0.22)$ & $(0.21)$ & $(0.21)$ & $(0.23)$ \\
\hline NEF x YRS & 0.24 & $0.48^{*}$ & 0.14 & 0.05 & -0.10 \\
\hline
\end{tabular}




\begin{tabular}{|c|c|c|c|c|c|}
\hline & $(1.02)$ & $(0.27)$ & $(0.21)$ & $(0.28)$ & $(0.19)$ \\
\hline \multirow[t]{2}{*}{$\begin{array}{c}\text { First -stage } \\
\text { Constant }\end{array}$} & $\begin{array}{c}71.55^{* * *} \\
(1.60) \\
\end{array}$ & & & & \\
\hline & Second stage & & & & \\
\hline Female & $\begin{array}{c}1.60 * * * \\
(0.37)\end{array}$ & $\begin{array}{c}0.19 \\
(0.27)\end{array}$ & $\begin{array}{c}0.31 \\
(0.28)\end{array}$ & $\begin{array}{l}-0.19 \\
(0.29)\end{array}$ & $\begin{array}{c}-0.70 * * * \\
(0.23)\end{array}$ \\
\hline $\mathrm{EF}$ & $\begin{array}{c}2.81 * * * \\
(1.05)\end{array}$ & $\begin{array}{l}-2.21 \\
(1.67)\end{array}$ & $\begin{array}{l}3.16^{*} \\
(1.64)\end{array}$ & $\begin{array}{c}0.87 \\
(1.50)\end{array}$ & $\begin{array}{c}0.37 \\
(1.43)\end{array}$ \\
\hline $\mathrm{NEF}$ & $\begin{array}{c}-4.00 * * * \\
(0.99)\end{array}$ & $\begin{array}{l}-0.82 \\
(1.81) \\
\end{array}$ & $\begin{array}{l}2.15^{*} \\
(1.18) \\
\end{array}$ & $\begin{array}{l}0.009 \\
(1.52) \\
\end{array}$ & $\begin{array}{c}-0.76 \\
(1.15) \\
\end{array}$ \\
\hline $\begin{array}{c}\text { Size of } \\
\text { residence }\end{array}$ & $\begin{array}{c}0.19 \\
(0.13)\end{array}$ & $\begin{array}{c}0.18^{*} \\
(0.1)\end{array}$ & $\begin{array}{c}0.06 \\
(0.13)\end{array}$ & $\begin{array}{c}0.08 \\
(0.11)\end{array}$ & $\begin{array}{l}0.14^{*} \\
(0.09)\end{array}$ \\
\hline Atlantic & $\begin{array}{l}-0.67 \\
(0.45)\end{array}$ & $\begin{array}{l}0.92 * * \\
(0.39)\end{array}$ & $\begin{array}{c}0.15 \\
(0.43)\end{array}$ & $\begin{array}{l}-0.44 \\
(0.43)\end{array}$ & $\begin{array}{c}0.46 \\
(0.34)\end{array}$ \\
\hline Quebec & $\begin{array}{c}1.87 * * * \\
(0.51)\end{array}$ & $\begin{array}{c}5.09 * * * \\
(0.43)\end{array}$ & $\begin{array}{c}4.45 * * * \\
(0.54)\end{array}$ & $\begin{array}{c}2.44 * * * \\
(0.45)\end{array}$ & $\begin{array}{c}1.96^{* * *} \\
(0.35)\end{array}$ \\
\hline Manitoba/Sask. & $\begin{array}{l}1.04 * * \\
(0.50)\end{array}$ & $\begin{array}{l}1.3 * * * \\
(0.44)\end{array}$ & $\begin{array}{c}1.48 * * * \\
(0.40)\end{array}$ & $\begin{array}{c}0.15 \\
(0.46) \\
\end{array}$ & $\begin{array}{c}0.39 \\
(0.36)\end{array}$ \\
\hline Alberta & $\begin{array}{c}2.00 * * * \\
(0.60)\end{array}$ & $\begin{array}{c}1.93 * * * \\
(0.5)\end{array}$ & $\begin{array}{c}2.35 * * * \\
(0.59)\end{array}$ & $\begin{array}{l}1.18^{* *} \\
(0.57) \\
\end{array}$ & $\begin{array}{c}2.03 * * * \\
(0.43)\end{array}$ \\
\hline $\begin{array}{c}\text { British } \\
\text { Columbia }\end{array}$ & $\begin{array}{c}2.02 * * * \\
(0.67)\end{array}$ & $\begin{array}{c}1.44 * * * \\
(0.55)\end{array}$ & $\begin{array}{c}1.90 * * * \\
(0.53)\end{array}$ & $\begin{array}{l}1.35^{* *} \\
(0.61)\end{array}$ & $\begin{array}{c}1.65 * * * \\
(0.48)\end{array}$ \\
\hline Spouse indicator & $\begin{array}{l}-0.82 \\
(0.60) \\
\end{array}$ & $\begin{array}{c}-2.51 * * * \\
(0.83)\end{array}$ & $\begin{array}{c}-1.76 * * \\
(0.83)\end{array}$ & $\begin{array}{l}-1.40^{*} \\
(0.95) \\
\end{array}$ & $\begin{array}{c}-1.28 * * \\
(0.65)\end{array}$ \\
\hline \multicolumn{6}{|l|}{$\begin{array}{c}\text { PMK's } \\
\text { education }\end{array}$} \\
\hline Elementary & $\begin{array}{c}-2.32 * * \\
(1.18)\end{array}$ & $\begin{array}{l}-1.39^{*} \\
(0.85)\end{array}$ & $\begin{array}{c}-3.01 * * * \\
(1.04)\end{array}$ & $\begin{array}{c}-4.01 * * * \\
(0.99)\end{array}$ & $\begin{array}{c}1.12 \\
(0.94)\end{array}$ \\
\hline $\begin{array}{l}\text { Secondary } \\
\text { without } \\
\text { graduation }\end{array}$ & $\begin{array}{c}-1.78 * * \\
(0.88)\end{array}$ & $\begin{array}{c}-1.96^{* * *} \\
(0.49)\end{array}$ & $\begin{array}{l}-0.65 \\
(0.59)\end{array}$ & $\begin{array}{c}-1.54 * * * \\
(0.56)\end{array}$ & $\begin{array}{c}-2.09 * * * \\
(0.47)\end{array}$ \\
\hline Post-secondary & $\begin{array}{c}0.55 \\
(0.43) \\
\end{array}$ & $\begin{array}{l}0.82^{* *} \\
(0.35) \\
\end{array}$ & $\begin{array}{l}0.91^{* *} \\
(0.39) \\
\end{array}$ & $\begin{array}{c}1.28 * * * \\
(0.38)\end{array}$ & $\begin{array}{c}1.13 * * * \\
(0.28)\end{array}$ \\
\hline University & $\begin{array}{c}4.11 * * * \\
(0.62)\end{array}$ & $\begin{array}{c}3.41 * * * \\
(0.52)\end{array}$ & $\begin{array}{c}2.89 * * * \\
(0.61)\end{array}$ & $\begin{array}{c}3.04 * * * \\
(0.55)\end{array}$ & $\begin{array}{c}2.39 * * * \\
(0.38)\end{array}$ \\
\hline \multicolumn{6}{|l|}{$\begin{array}{l}\text { Spouse's } \\
\text { education }\end{array}$} \\
\hline Elementary & $\begin{array}{c}-0.97 \\
(1.17) \\
\end{array}$ & $\begin{array}{c}-2.75 * * * \\
(0.70)\end{array}$ & $\begin{array}{c}-4.17 * * * \\
(0.84)\end{array}$ & $\begin{array}{l}-0.50 \\
(0.62) \\
\end{array}$ & $\begin{array}{c}-0.61 \\
(0.52)\end{array}$ \\
\hline $\begin{array}{l}\text { Secondary } \\
\text { without } \\
\text { graduation }\end{array}$ & $\begin{array}{c}-1.87 * * \\
(0.83)\end{array}$ & $\begin{array}{c}-1.01 * * \\
(0.48)\end{array}$ & $\begin{array}{c}-1.33 * * * \\
(0.50)\end{array}$ & $\begin{array}{c}-1.71 * * * \\
(0.39)\end{array}$ & $\begin{array}{c}-1.63 * * * \\
(0.30)\end{array}$ \\
\hline Post-secondary & $\begin{array}{l}1.01 * * \\
(0.47) \\
\end{array}$ & $\begin{array}{c}0.58 \\
(0.37) \\
\end{array}$ & $\begin{array}{l}-0.22 \\
(0.37) \\
\end{array}$ & $\begin{array}{c}0.15 \\
(0.28) \\
\end{array}$ & $\begin{array}{c}-0.03 \\
(0.23) \\
\end{array}$ \\
\hline University & $3.36 * * *$ & $2.48 * * *$ & $1.88 * * *$ & $2.08 * * *$ & $2.43 * * *$ \\
\hline
\end{tabular}




\begin{tabular}{|c|c|c|c|c|c|}
\hline & $(0.66)$ & $(0.50)$ & $(0.49)$ & $(0.40)$ & $(0.31)$ \\
\hline Constant & $\begin{array}{c}-0.73^{* * * *} \\
(0.26)\end{array}$ & $\begin{array}{l}43.79^{* * *} \\
(0.72)\end{array}$ & $\begin{array}{c}49.03^{* * *} \\
(0.78)\end{array}$ & $\begin{array}{c}45.18^{* * * *} \\
(0.72)\end{array}$ & $\begin{array}{c}42.89^{* * * *} \\
(0.58)\end{array}$ \\
\hline Sample Size & 10539 & 9821 & 6517 & 6533 & 3746 \\
\hline $\begin{array}{l}\text { P-value for } \\
\text { overall F-test }\end{array}$ & 0.00 & 0.00 & 0.00 & 0.00 & 0.00 \\
\hline $\begin{array}{c}\text { Hausman test } \chi^{2} \\
\text { values }\end{array}$ & 33.69 & 7.49 & 12.65 & 18.36 & 8.33 \\
\hline $\begin{array}{c}\text { Hausman test } p \\
\text { values }\end{array}$ & 0.00 & 0.1870 & 0.1793 & 0.1908 & 0.1388 \\
\hline \multicolumn{6}{|c|}{$\begin{array}{l}\text { Notes } \\
\text { 1. These regressions were estimated using National Longitudinal Survey of Children and Youth. } \\
\text { 3. Standard errors of the estimated coefficients are given in parentheses. } \\
\text { 4. The coefficient is statistically significant at the *ten percent level, } * * \text { five percent level, and } \\
\text { *** one percent level. } \\
\text { 5. EF takes value one for children of immigrant PMK whose mother tongue is either English or } \\
\text { French. } \\
\text { 6. NEF }=1 \text { for children of immigrant PMK whose mother tongue is neither English nor French. } \\
\text { 7. YRS is equal to the actual age of the child minus the minimum age } 7 \text { which is required to take } \\
\text { the reading the test. } \\
\text { 8. Spouse indicator is equal to one if the Person-most- Knowledgeable (PMK) about the child } \\
\text { does not have a spouse, and takes the value zero if the child's PMK has a spouse. } \\
\text { 9. The default category for place of residence is Ontario. } \\
\text { 10. The default category for education is high school graduation (only). } \\
\text { 11. The family size is captured by the number of siblings of the child. } \\
\text { 12. The size of residence is a categorical variable with four scales: } 1) \text { rural area; } 2 \text { ) urban, } \\
\text { population }<29,999 ; 3) \text { urban, } 30,000<\text { population }<99,999 ; 4) \text { urban, } 100,000<\text { population }<499,999 \text {; } \\
\text { 5) urban, population }>500,000 \text {. }\end{array}$} \\
\hline
\end{tabular}

\subsubsection{Cross-sectional Regression Results}

Next, we consider a group of test score models that we estimate by weighted least squares due to the lack of sufficient longitudinal variation in the data. Table 4 summarizes the results of regressions of the vocabulary, cognitive, literacy and numeracy scores. As expected, the NEF children have much lower scores (-19.18) than the CB children in the vocabulary test which was administered to children before they went to school at the time of their parent just arriving in Canada at age four. Each additional year spent in Canada by the PMK is associated with a 0.45 points increasing in their vocabulary scores. However, the significant disadvantages in the 
vocabulary test were not found among the EF children. The findings confirm the hypothesis that the disadvantage of NEF parents in the official language will transfer to their young children before school, which also verify the significant role of parents in educating and influencing their young children at home.

The fact that the coefficients on the NEF indicator are all positive (although not significantly different from zero at ten percent level) in the cognitive, literacy and numeracy models, is consistent with the idea that language fluency deficiencies of NEF will tend to disappear as the children age since these tests were administered to youths 16 years of age or older. The insignificant effects of NEF $\times$ YSM and NEF $\times$ YRS on the cognitive, literacy and numeracy test scores could also signal that the NEF children have caught up to their peers in terms of school performance by age 16 (which is consistent with what was found by Worswick, 2004). ${ }^{18}$

For the EF children, the findings in Table 4 are mixed. Although the EF children don't have lower performance in the cognitive and literacy tests, their numeracy scores are significantly lower than those of the $\mathrm{CB}$ children. One explanation is that the small sample size of the children of francophone parents could potentially bias the result ${ }^{19}$. While some Francophone immigrants in Canada come from France, many francophone immigrants who move to Canada immigrated from former French colonies such as Haiti and the countries of West Africa. It is possible that these individuals have challenges in terms of finding suitable work due to credential recognition problems. Consequently, they may live in lower income

\footnotetext{
${ }^{18}$ Quadratic effects of $Y S M$ and $Y R S$ were also estimated, but the results are similar to the linear specification.

${ }^{19}$ Children with Francophone parents are approximately ten percent of the EF children for cognitive, numeracy and literacy model.
} 
neighborhoods and this may have a number of negative consequences on their children's school performance. Warman (2007) finds not only a negative impact of residing in an enclave on earnings growth, but a negative correlation between living in an ethnic enclave and language ability. In order to explore whether the inclusion of the Francophone children in the EF group has important consequences for the results, we exclude these children from the EF group and reestimate the models of school performance. The results imply that the children with Anglophone immigrant parents achieve higher cognitive scores and similar numeracy scores compared to their peers with Canadian-born parent - the estimated coefficient on Anglophone is significantly positive (11.41) in the literacy model and insignificantly from zero at ten percent level in the numeracy model. This is consistent with the hypothesis that the lower numeracy scores of the EF children were mainly driven by the lower numeracy scores of children with Francophone parents.

Table 4 - Estimation results for vocabulary, cognitive, literacy and numeracy scores

\begin{tabular}{|l|c|c|c|c|}
\hline & Vocabulary & $\begin{array}{c}\text { Cognitive } \\
\text { measurement }\end{array}$ & $\begin{array}{c}\text { Literacy } \\
\text { assessment }\end{array}$ & $\begin{array}{c}\text { Numeracy } \\
\text { assessment }\end{array}$ \\
\hline EF & $(1)$ & $(2)$ & $(3)$ & $(4)$ \\
\hline NEF & -5.12 & 9.24 & 4.97 & $-17.22^{*}$ \\
& $(3.38)$ & $(5.78)$ & $(10.16)$ & $(9.07)$ \\
\hline EF x YSM & $-19.18^{* * *}$ & 10.68 & 3.05 & 2.08 \\
& $(3.16)$ & $(9.53)$ & $(7.83)$ & $(4.74)$ \\
\hline NEF x YSM & -0.03 & $-0.41^{* * *}$ & -0.25 & -0.03 \\
& $(0.12)$ & $(0.13)$ & $(0.28)$ & $(0.29)$ \\
\hline EF x YRS & $0.45^{* * *}$ & -0.11 & -0.08 & -0.14 \\
& $(0.11)$ & $(0.18)$ & $(0.23)$ & $(0.15)$ \\
\hline NEF x YRS & 1.87 & 2.35 & 1.08 & $10.83^{* *}$ \\
& $(1.51)$ & $(2.89)$ & $(2.70)$ & $(5.56)$ \\
\hline Spouse indicator & 0.01 & -2.07 & -1.34 & 2.37 \\
& $(1.32)$ & $(4.22)$ & $(2.07)$ & $(1.82)$ \\
\hline Female & $-2.28^{* * *}$ & -0.73 & -0.46 & $-2.57^{*}$ \\
& $(0.80)$ & $(1.65)$ & $(1.42)$ & $(1.64)$ \\
\hline Size of residence & 0.41 & -0.70 & 1.25 & $-2.02^{*}$ \\
& $(0.42)$ & $(0.92)$ & $(1.03)$ & $(1.10)$ \\
\hline
\end{tabular}




\begin{tabular}{|c|c|c|c|c|}
\hline Age & $\begin{array}{l}-0.14 \\
(0.27)\end{array}$ & $\begin{array}{c}2.75^{* * *} \\
(0.83)\end{array}$ & $\begin{array}{c}2.40 * * * \\
(0.79)\end{array}$ & $\begin{array}{c}1.28 \\
(0.86)\end{array}$ \\
\hline Atlantic & $\begin{array}{l}-0.85 \\
(0.55)\end{array}$ & $\begin{array}{c}0.47 \\
(1.11)\end{array}$ & $\begin{array}{c}-2.67^{* * *} \\
(0.96)\end{array}$ & $\begin{array}{l}-1.31 \\
(1.40)\end{array}$ \\
\hline Quebec & $\begin{array}{c}1.77 \\
(1.40)\end{array}$ & $\begin{array}{c}6.02 * * * \\
(1.28)\end{array}$ & $\begin{array}{c}0.66 \\
(1.61)\end{array}$ & $\begin{array}{l}1.50 \\
(2.24)\end{array}$ \\
\hline Manitoba/Sask. & $\begin{array}{l}-0.76 \\
(0.61)\end{array}$ & $\begin{array}{c}0.49 \\
(1.22)\end{array}$ & $\begin{array}{l}-0.77 \\
(1.11)\end{array}$ & $\begin{array}{l}-2.25^{*} \\
(1.27)\end{array}$ \\
\hline Alberta & $\begin{array}{c}0.60 \\
(0.66)\end{array}$ & $\begin{array}{c}4.47^{* * *} \\
(1.53)\end{array}$ & $\begin{array}{c}1.17 \\
(1.39)\end{array}$ & $\begin{array}{l}-0.31 \\
(1.14)\end{array}$ \\
\hline British Columbia & $\begin{array}{l}-0.85 \\
(0.77)\end{array}$ & $\begin{array}{c}6.27^{* * *} \\
(1.56)\end{array}$ & $\begin{array}{c}0.92 \\
(1.43)\end{array}$ & $\begin{array}{l}2.23^{*} \\
(1.48)\end{array}$ \\
\hline \multicolumn{5}{|l|}{ PMK's education } \\
\hline Elementary & $\begin{array}{c}-7.54 * * * \\
(1.55)\end{array}$ & $\begin{array}{c}-5.65^{* *} \\
(2.47)\end{array}$ & $\begin{array}{l}-0.34 \\
(1.43)\end{array}$ & $\begin{array}{l}-3.91 * \\
(2.50)\end{array}$ \\
\hline $\begin{array}{l}\text { Secondary without } \\
\text { graduation }\end{array}$ & $\begin{array}{l}-2.81^{* * *} \\
(0.99)\end{array}$ & $\begin{array}{l}-6.58^{* * * *} \\
(2.20)\end{array}$ & $\begin{array}{c}-4.59^{* * *} \\
(2.31)\end{array}$ & $\begin{array}{c}-5.29^{* *} \\
(2.26)\end{array}$ \\
\hline Post-secondary & $\begin{array}{c}2.04^{* * *} \\
(0.57)\end{array}$ & $\begin{array}{l}2.18^{*} \\
(1.22)\end{array}$ & $\begin{array}{l}2.70^{* *} \\
(1.32)\end{array}$ & $\begin{array}{l}2.38^{*} \\
(1.24)\end{array}$ \\
\hline University & $\begin{array}{c}5.97 * * * \\
(0.82) \\
\end{array}$ & $\begin{array}{c}5.69^{* * *} \\
(2.25) \\
\end{array}$ & $\begin{array}{c}7.86^{* * *} \\
(1.76) \\
\end{array}$ & $\begin{array}{l}4.00^{* *} \\
(1.83) \\
\end{array}$ \\
\hline \multicolumn{5}{|l|}{ Spouse's education } \\
\hline Elementary & $\begin{array}{l}-0.18 \\
(1.50)\end{array}$ & $\begin{array}{l}-1.97 \\
(2.50)\end{array}$ & $\begin{array}{l}-1.16 \\
(3.53)\end{array}$ & $\begin{array}{l}-2.43 \\
(2.59)\end{array}$ \\
\hline $\begin{array}{l}\text { Secondary without } \\
\text { graduation }\end{array}$ & $\begin{array}{c}-2.41 * * * \\
(0.83)\end{array}$ & $\begin{array}{c}0.40 \\
(2.38)\end{array}$ & $\begin{array}{l}-6.36^{* * *} \\
(2.48)\end{array}$ & $\begin{array}{l}-1.78 \\
(1.97)\end{array}$ \\
\hline Post-secondary & $\begin{array}{l}1.13^{*} \\
(0.62)\end{array}$ & $\begin{array}{c}1.58 \\
(1.41)\end{array}$ & $\begin{array}{c}0.62 \\
(1.26)\end{array}$ & $\begin{array}{c}1.28 \\
(1.34)\end{array}$ \\
\hline University & $\begin{array}{c}4.95^{* * *} \\
(0.89)\end{array}$ & $\begin{array}{l}2.03 \\
(2.16)\end{array}$ & $\begin{array}{c}1.61 \\
(1.65)\end{array}$ & $\begin{array}{c}5.27^{* * *} \\
(1.67)\end{array}$ \\
\hline Constant & $\begin{array}{l}100.78^{* * *} \\
(2.11)\end{array}$ & $\begin{array}{c}49.53^{* * * *} \\
(13.73)\end{array}$ & $\begin{array}{c}51.05^{* * *} \\
(14.53)\end{array}$ & $\begin{array}{c}73.31^{* * *} \\
(17.90)\end{array}$ \\
\hline Sample Size & 15383 & 2353 & 2081 & 1816 \\
\hline P-value for overall F-test & 0.00 & 0.00 & 0.00 & 0.00 \\
\hline $\begin{array}{l}\text { Notes. } \\
\text { 1. The covariates in the ab } \\
\text { 2. These regressions were }\end{array}$ & ed usin & Jongi & le 2. & th. \\
\hline
\end{tabular}




\subsection{Assimilation process of the school performance of children of immigrants}

Figures 2 and 3 depict the evolution of the school performance of NEF children and EF children, respectively, compared to their peers with Canadian-born parents over the relevant ages for each test. The predicted differences are based on the estimates on the immigrant status related variables (EF, NEF) and the immigrant status interacted variables (YRS, YSM) from the previous econometric models from Table 3 and Table $4^{20}$. The predictions are applied to the cases of NEF children or EF children who were age four at the time when their PMK immigrated to Canada. For example, when a child with an immigrant PMK is four years old and eligible to take the vocabulary test, the estimated difference in his/her vocabulary score relative to that of his/her peers with Canadian-born parents is calculated by holding $Y R S_{i t}=0$ and $Y S M_{i t}=$ 0. After two years, the child's age increases by two so that $Y R S_{i t}=2$ and also the number of years in Canada of his/her PMK increases by two so that $Y S M_{i t}=2$. When the child matures to age 18 and he/she is eligible to take the literacy assessment, the prediction of the difference in literacy scores between the two groups is calculated with $Y R S_{i t}=0$ and $Y S M_{i t}=14$. From Figures 2 and 3, not only can we see the change in the difference in performance within one particular test/assessment as the child ages, but we can also see the evolution process of differences in academic performance across each test/assessment.

\footnotetext{
${ }^{20}$ The mathematics regression results are for those in cohort one since they are the only ones who were able to take all of the tests through years.
} 
Figure 2 - Test Score Differences: NEF Children Relative to the Children of Canadianborn parents

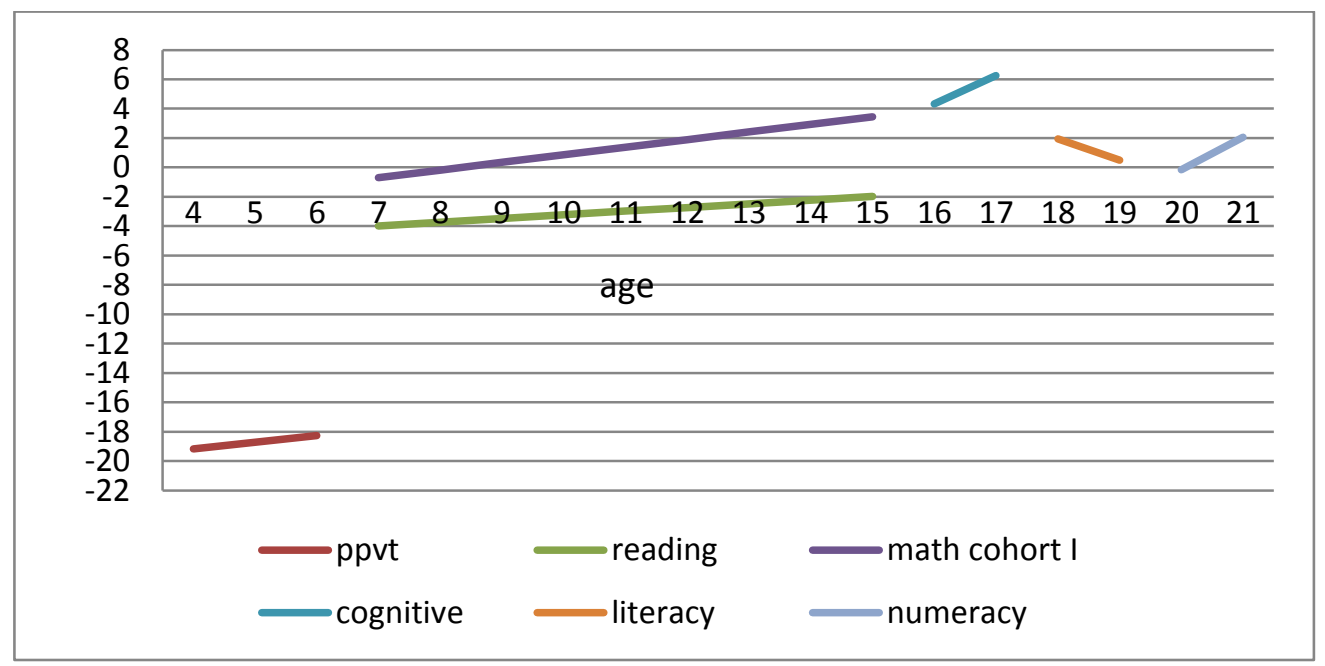

Notes.

1. Author's calculations based on Table 3 and Table 4 .

2. The vertical axis can be interpreted as differences in test/assessment scores of Allophone immigrant parents' child relative to the child of native-born parent; the horizontal axis represents the child's age.

3. The calculations are based on the immigrant family having arrived in Canada when the child was four years old.

4. The graphs did not take the significance of the estimates into account.

The findings for NEF children are quite clear. Although the NEF children have poor vocabulary performance when they are young, the magnitude of the disadvantage is reduced dramatically when the focus switches from vocabulary to the reading scores at age seven. The lower performance for NEF children in the reading test gradually disappears through to age 15. Unlike the vocabulary and reading scores, NEF children have comparable math scores relative to those with Canadian-born parents at age eight and their relative performance improves through to age 15 where they have a four point advantage in math relative to otherwise similar $\mathrm{CB}$ children. Also, higher performance in the cognitive, literacy, and numeracy scores is found in the age 16 through 21 range confirming the finding that the NEF children's lower language 
ability at younger ages does not lead to negative outcomes in terms of their future school success (at least along these dimensions of academic performance).

Figure 3 - Test Score Differences: EF Children Relative to the Children of Canadian-born parents

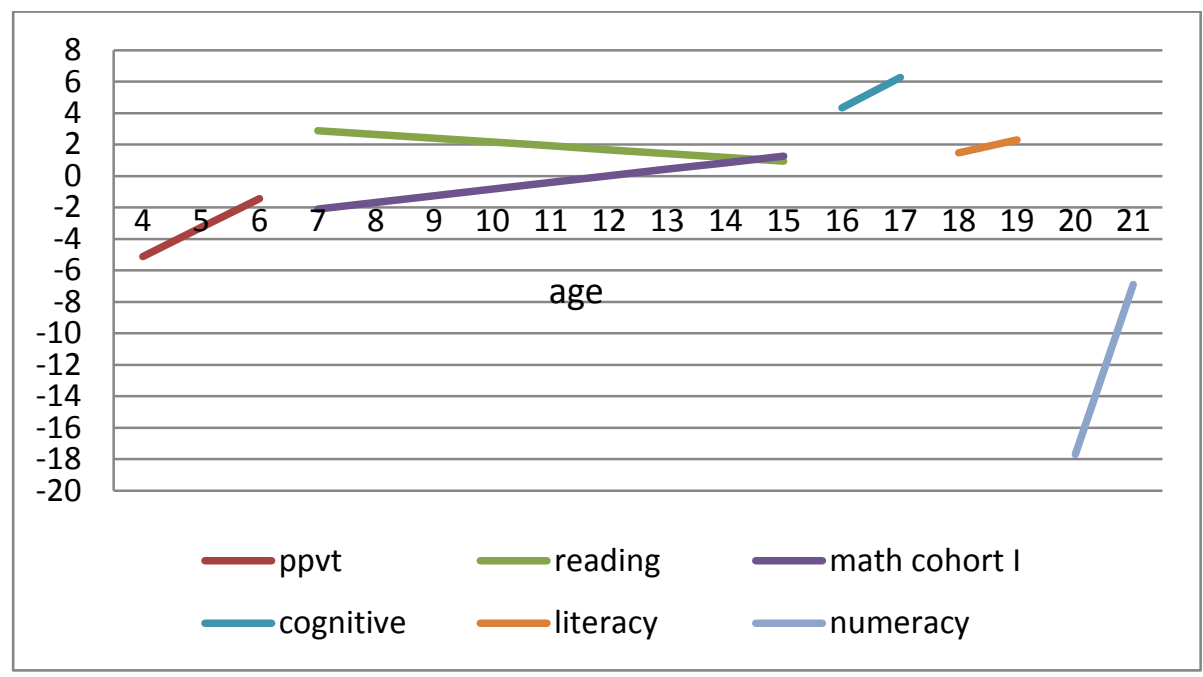

Notes.

1. This Figure has the same structure as that in Figure 2.

In Figure 3, the EF test score performance is generally equal to or higher than that of the CB children with the exceptions of: 1) the vocabulary test scores are roughly two points lower than those of the $\mathrm{CB}$ children at age four and the relative small disadvantage is reduced through to age six, 2) lower in math at age seven by two points and grow to be one point higher than the CB children in math by age 15 , and 3) the numeracy test scores where the outcomes at age 20 are 17 points lower but then are much higher by age 21 at only six points lower. It is worth reiterating that the latter outcome seems to be driven by the outcomes of the small number of EF children whose PMK is Francophone. As discussed in section 7, after dropping the children with Francophone immigrant PMKs from the EF children, the significantly lower school performance disappears. 


\subsection{Conclusions}

The test scores of children with an immigrant parent have been longitudinally tracked for up to 14 years and compared with those of children of native-born parents. The Canadian data from the first eight waves of the National Longitudinal Survey of Children and Youth (NLSCY) from Statistics Canada are employed in this study.

NEF children, whose immigrant parent has a native language neither English nor French, struggle at younger ages in vocabulary; however, their language skills are found to improve with more years of residence staying in Canada of their immigrant parent. By age seven, their performance on the reading tests are found to be only slightly lower than that of the children of Canadian born parents. In addition, by age eight, their performance on the mathematics test is on average equal to that of the children of Canadian born parents. By age 15 and older, the NEF children have average performance that is higher (although not significantly different from zero) than that of the children of Canadian born parents in the cognitive, literacy, numeracy tests. The fast assimilation process of the NEF children could be due to the nature of the adaptation ability for younger children, the interaction with their peers with native-born parents, and the positive impact of their parents' assimilation results.

The adaptation pattern for the children of Anglophone or Francophone immigrant parents (EF children) differs from that of the NEF children. The EF children have vocabulary test scores that are not significantly different from the ones of the children of Canadian born parents in kindergarten and have higher scores in reading and mathematics tests before age 15 , indicating that EF children do not face the same language obstacles as NEF children. However, at ages older than 15 , the EF children are found to have somewhat lower performances in the numeracy tests. Further investigation shows that the EF children with Francophone immigrant parents are 
those who pull the school performance of EF children down. The relatively weak performance of the EF children with Francophone parents may relate to the source country distributions of these immigrant families with significant numbers of these immigrants coming from Haiti and West African countries. Given that many Francophone immigrant parents in Canada are members of visible minority groups, they may face both challenges in terms of their credential recognition as well as possible labour market discrimination. Given this, the families and the local public schools of these children may lack the needed resources in order to support the education of these children to the same extent as the education of other EF children is supported. The educational outcomes of this group of children of immigrants with Francophone parents requires further research ideally with a data set with larger samples of these children than are available in the NLSCY.

Although children of immigrants (EF and NEF children) overall achieve either similar or better outcomes in the mathematics test, the cohort analysis provides some evidence on the change of the assimilation profiles across cohorts. Generally, the first two cohorts of children, who are more likely to have an immigrant parent selected by immigration policy based on the occupational needs in Canada, have higher mathematics scores compared to the children with a Canadian-born parent. On the contrary, the equivalent advantage found in the mathematics test score disappears for the children of immigrants in the last two cohorts whose parents are more likely to be admitted to Canada according to the new human capital oriented selection criteria. The difference revealed across cohorts here could serve as preliminary evidence on how the immigration policy affects the assimilation profiles of children of immigrants in Canadian schools. 
The negative impacts associated with language inefficiency on new immigrants in the immigrants-receiving country have been widely discussed. The findings in this paper suggest that the negative influences on their children are constrained within a small period and can be eliminated before their children are old enough to go to school. After age seven, the children of immigrants have comparable or slightly higher school performance than their classmates whose parents were born in Canada. What is more, after age 15, the children of immigrants perform as well on average as their peers with Canadian-born parents in different academic fields (such as cognitive, literacy, and numeracy) with the exception of children with Francophone immigrant parents. We are limited to get an unbiased conclusion for the relative school achievements of children with Francophone parents to those with native-born parents because of insufficient observations for children with Francophone immigrant parents in the samples. Therefore, the future analysis of the school performance for children of immigrant parents whose native language is French is still required. However, from the perspective of the comparison of school attainments of NEF children and the children of Anglophone immigrant parents with those of children with native-born parents, the current immigration policy and education system seem to work well in adapting the children of immigrants to Canadian schools. 


\subsection{References}

Abada, T., F. Hou, and B. Ram. 2008. Group Differences in Educational Attainment Among the Children of Immigrants. Statistics Canada, Analytical Studies Branch, Research Paper Series.

Amuedo-Dorantes, C., and S. Pozo. 2002. "Precautionary Saving by Young Immigrants and Young Natives." Southern Economic Journal 69 (1): 48-71.

Amuedo-Dorantes, C., and S. Pozo. 2006. "Remittances as Insurance: Evidence from Mexican Immigrants." Journal of Population Economics 19 (2): 227-254.

Aydemir, A., W. H. Chen, and M. Corak. 2009. "Intergenerational Earnings Mobility Among the Children of Canadian Immigrants." Review of Economics \& Statistics 91 (2): 377-397.

Aydemir, A., and M. Skuterud. 2005. "Explaining the Deteriorating Entry Earnings of Canada's Immigrants Cohorts, 1966-2000.” Canadian Journal of Economics 38 (2): 641-647.

Beach, C., Green, A.G., and Worswick C. 2006. "Impacts of the Point System and Immigration Policy Levers on Skill Characteristics of Canadian Immigrants." Queen's Economics Department Working Paper No. 1115.

Bjørg, C. 2006. "A Dynamic Analysis of Educational Progression of Children of Immigrants." Journal of Labor Economics 13 (4): 479-492.

Bonikowska, A. and F. Hou. 2011. Reversal of Fortunes or Continued Success? Cohort Differences in Education and Earnings of Childhood Immigrants. Research Report No. 330. Ottawa: Statistics Canada, Social Analysis Division.

Burton, P., and S. Phipps. 2010. "The Well-Being of Immigrant Children and Parents in Canada." Paper presented at the 31st General Conference of the International Association for Research in Income and Wealth, St. Gallen, Switzerland, 22-28 August.

Card, D. 2005. "Is the New Immigration Really So Bad?" Economic Journal 115 (507): F300F323.

Chiswick, B. R., and P. W. Miller. 2009. "Earnings and Occupational Attainment among Immigrants.” Industrial Relations 48 (3): 454-465.

Chiswick, B. R., and P. W. Miller. 1994. "Language Choice among Immigrants in a Multi-lingual Destination." Journal of Population Economics 7 (2): 119-131.

Cobb-Clark, D., M. D. Connolly, and C. Worswick. 2005. "Post-migration Investments in Education and Job Search: A Family Perspective." Journal of Population Economics 18 (4): 663-690. 
Cortes , K. E. 2006. "The Effects of Age at Arrival and Enclave Schools on the Academic Performance of Immigrant Children." Economics of Education Review 25 (2): 121-132

Cummins, J. 1992. "Language Proficiency, Bilingualism, and Academic Achievement." In The Multicultural Classroom: Readings for Content-Area Teachers, edited by P.A. RichardAmato and M.A. Snow, 16-26. New York: Longman.

Currie, J., and D. Thomas. 1999. “Does Head Start Help Hispanic Children?” Journal of Public Economics 74 (2): 235-262.

Damas de Matos, A. 2010. "The Integration of Children of Immigrants in European Cities: The Importance of Parental Background." Equal Opportunities? The Labour Market Integration of the Children of Immigrants, 55-78, OECD Publishing.

Domingues Dos Santos, M., and F. C. Wolff. 2011. "Human Capital Background and the Educational Attainment of Second-Generation Immigrants in France." Economics of Education Review 30 (5):1085-1096.

Dustmann, C., and F. Fabbri. 2003. "Language Proficiency and Labor Market Performance of Immigrants in the UK." Economic Journal 113 (489): 695-717.

Dustmann, C., and N. Theodoropoulos. 2010. "Ethnic Minority Immigrants and Their Children in Britain." Oxford Economic Papers 62 (2): 209-233.

Finnie, R., and R. E. Mueller. 2009. "Access to Post-Secondary Education in Canada among the Children of Canadian Immigrants.” A MESA Project Research Paper. Toronto: Educational Policy Institute.

Frenette, M and R Morissette 2005. "Will They Ever Converge? Earnings of Immigrant and Canadian-Born Workers over the Last Two Decades." International Migration Review 39(1): 228-257.

Green, A., and M. Mackinnon. 2001. "The Slow Assimilation of British Immigrants in Canada: Evidence from Montreal and Toronto." Explorations in Economic History 38 (3): 315338.

Health, A. 2010. "Main Determinants of Educational and Labour Market Outcomes." In Equal Opportunities? The Labour Market Integration of the Children of Immigrants, 115-127, OECD Publishing.

Hum, D., and W. Simpson. 2004. "Reinterpreting the Performance of Immigrant Wages from Panel Data." Empirical Economics 29 (1): 129-147.

Hum, D., and W. Simpson. 2007. "The Legacy of Immigration: Labour Market Performance and Education in the Second Generation." Applied Economics 39 (15): 1985-2007. 
Kirdar, M. 2010. "Source Country Characteristics and Immigrants' Migration Duration and Saving Decisions.” Discussion Paper No. 4899. Bonn, Germany: Institute for the Study of Labor (IZA).

Koenker, R. 2004. “Quantile Regression for Longitudinal Data.” Journal of Multivariate Analysis 91 (1): 74-89.

Kroneberg, C. 2008. "Ethnic Communities and School Performance among the New Second Generation in the United States: Testing the Theory of Segmented Assimilation." Annals of the American Academy of Political and Social Science 620 (1): 138-160.

Lahaie, C. 2008. "School Readiness of Children of Immigrants: Does Parental Involvement Play a Role?” Social Science Quarterly 89 (3): 684-705.

Li, P. S. 2003. "Initial Earnings and Catch-Up Capacity of Immigrants.” Canadian Public Policy 29 (3): 319-337.

Liebig, T., and S. Widmaier. 2010. "Overview: Children of Immigrants in the Labour Markets Of the OECD And EU Countries." In Equal Opportunities? The Labour Market Integration of the Children of Immigrants, 15-52, OECD Publishing.

McDonald , J. T., and C. Worswick. 2011. "Incidence and Returns to Apprenticeship Training in Canada: The Role of Family Background and Immigrant Status.” Working Paper No.72, Canadian Labour Market and Skills Researcher Network.

Meurs, D., A. Pailhe, and P. Simon. 2006. "The Persistence of Intergenerational Inequalities Linked to Immigration: Labour Market Outcomes for Immigrants and Their Descendants in France." Population 61 (5): 645-682.

Picot, G., and F. Hou. 2011. Seeking Success in Canada and the United States: The Determinants of Labour Market Outcomes among the Children of Immigrants. Research Paper No. 331. Ottawa, ON: Statistics Canada, Analytical Studies Branch.

Piracha, M., and Y. Zhu. 2012. "Precautionary Savings by Natives and Immigrants in Germany." Applied Economics 44 (21): 2767-2776.

Richmond, A. H., and A. Mendoza. 1990. "Education and Qualifications of Caribbean Immigrants and Their Children in Britain and Canada." In Search of a Better Life: Perspectives on Migration from the Caribbean, edited by R. W. Palmer, 73-90. New York: Greenwood.

Rumbaut, R. 2008. "The Coming of the Second Generation: Immigration and Ethnic Mobility in Southern California." Annals of the American Academy of Political and Social Science 620 (1): 196-236. 
Rumbaut, R. 1997. "Achievement and Ambition among Children of Immigrants in Southern California." Working Paper No. 215, Levy Economics Institute, the Economics Working Paper Archive.

Schröder, L. 2010. "Labour Market Characteristics and Their Impact on the Integration of Immigrants' Offspring." In Equal Opportunities? The Labour Market Integration of the Children of Immigrants, 129-45, OECD Publishing.

Sweetman, A. 2002. "Immigrant Children in Grade School: An International Perspective." Paper presented at the American Economic Association Meetings, Atlanta.

Wagner, G. G. 1998. "Education as a Keystone of Integration of Immigrants: Determinants of School Attainment of Immigrant Children in West Germany." Industrial Development and the Social Fabric: An International Series of Historical Monographs 14 (A): 35-46.

Warman, C. 2007. "Ethnic Enclaves and Immigrant Earnings Growth." Canadian Journal of Economics 40(2): 401-422.

Worswick, C. 2004. "Adaption and Inequality: Children of Immigrants in Canadian Schools." Canadian Journal of Economics 37 (1): 53-77. 


\section{Chapter 2 Is there a 'Tiger Mother' effect on Bullying? Theory and Evidence for Canada ${ }^{21}$}

\subsection{Introduction}

Bullying among children, which happens frequently and has severe consequences for the victims, has always been a serious social problem. Dinkes, Kemp, and Baum (2009) note that roughly 32 percent of students reported experiencing bullying behaviour at school during the academic year; 21 percent reported "being made fun of", 18 percent were the subject of rumours, 11 percent were "pushed, shoved, tripped or spit on," six percent were threatened, five percent were excluded from activities intentionally while four percent were made to do things against their will and experienced their property intentionally being destroyed. In Canada, among all adults surveyed, half of people report the experience of being bullied at childhood or adolescence. ${ }^{22}$ Most bullying behavior is similar, sharing the following characteristics: purposely causing pain to victims, involving two individuals with unequal power, and is persistent over time. In rare cases, bullying can lead to suicide. Kim and Leventhal (2008) revealed the connection between the participation of bullying and the risk of generating suicidal ideas for youths ${ }^{23}$. Besides direct negative impacts of children's bullying behavior on victims and their families, the adverse effects are not only limited to victims. Brown and Taylor (2008) found that being a bully or being bullied at school will deteriorate their educational attainments persistently, but victimization of bullying also has impacts on future earnings in the labour market. Recently, several school bullying incidents in Ontario, Canada have ignited a round of debate on the topic

\footnotetext{
${ }^{21}$ Although this is a joint paper with Christopher Worswick, my contribution to this paper is more than three fourths.

${ }^{22}$ Source is from the poll conducted by Harris/Decima for Big Brothers and Big Sisters.

${ }^{23}$ Other similar studies include: Hay and Meldrum (2010); Kaminski and Fang (2009).
} 
of anti-bullying. In response, an anti-bullying bill was passed by the Ontario government to create a safe and equal school environment ${ }^{24}$.

Due to both the ill effects of bullying and the interest of governments in this topic, researchers from various academic fields have carried out research in this area; however, these studies generally have difficulty providing an answer as to how children's bullying behavior can be successfully suppressed. In particular, the role of parents, who have often been missing in the anti-bullying mission, is not well understood.

In addition, the topic of relatively strict parenting styles has recently gained greater attention, triggered in part by the book Battle Hymn of the Tiger Mother written by Amy Chua (2011). Chua depicted herself as a "tiger mother" in the book, in the sense that her parenting style was strict when educating her two young daughters relative to typical Western parenting styles. She argues that the academic success of her daughters is the result of her tough parenting style. Although the "tiger mother" concept has received tremendous criticism due to the explicit tough parenting, it is of interest to explore the general relationship between parental behavior and children's behavior in the data. In particular, we are interested in assessing whether stricter parenting styles have the effect of either increasing or decreasing bullying behaviour among the children directly affected.

We set up an economic model to explore the interaction between a child's bullying behavior and the corresponding parental anti-bullying response. To the best of our knowledge, this is the first model of the relationship between the bullying and parental response in the existing child bullying literature. The conclusion we draw from our analysis of the model is that a stronger parental bullying response leads to a lower level of bullying intensity and this is the

\footnotetext{
${ }^{24}$ The Canadian Press, CBC news, (June 5, 2012)“Ontario anti-bullying bill passed”, Source: http://www.cbc.ca/news/canada/ottawa/story/2012/06/05/ontario-anti-bullying-bill-final-vote-controversy-over-gaystraight-alliance.html
} 
main hypothesis tested in the subsequent empirical section. In addition, the model reveals an identification challenge in correctly estimating the causal effect of the parental response to the child's bullying, which needs to be addressed in the estimation.

Our empirical analysis is carried out using data from the National Longitudinal Survey of Children and Youth (NLSCY) of Statistics Canada. The bullying behavior if present is reported by the child's parent for children age four to 11 . The bullying question used is surveyed every two years starting with the first cycle in 1994/95. Parenting bullying control and general parental strategies are represented by four parenting scores (punitive, hostile, consistency and positive interaction score). What we have found from the empirical analysis is consistent with the theoretical prediction. Specifically, a higher (or stricter) parental bullying control is beneficial for deterring bullying after controlling for the general parental behavior and time invariant unobserved heterogeneity. Hostile parental strategies are associated with a higher probability of bullying behaviour for children; however, having frequent positive interaction with parents makes children less likely to be bullies.

Studies related to bullying among children are rare in the economics literature and most studies on the topic are from other fields such as education and psychology. One related economic paper is Brown and Taylor (2008) who investigated the detrimental effects of bullying or being bullied experiences on the future income and human capital accumulation, but they failed to provide suggestions on how to stop bullying. Many studies ${ }^{25}$ focus on evaluations of specific anti-bullying programs around the world. In these studies, anti-bullying school programs are generally found to be moderately useful, but certain conditions have to be met for the success of the programs, more importantly, these programs are generally costly to be implemented.

${ }^{25}$ See Cross et al (2011); Allen (2010); Hong (2008); Midthassel, Bru and Idsoe (2008); Samara and Smith (2008). 
Based on the proposal of the ecological model of school bullying ${ }^{26}$, Lee (2011) argued that ecological elements (individual traits, family experiences, parental involvement, school climate, and community environment) are significant in influencing a child's bullying behavior. Totura et al. (2009) found that student-reported adult monitoring is associated with a decrease in the probability of bullying for students in middle school and this is especially true for girls. ${ }^{27}$ These studies failed to provide evidence on interventions of bullying. For example, what can be done to prevent the children/youths' bullying-related psychological attitudes when they might have already held these attitudes for a long period?

Gender differences in bullying behavior among boys and girls have been studied ${ }^{28}$ and the results show that school-aged boys are more likely to be associated with bullying or bullying/victimization experiences. Ma et al. (2009) found that the academic competence of youths is still negatively related to their bullying behaviors after controlling for demographic characteristics. Also, the principals' and teachers' roles in suppressing bullying were investigated extensively by researchers ${ }^{29}$ as well.

All of the factors associated with child bullying explored in previous studies will be considered in this study. Some recent studies mentioned the parents' impacts on their children's behavior. Rigby (2005) indicated that the perceived expectations of the parents have effects on bullying behavior but only for girls. Christie-Mizell et al. (2011) concluded that more time spent by fathers with their adolescent children decreased the likelihood of bullying. The necessity to increase parents' awareness about bullying was highlighted by Holt, Kantor and Finkelhor

\footnotetext{
${ }^{26}$ Swearer, Espelage, Vaillancourt and Hymel (2010).

${ }^{27}$ See also Ando and Simons-Moron (2005) who use Japanese data and find that psychological factors of the youths influence adolescents' bullying behaviorby

${ }^{28}$ See Marées and Petermann (2010).

${ }^{29}$ Dake, Price, Telljohann and Funk (2004); Sairanen and Pfeffer (2011); Marshall, Varjas, Meyers, Graybill and Skoczylas (2009); Novick and Isaacs (2010).
} 
(2008). Recently, a qualitative paper conducted by Powell and Ladd (2010) urgently called for "more research on the topic of family therapy of bullying". ${ }^{30}$ However, none of these studies has quantitatively examined the possible causal relationship between parental behavior and the children's bullying behavior.

Studies of bullying among children have been conducted in many countries. In Canada, specific anti-bullying programs have been evaluated by Beran, Tutty and Steinrath (2004), and Rawana, Norwood and Whitley (2011). The locations where childhood bullying tends to happen frequently have also been assessed by Craig, Pepler and Atlas (2000) and Vaillancourt et al. (2010). Larochette, Murphy and Craig (2010) find that although bullying is closely associated with personal characteristics, it is less likely to be racially based in supportive schools with higher levels of teacher diversity. Also, by employing the sample of Hong Kong Chinese Primary schoolchildren, Wong et al. (2008) identified that psychological factors and receiving violent concepts from various channels are related to bullying. In Germany, Marees and Petermann (2010) implied that lower parental education achievements are associated with a higher likelihood of the child bullying. This finding highlights the importance of further exploration into the potential channels through which the parents' characteristics and behavior may have impacts on their children's bullying behavior.

The most closely related paper in the literature is Burton, Phipps and Curtis (2002), who studied the relationship between parental strategy/behavior and children's behavior. Dooley and Stewart (2007) also found that the parenting style has consistent effects on children's behavioral and emotional wellbeing. However, these studies do not consider the way in which parental strategies may respond to bullying behaviour.

${ }^{30}$ See also Sawyer et al. (2011). 
Another related literature is by Kim et al. (2009), who studied time trends and trajectories of bullying among Korean adolescents. They concluded that children's participation in bullying is stable over time. However, they were only able to track children over one year. In 2010, Lee also carried out a study of bullying employing the same sample of Korean middle school students. He identified two persistent factors related to bullying: 1) previous victimization experience; and 2) fun-seeking tendency. This evidence is a necessary support for the assumption of our theoretical model that the bully tries to maximize his/her utility when he/she bullies another child. Moreover, the relationship between the parental style and child bullying and victimization experiences at school was explored by Georgiou (2008). Georgiou confirmed the existence of the relationship, but he fails to identify which factor is the cause and which one is the result due to the inside knowledge about children possessed by parents.

In summary, our paper contributes to the existing literature from the following perspectives: 1) this is a quantitative study in contrast to much of the literature which is qualitative in nature; 2) the data employed in this paper is a Canadian national survey (NLSCY) with a large sample size compared to that collected within self-initiated experiments with small sample sizes; 3) this is the first study which includes an economic model of bullying behavior and parental control; and 4) the focus of this paper is the investigation of effects of parental bullying control on child's bullying and the unique longitudinal data allows us to identify the causal relationship.

The paper is structured as follows. Section 2 presents a simple bullying model, based on which theoretical propositions are derived. In section 3, the data (NLSCY) and sample selection are described. The empirical results are presented in section 4 . Section 5 contains several robustness checks against various potential biases. Section 6 concludes. 


\subsection{A simple model}

In this section, we introduce a simple economic model to analyze the bullying behavior of children and the implications of parenting strategies. The equilibrium strategies from our model are both helpful in terms of understanding the underlying behaviour but also shed light on the identification challenges for our subsequent empirical analysis.

We assume that there is a representative child and a representative parent in our model. Consistent with the data, the child is assumed to be young so that he/she can completely discounts the future and thus the child's dynamic problem can be approximated by a static design $^{31}$. In our model, the children's bullying behavior and the corresponding parental response to bullying are strategically dependent on each other. We also assume that each player maximizes his/her utility by treating the other player's strategy as given. This assumption allows us to set up a model similar to the simultaneous game model where each player treats the other player's strategy as given when making his/her decision. In equilibrium, the Nash Equilibrium will be achieved. We argue that the simultaneous game assumption posed here, which will greatly simplify our model, is valid to certain extent considering the following rationales. The child at younger ages may not have information on how their parents will respond to their bullying behavior. Therefore, the child is most likely to take the parental response as given when maximizing his/her bullying utility. On the other hand, since most parents will respond to the bullying behavior after he/she has observed the bullying, combined with the fact that the parents might have limited information on their children's bullying behavior when the children are young and just started bullying, the observed intensity of the child bullying is also treated as given by parents when they choose their anti-bullying strategies.

\footnotetext{
${ }^{31}$ Burton, Phipps and Curtis (2002) employed a static model to approximate the child-parent dynamic interactions.
} 
For simplicity, we consider a representative child, who only cares about the present and maximizes his/her utility by choosing bullying intensity, $b$. The bullying intensity captures the degree of severity of the behavior. For example, a verbal bullying will be associated with lower intensity and, on the other hand, a physical bullying will have a higher level of intensity. We restrict $b$ to be strictly larger than zero ${ }^{32}$. If the bullying intensity is very small, we consider the bullying behavior as relatively unimportant since it would be difficult for most parents to detect their child's bullying given a very small bullying intensity and because in this case the parents will most likely report the child to be a non-bully and thus this assumption is consistent with our data.

The child is aware that not every bullying incident could be detected by parents; however, once the bullying is noticed, he/she believes that a control measure, $P$, leading to disutility $V(P)$, will be implemented by parents and also $\frac{d V(P)}{d P}>033$. It is worth noting that the bullying control, $P$, is the control measure that is applied to the child's bullying by the parent. We should differentiate the bullying control $P$ from the general parental behavior/strategies which captures the general interactions between parents and children ${ }^{34}$.

The bullying is not perfectly observed and its detection is determined by a function:

$$
d=b+s+\varepsilon
$$

\footnotetext{
${ }^{32}$ The strict inequality assumption simplifies our analysis allowing us to focus on interior solutions.

${ }^{33}$ The control measures include interactions with the child, persuasion of the child, or even the censure and punishment resulted from the child's bullying behavior.

${ }^{34}$ In the paper of Peter Burton, Shelley Phipps and Lori Curtis (2002), they investigate the relationship between the general parental strategies and children's behavior, which is different from our paper with a focus of parental bullying controls at the time of bullying detection.
} 
where $d$ designates a detection score, with a higher $d$ leading to a higher probability of detecting bullying ${ }^{35} . s$ captures a supportive environment provided by parents and could refer to the extent to which parents/educators consistently monitor the child's behavior. The detection score also depends on the bullying intensity, $b$. This specification assumes that it is difficult to detect bullying if the bullying happens with relatively lower intensity, ceteris paribus. $\varepsilon$ is a random shock with $\psi(\cdot)$ as its cumulative distribution function ${ }^{36}$. The randomness plays a role in the detection of bullying. For example, if the parent just happens to pass by the street at the time when the child conducts bullying, then the bullying is detected by the parent. If $d \geq \bar{d}$, the bullying is detected. Therefore, the bullying will be detected with a probability of $1-$ $\psi(\bar{d}-s-b) . \bar{d}$ is determined by nature.

\subsubsection{The child's bullying problem}

$$
\max _{b} U^{C}=\left\{U_{c}(b \mid \boldsymbol{x})-[1-\psi(\bar{d}-s-b)] V(P \mid z, x)\right\}
$$

subject to $b>0$

In the model, higher bullying intensity is assumed to bring more happiness and enjoyment to children, while the higher bullying intensity will also lead to higher likelihood of being detected and cause higher expected disutility due to bullying controls. The bullying function is assumed to be quasi-concave in the bullying intensity. The vector $\boldsymbol{x}$ includes a group of covariates representing children's characteristics, and $\mathbf{z}$ represents the general parenting strategy. However, only those children with certain genetic and psychological characteristics will enjoy bullying and our bullying analysis is not relevant to those who naturally do not enjoy bullying. The disutility felt by children due to parental bullying controls differs across children with different

\footnotetext{
${ }^{35}$ This imperfect bullying detection setup carries the same spirit as that in the tournament model by Malcomson (1984).

${ }^{36}$ There is no restriction imposed on the distribution of the random shock in our analysis.
} 
characteristics and heterogeneous styles of parent-child interactions. Specifically, a child with a sensitive personality will feel a greater amount of disutility for a given bullying control, while a child under a general hostile parental strategy might be used to a tough control and will consequently feel less painful facing the given bullying control.

Thus, the first-order condition is

$$
\frac{\partial U_{c}(b \mid x)}{\partial b}-\frac{\partial \psi(\bar{d}-s-b)}{\partial b} V(P \mid z, x)=0 .
$$

At the optimal bullying intensity, the marginal utility from bullying is equal to the marginal expected disutility due to the punishment from bullying detection. In particular, the resulting implicit best response function for the child outlines the factors that will affect the optimal bullying intensity,

$$
b^{*}=b(P, \boldsymbol{x}, \mathbf{z}, s, \bar{d})
$$

which shows that the bullying intensity depends on the parental bullying control measure, $P$, the characteristics of the child, $\boldsymbol{x}$, the general parental strategy, $\boldsymbol{z}$, the positive support and the degree of monitoring of the child's behavior, $s$, and the secretive nature of the bullying incident $\bar{d}$.

\subsubsection{The parent's control problem}

Similar to the model of Burton, Phipps and Curtis (2002), the parent's utility function in our analysis is also determined by three components: 1) the parent's current utility due to the observed child's bullying and bullying control ${ }^{37}, 2$ ) the child's current utility, and 3) the child's future utility. However, the parent in our analysis chooses the corresponding parental bullying control/punishment to maximize his/her utility due to the child's bullying and parental control, which is different from the case where the parent chooses a general parental strategy/behavior as in Burton et.al. (2002). Therefore, the parent's problem can be expressed as:

\footnotetext{
${ }^{37} \mathrm{We}$ assume that the parental bullying control will be implemented to the child once the bullying is detected.
} 


$$
\max _{P} W\left(U_{0}^{p}, U_{0}^{c}, U_{1}^{c}\right)
$$

Subject to $P>0$.

In particular, the parent's current utility is described by the function

$$
U_{0}^{p}=-U_{p}(b \mid \boldsymbol{y})-C(P \mid \boldsymbol{y}),
$$

in which, higher bullying intensity makes the parent feel more disappointed and thus leads to higher disutility to the parent, while higher parental bullying punishment will cause higher parental stress and disutility as well. But the level of the disutility will also depend on the characteristics of the parent, $\boldsymbol{y}$. The child's current bullying utility is similar to the child's problem mentioned previously:

$$
U_{0}^{c}=U_{c}(b \mid \boldsymbol{x})-V(P \mid \mathbf{z}, \boldsymbol{x})
$$

The child's future utility function is described by a function,

$$
U_{1}^{c}=G\left(b_{1}(P \mid \boldsymbol{x}) \mid \boldsymbol{y}\right)
$$

We argue that the parent expects that the child's future utility will negatively depend on his/her future bullying intensity $b_{1}, \frac{\partial U_{1}^{c}}{\partial b_{1}}<0$. Also, the future bullying intensity $b_{1}$ is a function of current bullying controls/punishments with $\frac{\partial b_{1}(*)}{\partial P}<0$. This assumption is valid considering that it is the only incentive for any parent to implement bullying control to the child given that the control will lead to disutility to both parent's and the child's current wellbeing. The parent considers his/her current bullying control as an inhibition method to stop the child's future bullying. The parent believes that no control today will enable the child to bully in the future and will decrease the child's future wellbeing given the expected potential detrimental effects of bullying behavior. In addition, the expected child's future wellbeing from bullying will also depend on the parent's and the child's characteristics. For instance, a parent who is able to recognize adverse consequences of bullying will credit the current bullying control more. Also, a 
child who is more prone to the parental control will make the current bullying control more effective to stop the future bullying. We are aware of that our analysis is not relevant to those parents who do not recognize the negative effects of the bullying and also those who do not believe that their bullying control will have some effects on the child's behavior at all. However, we argue that the first scenario will be rare to find in reality especially when the parents are in an anti-bullying environment. Also, when the child is young, parents generally have more control on the child's behavior and thus the second scenario is also not likely to happen ${ }^{38}$.

The parent's overall wellbeing function is assumed to be quasi-concave so that the unique maximization solution exists and the function could be written as

$$
W=U_{0}^{p}+\alpha U_{0}^{c}+\beta U_{1}^{c},
$$

in which, $\alpha \geq 0, \beta \geq 0 . \alpha$ and $\beta$ are parental altruism parameters. Higher $\alpha$ indicates that the parent puts more weights on children's current happiness from bullying, while a parent with higher $\beta$ allocates more weight on the child's future wellbeing due to the current bullying. The first-order condition of the parent's problem is,

$$
-\frac{\partial C(P \mid \boldsymbol{y})}{\partial P}-\alpha \frac{\partial V(P \mid x, \boldsymbol{z})}{\partial P}+\beta \frac{\partial G}{\partial b_{1}} \frac{\partial b_{1}}{\partial P}=0 .
$$

We can derive from this condition, the best response function for the parent:

$$
P^{*}=P(\alpha, \beta, \boldsymbol{x}, \boldsymbol{z}, \boldsymbol{y}) .
$$

In equilibrium, the best response function for the child (equation (4)) is evaluated at $P^{*}$. The equilibrium relationship between the children's bullying intensity and parental control is derived as

$$
b^{*}=b\left(P^{*}, \boldsymbol{x}, \mathbf{z}, s, \bar{d}\right),
$$


Based on which, we derive the following two propositions ${ }^{39}$.

\subsubsection{Proposition 1}

Parental bullying punishment $P$ will be endogenous if not all the relevant variables included in $\boldsymbol{Z}$ and $\boldsymbol{x}$ are controlled in the empirical bullying regression model. In particular, the real impact of parental bullying control $P$ will be confounded by the heterogeneous characteristics of children as well as by different general parenting styles. Thus, controlling for the unobserved time invariant heterogeneity is a necessary condition for correctly identifying the true causal relationship between the parental control and the child's bullying behavior.

\subsubsection{Proposition 2}

Higher parental bullying control/punishment $P$ will lead to the lower bullying intensity ${ }^{40}$. This inhibition effect of parental bullying control on the child's bullying is the main hypothesis that will be tested in the following empirical part. In this paper, we make efforts to correctly identify the causal relationship between the two variables. However, Proposition 1 has outlined the challenges for the task. In addition, the potential simultaneous relationship between the two variables mentioned before would cause a downward bias in our estimated results. We will keep these challenges in mind when investigating the influence of parental bullying control on child's bullying behavior.

\subsection{Data}

This study uses data from the National Longitudinal Survey of Children and Youth (NLSCY). The NLSCY is a longitudinal survey designed to measure child development and well-being. It includes rich and specific information on the child over time such as his/her health, education,

\footnotetext{
${ }^{39}$ We assume that there is only one Nash equilibrium existing.

${ }^{40}$ This could be easily derived by conducting the comparative static on the equation (3).
} 
personality, behaviors, the Person Most Knowledgeable about the child (PMK) ${ }^{41}$, the child's demographic background, and many school-related factors. The data is collected by conducting surveys to children, their PMK, and their school teachers/principals. There are three files in the survey: a primary file reported by the PMK whose child is younger than 16 years old; a selfreported file by the child whose age is 10 years or above; and an education file completed by the child's teachers and principals. The school-related questions are included in the education file, while the family-related questions are surveyed to the PMK. Generally, there is a higher noresponse rate in the teacher's file, which leads to a smaller sample size compared to that of the PMK's file.

In 1994, a sample of children aged 0 to 11 years old were surveyed and then followed every two years until 2008. Thus, there are eight cycles, each containing the same group of children at different ages. For example, in cycle eight, the oldest child is 25 years of age. However, most questions in the survey are given to children within certain age groups. The question we use to identify a bully is "How often would you say this child: Is cruel, bullies or is mean to others?" The answers are "(1) never or not true; (2) sometimes or somewhat true; (3) often or very true." The first response of "never or not true" would correspond to non-bullying behaviour, while the other two answers correspond to bullying behaviour.

The same bullying question is asked of: the child, the PMK of the child, and the teacher of the child. Only children who are above 10 years of age could self -respond to the bullying questions, while the PMK and teacher are required to answer the bullying question for the children aged four to 11 years old. In addition to the age inconsistency of children between the self-reported sample and the PMK/teacher samples, we are also concerned that children might have higher incentive not to self-identify themselves as bullies. We thus decide to disregard the

\footnotetext{
${ }^{41}$ In around 90 percent of cases PMK refers to the child's mother.
} 
children's self-reported sample. The main variables of interest (parental control and parental strategy) are reported by PMKs. Also, given the lower response rate of the teacher's file and the short available cycles in the teacher's file (only available for the first four cycles), our investigation is mainly focused on the PMK file from cycle one to cycle six and after cycle six all the longitudinal children have outgrown the age group (four to 11) eligible for the bullying question.

Although the same bullying question is administered to the PMK every two years, the composition of the sample is changing through cycles since some children grow into the sample and others grow out of the sample due to age restrictions of the survey question. In particular, there might be some children who are in the NLSCY survey, but are not included in the bullying survey due to mismatch of their age with the bullying question age restrictions. Thus, we have an unbalanced panel. Figure 4 reveals the age composition of the sample for each cycle. Because the data set uses a frequency of two years, the longitudinal cycles in which the same child is tracked could last for a maximum of four cycles (equivalent with eight years). From Figure 4 we can see that the sample comes from the first six cycles of the NLSCY. 


\section{Figure 4 - The age dynamics of the PMK bullying sample}

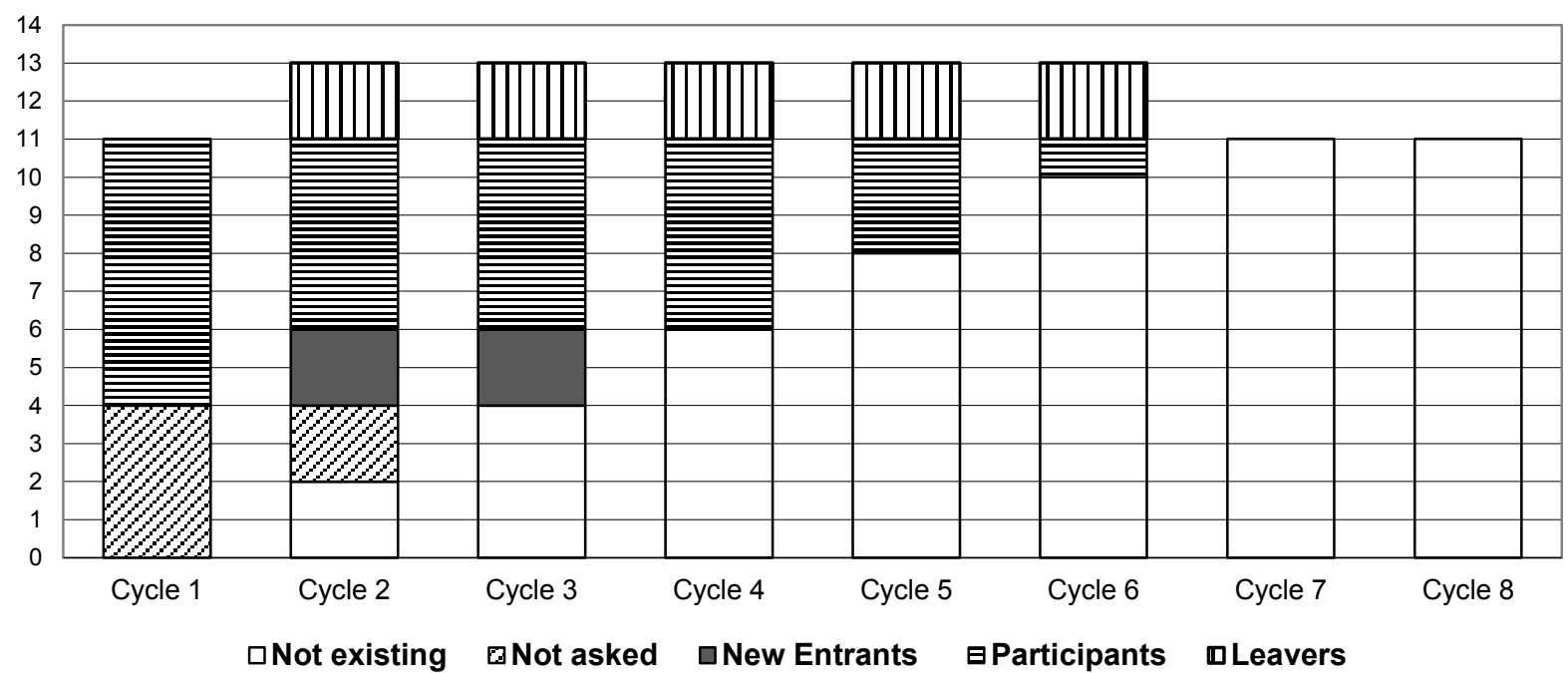

Notes. (i) Leavers are the children who grow out of the age range for the bullying question in the current cycle; (ii)Participants are those who are included in the bullying survey in the current cycle;(iii) New entrants are those who were in the NLSCY and were not included in the bullying survey due to their young age in the previous cycle, however, they entered in the bullying survey of the current cycle; (iv) Not asked are those who are in the current NLSCY survey but are not old enough to respond the bullying question; (v) Not existing are those children who are not in the current NLSCY survey at all.

In addition to the natural age attrition (grow into and out of the bullying sample) mentioned above, the NLSCY also has the survey attrition, as does every other longitudinal survey data, due to lack of response and loss of contact through years of tracking. Statistics Canada made every effort to track each child and they carefully make sure that the response rate is high enough to allow researchers to conduct longitudinal studies. Still, we list the longitudinal attrition in Table 5. Except for a higher than usual attrition rate from cycle three to cycle four (around 16 percent), the overall non-response rate is around 10 percent from one cycle to another. 
Table 5 - The longitudinal attrition of the sample of PMK-reported bullying variable

\begin{tabular}{|c|c|c|c|c|c|}
\hline$(\%)$ & C1 to C2 & C2 to C3 & C3 to C4 & C4 to C5 & C5 to C6 \\
\hline Longitudinal & 9.32 & 12.70 & 16.16 & 11.40 & 11.14 \\
survey & $(685)$ & $(919)$ & $(1296)$ & $(614)$ & $(339)$ \\
attrition & {$[7352]$} & {$[7237]$} & {$[8020]$} & {$[5385]$} & {$[3042]$} \\
\hline
\end{tabular}

Notes. The sample size of the lost sample is in the round bracket, while the total sample size is in the square bracket.

The hostile parenting score, the consistency score, and the positive interaction score are used to represent the general parental strategy/behavior $(\mathbf{z})$, while the punitive parenting score is employed to capture the parental bullying control $(\boldsymbol{P})$. These four scores are derived using four sets of weighted items ${ }^{42}$. Overall, the three parental strategy scores (hostile, consistency and positive interaction) measure the general parenting styles and the interaction between parents and children. In particular, they reveal the information about whether or not the parent is generally hostile, strict/consistent and friendly to the child. Additionally, the three parental behavior scores are also reflections of the child's behavior. For instance, how often parents praise/punish their children not only depends upon the parental strategy but also depends upon how often the children misbehave. However, the punitive parenting score differs from the three parental strategy scores (hostile, consistency and positive interaction) in terms of the survey questions used to derive them. Given that the child has "broken rules or have done something he/she is not supposed to do", the punitive score measures the level of parental punishment with a higher score indicating a higher parental control. Compared to the parental strategy scores, which are reflections of both parental behavior and the frequency of the child's misconduct, the punitive score is a best candidate to represent the bullying control $P$ given that the bullying is regarded to be one of the inappropriate behaviors. The three parenting scores are used to represent the general parental strategy $\mathbf{z}$.

\footnotetext{
${ }^{42}$ The questions used in each score are listed in Appendix II.
} 
Moreover, other covariates, controlling for children's demographic characteristics, such as health, personality, and family background are also included in the empirical analysis ${ }^{43}$. Table 6 outlines the summary statistics of age distributions of the PMK-reported sample. The PMK sample is obtained by pooling all the longitudinal observations from cycle one to cycle six with non-missing values in the PMK-reported bullying question ${ }^{44}$. Overall, children in the sample are evenly distributed across all the ages, which is also true for the PMK-reported bully sample. The percentage of bullies reported by the PMK is around 12 percent. Among the bullies, there is a higher percentage of boys compared to girls (54 percent versus 46 percent).

Table 6 - Summary statistics of age distributions of the PMK-reported sample

\begin{tabular}{|c|c|c|}
\hline Age & $\begin{array}{c}\text { PMK reported total sample } \\
(\%)\end{array}$ & PMK reported bully \\
4 & 10.44 & 11.77 \\
5 & 9.47 & 9.77 \\
6 & 12.45 & 12.08 \\
7 & 10.84 & 11.11 \\
8 & 13.78 & 14.08 \\
9 & 13.14 & 13.30 \\
10 & 15.95 & 14.46 \\
11 & 14.57 & 13.43 \\
Bully & 11.69 & 100.00 \\
Girls & 49.60 & 45.58 \\
Total Observations & 38,639 & 5,114 \\
\hline
\end{tabular}

Notes. The descriptive statistics is based on the pooled data from cycle one to cycle six of NLSCY for PMK -reported sample.

The statistical summaries of the four parenting scores are presented in Table 7. The higher values of scores indicate more punitive, hostile, consistent and more positive interaction

\footnotetext{
${ }^{43}$ We excluded school-related factors in the analysis here due to three reasons: 1) the school factors are reported by teachers/principals in the education file which is only available for the first four cycles rather than six cycles; 2) there is a higher non-response rate in the teacher's file compared to the PMK file; 3) We argue that school factors are generally time-invariant and will be irrelevant to our longitudinal analysis. However, this issue will be further investigated in the last robustness section.

${ }^{44}$ The NLSCY data includes some children for only cross-sectional analysis, which are excluded in this paper.
} 
respectively. We compare the parenting scores of bullies with those of non-bullies. The bullies' PMKs are more punitive, hostile, while they are less consistent and have fewer positive interaction with children relative to that of non-bullies' PMKs. And these differences are all statistically significant different from zero at one percent level. This could be explained by the fact that the parental bullying control (punitive score) is confounded by parental strategies (three parenting scores) as discussed in the model part, which are then influenced by the child's bullying behavior due to the simultaneous relationship between the parental strategy and the child's behavior. Thus, we observe higher average parental scores among bullies.

Table 7 - Descriptive statistics of parenting scores

\begin{tabular}{|c|c|c|c|}
\hline & PMK total sample & PMK reported bully & $\begin{array}{l}\text { PMK reported non- } \\
\text { bully }\end{array}$ \\
\hline $\begin{array}{l}\text { Parental bullying control } \\
\text { (Punitive score) }\end{array}$ & $\begin{array}{c}7.92 \\
(2.58) \\
{[0,19]}\end{array}$ & $\begin{array}{l}8.91 * * * \\
(2.52)\end{array}$ & $\begin{array}{l}7.85 \\
(2.55)\end{array}$ \\
\hline $\begin{array}{l}\text { Parental strategy } \\
\text { (Hostile score) }\end{array}$ & $\begin{array}{c}8.80 \\
(3.74) \\
{[0,26]}\end{array}$ & $\begin{array}{c}11.59 * * * \\
(3.82)\end{array}$ & $\begin{array}{c}8.32 \\
(3.41)\end{array}$ \\
\hline $\begin{array}{l}\text { Parental strategy } \\
\text { (Consistency score) }\end{array}$ & $\begin{array}{l}15.10 \\
(3.25) \\
\Gamma 0.200\end{array}$ & $\begin{array}{c}14.32 * * * \\
(3.46)\end{array}$ & $\begin{array}{l}15.29 \\
(3.19)\end{array}$ \\
\hline $\begin{array}{l}\text { Parental strategy } \\
\text { (Positive score) }\end{array}$ & $\begin{array}{l}12.64 \\
(2.82) \\
{[0,20]}\end{array}$ & $\begin{array}{l}12.50 * * * \\
(2.96)\end{array}$ & $\begin{array}{l}13.17 \\
(2.83)\end{array}$ \\
\hline
\end{tabular}

Notes. 1. The standard deviation is included in the round bracket, while the minimum and maximum values of each score are in the square bracket. 2 . The mean equality test was conducted on the PMK reported bully versus PMK reported non-bully with *** representing significance at $1 \%, * * 5 \%, * 10 \%$.

In Table 8, the descriptive statistics of other covariates are compared between PMKreported bullies and those of non-bullies. Compared to non-bullies, a significantly higher percentage of bullies are obese or overweight, have no religious affiliation, have more average siblings, and are diagnosed with psychological difficulties. For the other categorical variables, a 
higher proportion of bullies often or sometimes cannot concentrate and a higher percentage of bullies are from families with lower household income and home violence. All of these statistics are consistent with our expectations. However, striking evidence is found in the overall health of bullies. Generally, one might speculate that children who are in excellent health tend to have extra energy and thus more likely to bully. The statistics show that a lower percentage of bullies have excellent health compared to that of non-bullies. On the contrary, a significant larger proportion of bullies have very good, good and fair/poor health conditions. The previous grades are also compared between bullies and non-bullies in Table 8, which shows that more bullies tend to do average or poorly/very poorly on their academic work, however, the dependence of the previous grades and the child's current bullying status is generally tested to be insignificant at conventional levels except for the last category (poorly and very poorly) with the ten percent significance level. In our analysis, we control for the previous grades rather than current grades for two concerns: 1) to reduce the simultaneous association between current grades and bullying behavior; and 2) we also suspect that not only will children's behavioral problems be affected by parental control/strategy, but also the parenting will have impacts on children's academic achievement. Thus, the child's current academic performance might already capture some of the parental behavior, which will blur the true effects of parental control/strategy on the child's bullying.

Table 8 - Descriptive Statistics of other covariates

\begin{tabular}{|c|c|c|}
\hline & PMK reported bully & PMK reported non-bully \\
\hline Obese \& Overweight (\%) & $50.47^{* * *}$ & 47.44 \\
& {$[2,530]$} & {$[18,330]$} \\
\hline Child is religious (\%) & $79.64^{* * *}$ & 84.58 \\
& {$[4,034]$} & {$[32,356]$} \\
\hline Siblings & $1.46^{* * *}$ & 1.35 \\
& {$[5114]$} & {$[38,639]$} \\
\hline Annul household income & & \\
\hline
\end{tabular}




\begin{tabular}{|c|c|c|}
\hline (grouped) (\%) & & \\
\hline Less than 20,000 & $\begin{array}{c}15.37 * * * \\
{[786]}\end{array}$ & $\begin{array}{c}10.08 \\
{[3893]}\end{array}$ \\
\hline Between 20,000 and 40,000 & $\begin{array}{c}27.73 * * * \\
{[1418]}\end{array}$ & $\begin{array}{c}24.04 \\
{[9,286]}\end{array}$ \\
\hline 40,000 or more & $\begin{array}{c}56.90^{* * *} \\
{[2910]}\end{array}$ & $\begin{array}{c}65.89 \\
{[25,460]}\end{array}$ \\
\hline \multicolumn{3}{|l|}{ Violence at home (\%) } \\
\hline Often \& Sometimes & $\begin{array}{c}4.64 * * * \\
{[267]}\end{array}$ & $\begin{array}{c}1.89 \\
{[823]}\end{array}$ \\
\hline Seldom & $\begin{array}{c}9.70^{* * *} \\
{[558]}\end{array}$ & $\begin{array}{c}5.62 \\
{[2441]}\end{array}$ \\
\hline Never & $\begin{array}{c}85.65^{* * * *} \\
{[4926]}\end{array}$ & $\begin{array}{c}92.48 \\
{[40,159]}\end{array}$ \\
\hline \multicolumn{3}{|l|}{ Overall health (\%) } \\
\hline Excellent & $\begin{array}{c}48.34^{* * *} \\
{[2,472]}\end{array}$ & $\begin{array}{c}57.10 \\
{[22,064]}\end{array}$ \\
\hline Very good & $\begin{array}{c}34.12^{* * *} \\
{[17,45]}\end{array}$ & $\begin{array}{c}30.75 \\
{[11,882]}\end{array}$ \\
\hline Good & $\begin{array}{c}14.92^{* * *} \\
{[763]}\end{array}$ & $\begin{array}{c}10.77 \\
{[4,161]}\end{array}$ \\
\hline Fair and poor & $\begin{array}{c}2.62 * * * \\
{[134]}\end{array}$ & $\begin{array}{c}1.37 \\
{[432]}\end{array}$ \\
\hline Psychological problem (\%) & $\begin{array}{c}5.08^{* * *} \\
{[206]}\end{array}$ & $\begin{array}{c}1.23 \\
{[385]}\end{array}$ \\
\hline \multicolumn{3}{|l|}{ Cannot concentrate (\%) } \\
\hline Never & $\begin{array}{c}35.94 * * * \\
{[1,837]}\end{array}$ & $\begin{array}{c}63.14 \\
{[24,383]}\end{array}$ \\
\hline Sometimes & $\begin{array}{c}50.41 * * * \\
{[2,577]}\end{array}$ & $\begin{array}{c}31.53 \\
{[12,175]}\end{array}$ \\
\hline Often & $\begin{array}{c}13.65^{* * * *} \\
{[698]}\end{array}$ & $\begin{array}{c}5.33 \\
{[2,060]}\end{array}$ \\
\hline \multicolumn{3}{|l|}{ Lag Grade (\%) } \\
\hline Very well & $\begin{array}{c}47.32 \\
{[1,120]}\end{array}$ & $\begin{array}{c}48.38 \\
{[8,688]}\end{array}$ \\
\hline Well & $\begin{array}{l}27.04 \\
{[640]}\end{array}$ & $\begin{array}{c}27.50 \\
{[4,939]}\end{array}$ \\
\hline Average & $\begin{array}{l}21.84 \\
{[517]}\end{array}$ & $\begin{array}{c}21.02 \\
{[3,775]}\end{array}$ \\
\hline Poorly and very poorly & $\begin{array}{c}3.80^{*} \\
{[90]}\end{array}$ & $\begin{array}{c}3.11 \\
{[557]}\end{array}$ \\
\hline
\end{tabular}

Notes. 1. The sample size for each category is included in the square bracket. 2. The mean equality test was conducted on the non-categorical variable for PMK reported bullies versus PMK reported non-bullies, while the bivariate chi square test for the hypothesis that the bully status and the variable of interest are independent is applied to the categorical variables with $* * *$ representing significance at $1 \%, * * 5 \%, * 10 \%$. 


\subsection{Empirical Strategy}

\subsubsection{Empirical model}

By carrying out multivariate analysis, we are able to test whether the parental bullying control has a significant impact on the children's bullying behavior as predicted in the theoretical model - greater control from parents inhibits bullying.

The investigation of the causal relationship between parental control (measured by the parenting punitive score) and the children's bullying behavior requires care due to identification problems which could potentially bias our estimates of the causal relationship. There are several issues needed to be taken care of during estimation: 1) proposition 1 has outlined the endogenous problem associated with parental bullying control caused by the potential correlation between the parenting control and some unobserved characteristics $(\boldsymbol{x})$ of children and general parental strategies (z) left out in the error term; 2) the real power of the parental bullying control could be confounded by the general parental behavior. In order to generate an unbiased estimate of the bullying control's impact, the parental behavior variables need to be included in the econometric model; 3) given the simultaneity and reverse causality between parental strategy/behavior and the children's behavior, the estimates on the general parental behavior could only be treated as associations rather than causality; and 4) the theoretical model and also the following estimation are based on the assumption that there is no simultaneous relationship between the parental bullying control and the bullying behavior of children.

We employ a conditional fixed-effects logistic model (Chamberlain, 1980) to account for the endogeneity related to the parental control variable. The NLSCY data is longitudinal which can be used to eliminate bias so long as the unobserved heterogeneity causing the bias does not vary through time. 


$$
y_{i t}^{*}=\beta P_{i t}+z_{i t}^{\prime} \theta+x_{i t}^{\prime} \gamma+u_{i}+v_{i t} \quad i=1, \ldots, N, t=1, \ldots, T .
$$

We estimate the above fixed-effects panel logit model (13) where if $y_{i t}^{*}>0, y_{i t}=1$ for bullying, and if $y_{i t}^{*} \leq 0, y_{i t}=0$ for non-bullying. $u_{i}$ is an individual specific fixed effect. $P_{i t}$ is the bullying punishment represented by the punitive score. The parental strategy vector, $\mathbf{z}_{\boldsymbol{i t}}^{\prime}$, includes the hostile score, the consistency score and the parenting positive interaction score. The inclusion of the general parental behavior (z) allows us to disentangle the real effect of the parental bullying control on child's bullying from the general parental strategies/interactions. $\boldsymbol{x}_{i t}$ is a vector of variables controlling for the child's economic and demographic characteristics. $v_{i t}$ is a random error. $\beta, \theta$ and $\gamma$ are unknown parameters. The coefficients are estimated by maximizing a conditional likelihood function. The conditional likelihood function will sweep away the fixed effect $u_{i}$. The fixed-effects logistic estimation requires variation in both the dependent variable and covariates. Those children whose bullying statuses are the same over time have no contribution to the log-likelihood function, although they are valid observations. The consistent estimates are identified by intertemporal variation in the variables for each individual. Only individuals whose bullying status varies across time will contribute to the estimation. From now on, we call these individuals as "switchers". Moreover, for the covariates which are constant across time, their effects cannot be estimated and they will be automatically swept away together with the fixed effect $u_{i}$.

\subsubsection{Findings from the regressions}

Different logistic estimates are shown in Table 9. Since both parental bullying control and general parenting strategies variables are reported by the Person-Most-Knowledgeable about 
the child (PMK $)^{45}$, we use the sample of children whose bullying/not-bullying behavior is identified by their PMK.

The first five columns in Table 9 contain results of conditional fixed-effects logit regressions with different model specifications. Only characteristics of children and familyrelated factors are included in column (1) of Table 9, while estimations in columns (2) - (5) gradually include the parental bullying control (punitive score) and a set of general parenting behavior scores (the hostile, consistency, and positive interaction scores). The estimated coefficient on the parental bullying control $(\boldsymbol{P})$ is positive and significant at the one percent level in column (2) of Table 9 when the general parental strategies (z) are not included in the model, which is opposite with the prediction in the theoretical model that the higher parental bullying control lead to the better inhibition of bullying. However, after the general parental behavior scores (hostile, consistency and positive interaction) gradually enter in the estimations in columns (3) to (5), the estimates on the bullying control become significantly negative with increasing magnitudes of effects, which are in line with the prediction. This change serves as evidence to support the conclusion outlined in proposition 1 that the real impact of parental bullying control is biased by different general parental styles.

According to the estimate in column (5) of Table 9, a one standard deviation increase in the parental bullying control score will lead to a 0.10 (calculated as $2.58 * 0.039=0.10$ ) unit reduction in the log odds of being a bully versus a non-bully, which is equivalent to roughly a 9.57 percent $^{46}$ decrease in the odds ratio. Hostile parental behavior is found to be positively associated with the probability of being a bully for the child. The estimated coefficient on the hostile score is 0.231 which is significantly different from zero at the one percent level in column

\footnotetext{
${ }^{45}$ For approximately $90 \%$ of all respondents, the PMK is the child's mother.

${ }^{46}\{\exp (-0.039 * 2.58)-1\}=-0.0957$.
} 
(5), implying that a one standard deviation increase in the hostile score is associated with a 89.6 percent rise in the odds ratio of being a bully. In contrast, the higher parental positive interaction score is related to a lower probability of the child bullying (a one standard deviation increase in the score is connected with an 8.4 percent decrease in the odds ratio of child's bullying).

However, the consistency score is not statistically significant from zero.

The consistency score mainly measures how consistent the parents are in educating their children. Specifically, under situations that parents feel like they should discipline their children, do they really act on it or just let it go in the end? Ignoring the children's inappropriate behavior will cause lower consistency scores. However, we argue that the parenting consistency score is also prone to the simultaneity and reverse causality problem. For instance, a parent with a child who always commits inappropriate behavior tends to have a lower consistency score since the parent will not have sufficient energy to discipline the child for so many problems compared to the parent whose child seldom breaks rules. The same rational could also be applied to the other two scores capturing general parenting styles (hostile and positive interaction). Table A1 in the Appendix I lists the correlations among the four parenting scores. The hostile and punitive scores are positively correlated with each other and the consistency and positive interaction scores are negatively correlated with the other two scores. The simultaneous relationship between the parental strategy/behavior and children's behavior allow us only to identify the connections between them rather than causal effects.

It is worth noting that changes in general parenting strategies/styles over time could be due to two sources: 1) changes in child's behavior (reverse causality); and 2) changes in characteristics of parents such as parents attending school, work stress, changing jobs and peer effects of parenting behavior. However, this paper focuses on the identification of effects on the 
child's bullying behavior of the specific bullying control $P$ (punitive score) rather than the general parenting. Controlling for the general parenting style could be seen as an intermediate step for reducing the endogenous problem associated with the bullying control and identifying the real causality between bullying and parental bullying control.

We also conducted a series of random effects logistic estimations with the same model specification as that in columns (2) to (5) of Table 9. Since the random effects logit estimation produce fairly similar results to those from logistic estimation, we do not report random effects results here and we will identify the differences in estimates between fixed effects and random effects by comparing the results of fixed effects to those from logit estimation reported in columns (6) and (7) of Table 9. Column (6) reports the result of simple logit estimation on the sample of children whose bullying statuses change over time, who were referred as "switchers" earlier in this paper. Therefore, columns (5) and (6) list the estimates from regressions on the same group of children. The difference between the two columns is due to different methodologies (longitudinal versus cross-sectional). However, it is natural to raise the question of whether or not the "switchers" who contributed to the estimation of the conditional fixed effects logit model in columns (5) are representative of all the population. Comparing the logit regression estimates on the "switchers" in column (6) to the logit estimates from the regression on the overall sample ${ }^{47}$ in column (7) of Table 9 will contribute to the robustness check of the sensitivity of our results to the sample selection issue, which is common to fixed effects models.

In comparison to the cross-sectional insignificant estimated coefficients in columns (6) and (7) of Table 9 on the parenting bullying control variable (punitive score), controlling for the unobserved time-invariant individual characteristics leads to a significant inhibition effect of bullying control on stopping the child from bullying. Although, the results are quantitatively

\footnotetext{
${ }^{47}$ We pool all observations from cycle one to cycle six from PMK- reported samples.
} 
different between estimations on "switchers" in column (6) and those on the overall sample in column (7), they are qualitatively consistent with each other for all variables except for one variable of the annual household income higher than $\$ 40,000$.

Restricted in the longitudinal tracking widow (maximum up to eight years of four waves), children in the overall sample could be decomposed into three components: 1) children who never bully; 2) children whose bullying behavior changes over time; 2) children who are bullies through all the years. Children in the second category are the "switchers" who contribute to longitudinal estimations, while all the children in the three categories are included in the overall cross-sectional sample. Therefore, to a certain extent, the fixed-effects estimation does cause the sample selection problem. Our fixed effects results only apply to children in the second category. However, if we assume that every child's bullying behavior could be affected by the same group of external factors in the same fashion and also follows a similar development/evolvement path since its formation, our conclusion could be generalized to all relevant children at a certain bullying development phase/stage ${ }^{48}$. On the contrary, if the influence of external attributes on children's bullying behavior is vitally responsive to some unobserved genetic characteristics unique to different children, our conclusions here could not be generalized to all the relevant children. Later, we will continue illustrating the issues with respect to the sample selection in the robustness check section.

All the other variables controlled in the estimation capture children's characteristics and family background to reduce omitted variable bias. Most of the covariates are found to be significantly different from zero and the effects might be of interest to some readers. Here, we want to mention four interesting points which could trigger further investigations.

\footnotetext{
${ }^{48}$ The conclusions do not apply to those who will never develop bullying behavior by nature and we treat them as the non-relevant children in our analysis.
} 
First, the relationship between obesity/overweight and the bullying behavior is found to be statistically insignificant from zero in all the estimations. ${ }^{49}$ This is evidence against the claim that obese or overweight children aged from 4 to 11 years old are more likely to be bullies compared to those children with normal or lower weights. Some researchers have found the relationship between the body weight and bullying tendency for children in a given age range. Most of the existing literature has shown that the association exists among children at older ages $^{50}$. However, Griffiths, et. al. (2006) has found that obese children at seven and a half years are more likely to commit bullying after one year by using data from Southwest England. Our analysis on Canadian children contributes to the literature on obesity and bullying.

Second, we find that children who are reported by their PMK to have a religious belief have lower log odds of being bullies by around 0.263 units (equivalent to 23.12 percent lower in odds ratio of being bullies). Few researchers have linked religion with the children's bullying behavior. It is possible that the religion dummy actually captures the effects of some covariates that are omitted from the model, but it is also possible that religion by itself might have a restrictive power on children's behavior. This topic requires further exploration.

Third, having an additional sibling is estimated to be associated with a 27 percent increase in the odds ratio of bullying. Having more siblings could affect children's behavior through two potential channels: 1) It is more likely to have conflicts among siblings when more siblings are present, which could then be easily observed by parents and reported as bullying; and 2) children with more siblings might feel stronger and have more power over other children

\footnotetext{
49 The obese indicator was also found to be insignificant from zero.

${ }^{50}$ Ian Janssen, Wendy M. Craig, William F. Boyce and William Pickett(2004). Tilda Farhat, Ronald J. Iannotti and Bruce G. Simons-Morton (2010).
} 
and the imbalance of power might lead to child bullying. We could not disentangle these two effects from each other at this moment and further investigation still requires.

Finally, compared to children whose health condition is excellent, those who are in very good/ good health are more likely to bully. The estimate is significantly different from zero at conventional levels from most estimation models in Table 9 and is significant at around 15 percent significance level according to column (5) of Table 6. However, no significant differences in bullying behavior are present for children with either fair/weak health and those with excellent health (default). In particular, children in a very good/good health condition have a higher odds ratio of being bullies by around 14.91 percent relative to those in an excellent health condition based on the results in column (6) of Table 9. One might suspect that the overall health variables could have reflected the effects of mental health conditions. However, the results are from models after controlling for children's reported psychological problems. It seems like that when children's physical health condition deteriorates to certain level, they become more violent. The finding raises a question: is the physical health condition actually related to children's mental tolerance, emotion, temper control and attitudes, which will then affect their behavior? Definitely, the issue needs further investigation in the future. 
Table 9 - The estimated coefficients of regressions of PMK- reported child bullies

\begin{tabular}{|c|c|c|c|c|c|c|c|}
\hline & $\begin{array}{l}\text { (1) } \\
\text { Fixed } \\
\text { effects }\end{array}$ & $\begin{array}{c}\text { (2) } \\
\text { Fixed } \\
\text { effects }\end{array}$ & $\begin{array}{l}\text { (3) } \\
\text { Fixed } \\
\text { effects }\end{array}$ & $\begin{array}{l}\text { (4) } \\
\text { Fixed } \\
\text { effects }\end{array}$ & $\begin{array}{l}\text { (5) } \\
\text { Fixed } \\
\text { effects }\end{array}$ & $\begin{array}{c}(6) \\
\text { Logit on } \\
\text { switchers }\end{array}$ & $\begin{array}{c}\text { (7) } \\
\text { Logit on } \\
\text { overall } \\
\text { sample } \\
\end{array}$ \\
\hline $\begin{array}{l}\text { Parental } \\
\text { bullying } \\
\text { control } \\
\text { (punitive } \\
\text { score) }\end{array}$ & & $\begin{array}{c}0.085^{* * *} \\
(0.015)\end{array}$ & $\begin{array}{l}-0.030^{*} \\
(0.017)\end{array}$ & $\begin{array}{c}-0.035^{* *} \\
(0.018)\end{array}$ & $\begin{array}{c}-0.039 * * \\
(0.018)\end{array}$ & $\begin{array}{l}-0.026 \\
(0.016)\end{array}$ & $\begin{array}{c}0.002 \\
(0.010)\end{array}$ \\
\hline 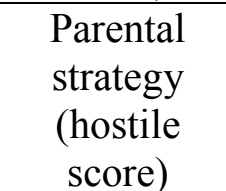 & & & $\begin{array}{c}0.241 * * * \\
(0.015)\end{array}$ & $\begin{array}{c}0.236 * * * \\
(0.015)\end{array}$ & $\begin{array}{c}0.231 * * * \\
(0.015)\end{array}$ & $\begin{array}{c}0.227 * * * \\
(0.013)\end{array}$ & $\begin{array}{c}0.211^{* * *} \\
(0.008)\end{array}$ \\
\hline $\begin{array}{c}\text { Parental } \\
\text { strategy } \\
\text { (consistency } \\
\text { score) }\end{array}$ & & & & $\begin{array}{l}-0.018 \\
(0.015)\end{array}$ & $\begin{array}{l}-0.017 \\
(0.015)\end{array}$ & $\begin{array}{l}-0.004 \\
(0.013)\end{array}$ & $\begin{array}{c}0.007 \\
(0.008)\end{array}$ \\
\hline $\begin{array}{c}\text { Parental } \\
\text { strategy } \\
\text { (positive } \\
\text { interaction } \\
\text { score) }\end{array}$ & & & & & $\begin{array}{l}-0.031^{*} \\
(0.017)\end{array}$ & $\begin{array}{l}-0.030^{*} \\
(0.015)\end{array}$ & $\begin{array}{c}-0.032 * * * \\
(0.010)\end{array}$ \\
\hline Age & $\begin{array}{c}0.194 \\
(0.277)\end{array}$ & $\begin{array}{c}0.355 \\
(0.281)\end{array}$ & $\begin{array}{c}0.129 \\
(0.315)\end{array}$ & $\begin{array}{c}0.130 \\
(0.316)\end{array}$ & $\begin{array}{c}0.109 \\
(0.3170\end{array}$ & $\begin{array}{c}0.113 \\
(0.287)\end{array}$ & $\begin{array}{c}0.027 \\
(0.181)\end{array}$ \\
\hline $\begin{array}{c}\text { Obese or } \\
\text { Overweight }\end{array}$ & $\begin{array}{c}0.040 \\
(0.078)\end{array}$ & $\begin{array}{c}0.056 \\
(0.079)\end{array}$ & $\begin{array}{c}0.071 \\
(0.089)\end{array}$ & $\begin{array}{c}0.073 \\
(0.089) \\
\end{array}$ & $\begin{array}{c}0.071 \\
(0.089)\end{array}$ & $\begin{array}{c}0.050 \\
(0.080)\end{array}$ & $\begin{array}{c}0.074 \\
(0.051)\end{array}$ \\
\hline $\begin{array}{l}\text { Very good } \\
\text { or good } \\
\text { health }\end{array}$ & $\begin{array}{c}0.249 * * * \\
(0.080)\end{array}$ & $\begin{array}{c}0.232 * * * \\
(0.081)\end{array}$ & $\begin{array}{l}0.150^{*} \\
(0.090)\end{array}$ & $\begin{array}{l}0.144^{*} \\
(0.081)\end{array}$ & $\begin{array}{c}0.139 \\
(0.091)\end{array}$ & $\begin{array}{l}0.139^{*} \\
(0.081)\end{array}$ & $\begin{array}{c}0.144 * * * \\
(0.051)\end{array}$ \\
\hline $\begin{array}{l}\text { Fair or Poor } \\
\text { health }\end{array}$ & $\begin{array}{l}-0.047 \\
(0.320)\end{array}$ & $\begin{array}{l}-0.067 \\
(0.323) \\
\end{array}$ & $\begin{array}{c}0.133 \\
(0.372)\end{array}$ & $\begin{array}{c}0.161 \\
(0.375)\end{array}$ & $\begin{array}{c}0.181 \\
(0.374)\end{array}$ & $\begin{array}{l}-0.151 \\
(0.350)\end{array}$ & $\begin{array}{c}0.102 \\
(0.204)\end{array}$ \\
\hline $\begin{array}{l}\text { Psychologic } \\
\text { al problem }\end{array}$ & $\begin{array}{c}0.811 * * * \\
(0.272)\end{array}$ & $\begin{array}{c}0.826^{* * *} \\
(0.275)\end{array}$ & $\begin{array}{c}0.486^{*} \\
(0.297)\end{array}$ & $\begin{array}{c}0.450 \\
(0.303)\end{array}$ & $\begin{array}{c}0.448 \\
(0.302)\end{array}$ & $\begin{array}{c}0.575^{* *} \\
(0.273)\end{array}$ & $\begin{array}{c}0.658^{* * *} \\
(0.147)\end{array}$ \\
\hline $\begin{array}{c}\text { Often } \\
\text { cannot } \\
\text { concentrate }\end{array}$ & $\begin{array}{c}1.402 \\
(0.148)\end{array}$ & $\begin{array}{c}1.335^{* * * *} \\
(0.149)\end{array}$ & $\begin{array}{c}0.748 * * * \\
(0.170)\end{array}$ & $\begin{array}{c}0.718 * * * \\
(0.171)\end{array}$ & $\begin{array}{c}0.724 * * * \\
(0.171)\end{array}$ & $\begin{array}{c}0.726^{* * * *} \\
(0.151)\end{array}$ & $\begin{array}{c}0.682^{* * * *} \\
(0.089)\end{array}$ \\
\hline $\begin{array}{c}\text { Sometimes } \\
\text { cannot } \\
\text { concentrate }\end{array}$ & $\begin{array}{c}1.027 * * * \\
(0.087)\end{array}$ & $\begin{array}{c}0.988^{* * * *} \\
(0.088)\end{array}$ & $\begin{array}{c}0.778 * * * \\
(0.097)\end{array}$ & $\begin{array}{c}0.756^{* * *} \\
(0.098)\end{array}$ & $\begin{array}{c}0.757^{* * * *} \\
(0.098)\end{array}$ & $\begin{array}{c}0.739 * * * \\
(0.085)\end{array}$ & $\begin{array}{c}0.697 * * * \\
(0.054)\end{array}$ \\
\hline $\begin{array}{c}\text { Annual } \\
\text { household } \\
\text { income } \\
<\$ 20,000\end{array}$ & $\begin{array}{l}0.267^{*} \\
(0.149)\end{array}$ & $\begin{array}{l}0.279 * \\
(0.151)\end{array}$ & $\begin{array}{l}0.310^{*} \\
(0.167)\end{array}$ & $\begin{array}{l}0.329^{*} \\
(0.168)\end{array}$ & $\begin{array}{c}0.347^{* *} \\
(0.169)\end{array}$ & $\begin{array}{c}0.305^{* *} \\
(0.154)\end{array}$ & $\begin{array}{c}0.225^{* *} \\
(0.091)\end{array}$ \\
\hline
\end{tabular}




\begin{tabular}{|c|c|c|c|c|c|c|c|}
\hline $\begin{array}{c}\text { Annual } \\
\text { household } \\
\text { income } \\
>\$ 40,000\end{array}$ & $\begin{array}{c}-0.209^{* *} \\
(0.093)\end{array}$ & $\begin{array}{c}-0.148 \\
(0.094)\end{array}$ & $\begin{array}{c}-0.207^{*} \\
(0.107)\end{array}$ & $\begin{array}{c}-0.202^{*} \\
(0.107)\end{array}$ & $\begin{array}{c}-0.199^{*} \\
(0.107)\end{array}$ & $\begin{array}{c}-0.141 \\
(0.096)\end{array}$ & $\begin{array}{c}-0.228^{* * *} \\
(0.060)\end{array}$ \\
\hline $\begin{array}{c}\text { Number of } \\
\text { siblings }\end{array}$ & $\begin{array}{c}0.238^{* * *} \\
(0.042)\end{array}$ & $\begin{array}{c}0.228^{* * *} \\
(0.042)\end{array}$ & $\begin{array}{c}0.249^{* * *} \\
(0.047)\end{array}$ & $\begin{array}{c}0.246^{* * *} \\
(0.048)\end{array}$ & $\begin{array}{c}0.239^{* * *} \\
(0.048)\end{array}$ & $\begin{array}{c}0.219^{* * *} \\
(0.043)\end{array}$ & $\begin{array}{c}0.179^{* * *} \\
(0.026)\end{array}$ \\
\hline $\begin{array}{c}\text { Violence } \\
\text { Dummy }\end{array}$ & $\begin{array}{c}0.731^{* * *} \\
(0.236)\end{array}$ & $\begin{array}{c}0.716^{* * *} \\
(0.237)\end{array}$ & $\begin{array}{c}0.367 \\
(0.266)\end{array}$ & $\begin{array}{c}0.404 \\
(0.268)\end{array}$ & $\begin{array}{c}0.391 \\
(0.268)\end{array}$ & $\begin{array}{c}0.649 * * * \\
(0.245)\end{array}$ & $\begin{array}{c}0.559^{* * *} \\
(0.129)\end{array}$ \\
\hline $\begin{array}{c}\text { Dummy } \\
\text { indicating } \\
\text { the child is } \\
\text { religious }\end{array}$ & $\begin{array}{c}-0.280^{* * *} \\
(0.108)\end{array}$ & $\begin{array}{c}-0.293^{* * *} \\
(0.108)\end{array}$ & $\begin{array}{c}-0.247^{* *} \\
(0.124)\end{array}$ & $\begin{array}{c}-0.260^{* *} \\
(0.125)\end{array}$ & $\begin{array}{c}-0.263 * * \\
(0.125)\end{array}$ & $\begin{array}{c}-0.189 * \\
(0.108)\end{array}$ & $\begin{array}{c}-0.158^{* *} \\
(0.065)\end{array}$ \\
\hline $\mathrm{N}$ & & & & & & & \\
\hline
\end{tabular}

Notes.

1.The samples are from Cycle 1 to Cycle 6 of National Longitudinal Survey of Children and Youth. The Logit regression in column (7) is based on the sample by pooling the PMK-reported samples from cycle 1 to cycle 6 of NLSCY.

2. Age $^{2}$ and lagged academic grades dummies are also included in all the regressions.

3. Standard errors are included in the bracket.

4.Significance level is represented by *** $1 \%, * * 5 \%, * 10 \%$.

5.The dummy variable obese $\&$ overweight takes value 1 indicating the child is either obese or overweight, and 0 for normal weight. The obese \& overweight dummy is based on the kids Body Mass Index Charts which take age, gender, height and weight into consideration.

6 . The default health dummy is the excellent health dummy.

7. The violence dummy is equal to one if there is often and sometimes violence at home, and is equal to zero if the violence has never or seldom happened at home.

8 . The default dummy is never cannot concentrate for the dummies often cannot concentrate and sometimes cannot concentrate.

9. The default annual household income dummy is between $(\$ 20,000, \$ 40,000)$.

10. The child's religion is reported by the PMK and the religious dummy indicating whether or not the child is religious is created based on the response of the PMK.

11.The constant is also included in the logit regression and not shown here.

Table 10 reports fixed-effects logit estimates from a model of bullying separately for boys and girls. The same specification as in column (5) of Table 9 is employed. Comparing column (1) with column (2) in Table 10, we find that the parental discipline on bullying (punitive parenting) works more effectively on girls to stop bullying compared to boys. Although the log 
odds for boys will be reduced by a unit of 0.083 with a one standard deviation increase in the punitive score, the magnitude of the effect is less than the equivalent effect of 0.114 for girls and is also statistically insignificantly different from zero at conventional levels. Additionally, a higher positive interaction score is estimated to be associated with a lower probability of bullying behavior for boys but not for girls. We speculate that this could be due to different parent-child relationships between boys and girls. For instance, if boys are generally harder to manage/control and are more likely to develop adverse behavior, their parents' strategy would be easily affected by their boys' negative behavior. Therefore, the simultaneous association between male children behavior and parental behavior may be more prevalent than female children. As well, a larger estimated connection between higher hostile parenting score and higher probability of bullying for boys ( 0.246$)$ than for girls $(0.222)$ is also consistent with our speculation that there is a greater simultaneous influence between boys and their parents relative to girls.

Also, there are some obvious gender differences in impacts of other controlled covariates on the bullying log odds. The probability of bullying for girls increases with the deterioration of their health status from an excellent condition to a very good/good condition. However, that is not the case for boys with statistically insignificant estimates. In addition, boys living in a richer family (annual household income $>\$ 40,000$ ) are less likely to be bullies, which is not statistically significant for girls. One explanation for this phenomenon could be that a family with higher income might have more resource access to put their children to participate in many extracurricular activities to divert their attention from bullying. The estimated results show that the attention diversion is more effective in controlling boy bullying compared with girl bullying. This finding is especially helpful when parental bullying control fails on boys. Further, the sibling influence is higher on boys with 0.282 units increase in the log odds of bullying 
associated with an additional sibling compared to 0.205 units increase for girls. Finally, having a religious belief is associated with a reduction in boys' bullying behavior but the effects are not statistically significant for girls.

Table 10 - The estimated coefficients of regressions of child bullies for girls and boys respectively

(1) (2)

Fixed-effects logit for girls $\quad$ Fixed-effects logit for boys

\begin{tabular}{|c|c|c|}
\hline $\begin{array}{c}\text { Parental bullying control } \\
\text { (punitive score) }\end{array}$ & $-0.044^{*}$ & -0.032 \\
\hline Parental strategy & $(0.025)$ & $0.025)$ \\
(hostile score) & $0.222^{* * *}$ & $(0.023)$ \\
\hline Parental strategy & $(0.021)$ & -0.017 \\
(consistency score) & -0.017 & $(0.022)$ \\
\hline Parental strategy & $(0.022)$ & $-0.046^{*}$ \\
(positive interaction score) & -0.015 & $(0.025)$ \\
\hline Very good or good health & $(0.024)$ & 0.0001 \\
& $0.280^{* *}$ & $(0.131)$ \\
\hline Fair or poor health & $(0.132)$ & 0.204 \\
& 0.116 & $(0.522)$ \\
\hline Annual household income & $(0.530)$ & 0.368 \\
$<$ \$20,000 & 0.281 & $(0.237)$ \\
\hline Annual household income & $(0.249)$ & $-0.270^{*}$ \\
$>$ \$40,000 & -0.184 & $(0.156)$ \\
\hline Number of siblings & $(0.152)$ & $0.282^{* * *}$ \\
& $0.205^{* * *}$ & $(0.071)$ \\
\hline Dummy indicating the child is & $(0.065)$ & $-0.374^{* *}$ \\
religious & -0.142 & $(0.176)$ \\
\hline $\mathrm{N}$ & $(0.183)$ & 1690 \\
\hline
\end{tabular}

Notes.

1. The samples are from Cycle 1 to Cycle 6 of National Longitudinal Survey of Children and Youth.

2. Age $^{2}$ and lagged academic grades dummies are also included in all the regressions, but estimates on these variables are not statistically significant at conventional levels. Age, psychological problem dummy, obese/overweight dummy, home violence dummy, and often and sometimes cannot concentrate dummies are also included in the regressions.

3. Standard errors are included in the bracket.

4. Significance level is represented by *** $1 \%, * * 5 \%, * 10 \%$.

5. The default health dummy is the excellent health dummy. 


\subsection{Robustness Check}

\subsubsection{Omitted school-related characteristics}

One concern about robustness of the multivariate estimation results reported in Tables 9 and 10 is that none of the school characteristics are controlled in the models. We did not include the school-related covariates due to the following three reasons: 1) the school-related variables reported by teachers and principals are only available from cycle one to cycle four in the NLSCY data, whereas the parent-reported covariates are from cycle one to cycle six which means that the school variables have less observations that reduce the regression sample size significantly and may result in sample selection biases; 2) over the survey years, many of the school-related covariates are relatively stable, which would not lead to a change in the bullying status of children across years; and 3) the non-response rate in the teacher/principal survey is much higher than that of the PMK-reported survey, which leads to a larger number of missing values for the school-related variables ${ }^{51}$.

Table 11 shows school-related covariate variations over cycles. Except for the class size and homework monitoring variables, the average proportion of observed individuals whose school characteristics vary across cycles is relatively small at around 53 percent. For these school-related covariates, 47 percent of the sample does not change through the years.

Table 11 - Variation dynamics of school-related covariates

\begin{tabular}{|c|c|}
\hline School related covariates & Variation (\%) \\
\hline Class size & 79.33 \\
\hline Homework monitoring by teachers & 68.65 \\
\hline Class easily disrupted & 56.07 \\
\hline Class misbehaves with absence of teacher & 58.43 \\
\hline Teachers overlook physical problem & 50.89 \\
\hline Teachers overlook verbal aggression & 54.76 \\
\hline
\end{tabular}

\footnotetext{
${ }^{51}$ On average, around 0.1 percent of the pooled population from Cycle 1 to Cycle 4 has non-response values in the parenting variables reported by PMK, while roughly fifty percent of the pooled population from Cycle 1 to Cycle 4 has non-response values in the school-related variables reported by teachers.
} 


\begin{tabular}{|c|c|}
\hline Physical conflicts disciplined by principal (\%) & 51.85 \\
\hline Verbal conflicts disciplined by principal (\%) & 48.07 \\
\hline
\end{tabular}

Notes.

1. The variations are calculated conditional on the variations in the bullying status.

2. The statistics are from the pooled sample from cycle one to cycle four of NLSCY.

Estimation from models with the inclusion of the above school variables will suffer from sample selection bias. As well, it will be hard to correctly identify the real effects of variables of interest. In addition, based on the evidence that the variation of school environments on average accounts for roughly half of the variation of children's bullying status, it will be difficult to precisely derive any causal relationship between school characteristics and children's bullying. Also, the selection of school is a choice of parents and children, and to some extent, the family's social-economic background could capture some of the school effects on children's behavior. However, the parental control and general parenting behavior are unlikely to correlate with the omitted school variables. Consistent with our argument, most variables become insignificantly different from zero once we include the school characteristics in the fixed effects logit model, which is due to dramatic decrease in the sample size. Particularly, almost every school-related covariate is estimated to be insignificantly different from zero at conventional levels ${ }^{52}$. Thus, the omission of school-related covariates could not alter our results.

\subsubsection{Multinomial and ordered logit regressions}

The original bullying question in the NLSCY survey has three possible responses: 1) never bully; 2) sometimes bully; and 3) often bully. In the previous analysis, we combine the last two categories (sometimes bully or often bully) to indicate a bully and treat the first category (never bully) as a non-bully. In this session, by employing the original three-scale discrete bullying variable, we separately run the multinomial logit and ordered logit regressions of child's bullying

\footnotetext{
${ }^{52}$ We do not report the results here, but they are available upon request.
} 
behavior due to parental bullying control and parenting behavior. As well, the estimations are applied on the longitudinal sample comprised of children (switchers) whose bullying status changes through cycles and also on the overall pooled sample from cycle one to cycle six of the NLSCY.

Since the multinomial logit and ordered logit regressions are cross-sectional analyses, the results reported in columns (1) to (4) of Table 12 are generally consistent with those of logit estimations in columns (6) and (7) of Table 9. In particular, the parental bullying control measure (punitive score) is found to be statistically insignificant from zero, however, hostile parenting strategy is related to the higher likelihood of child bullying and positive parental interaction is associated with the reduction of bullying among children. No effects of the consistency parenting behavior are found on the children's bullying behaviour. Consistently, all of the cross-sectional regressions tell a different story that the degree of parental control does not matter in terms of stopping bullying when parents confront their children's bullying behavior, which could be biased by the unobserved individual characteristics.

There are noticeable differences between the two bullying intensities (sometimes bullying versus often bullying) due to several covariates. Generally, the magnitude of the estimated connection between negative family environment/parental strategy (hostile score, annual household income $<\$ 20,000$, number of siblings, and home violence dummy) and the higher probability of bullying is larger for often bullying, while the magnitude of the association between positive characteristics (parenting positive interaction score, annual household income $>\$ 40,000$, and religious belief) and the reduction of child's bullying is smaller for often bullying relative to sometimes bullying. In addition, those children, who are reported by their 
parent to have very good/good health, are more likely to conduct sometimes bullying compared to those who are in an excellent health condition. But this is not true for the often bullying case.

Table 12 - The estimated coefficients of multinomial logit and ordered Logit regressions of PMK-reported bullying status

\begin{tabular}{|c|c|c|c|c|}
\hline & $\begin{array}{l}\text { Multinomial } \\
\text { logit on the } \\
\text { longitudinal } \\
\text { subsample } \\
\text { (1) }\end{array}$ & $\begin{array}{l}\text { Multinomial } \\
\text { logit on the } \\
\text { overall } \\
\text { sample } \\
(2)\end{array}$ & $\begin{array}{l}\text { Ordered logit } \\
\text { on the } \\
\text { longitudinal } \\
\text { subsample } \\
\text { (3) }\end{array}$ & $\begin{array}{c}\text { Ordered logit } \\
\text { on the } \\
\text { overall } \\
\text { sample } \\
\text { (4) }\end{array}$ \\
\hline $\begin{array}{c}\text { Base outcome: Never } \\
\text { bully }\end{array}$ & $\begin{array}{c}\text { Sometimes } \\
\text { bullying }\end{array}$ & $\begin{array}{c}\text { Sometimes } \\
\text { bullying }\end{array}$ & & \\
\hline $\begin{array}{l}\text { Parental bullying control } \\
\text { (punitive score) }\end{array}$ & $\begin{array}{l}-0.026 \\
(0.016)\end{array}$ & $\begin{array}{c}0.001 \\
(0.010)\end{array}$ & $\begin{array}{l}-0.024 \\
(0.016)\end{array}$ & $\begin{array}{c}0.002 \\
(0.010)\end{array}$ \\
\hline $\begin{array}{l}\text { Parental strategy } \\
\text { (hostile score) }\end{array}$ & $\begin{array}{c}0.222 * * * \\
(0.013)\end{array}$ & $\begin{array}{l}0.206^{* * *} \\
(0.008)\end{array}$ & $\begin{array}{c}0.230 * * * \\
(0.013)\end{array}$ & $\begin{array}{c}0.214 * * * \\
(0.008)\end{array}$ \\
\hline $\begin{array}{l}\text { Parental strategy } \\
\text { (consistency score) }\end{array}$ & $\begin{array}{l}-0.004 \\
(0.014)\end{array}$ & $\begin{array}{c}0.007 \\
(0.008)\end{array}$ & $\begin{array}{l}-0.003 \\
(0.013)\end{array}$ & $\begin{array}{c}0.007 \\
(0.008)\end{array}$ \\
\hline $\begin{array}{c}\text { Parental strategy } \\
\text { (positive interaction } \\
\text { score) }\end{array}$ & $\begin{array}{c}-0.030 * * \\
(0.015)\end{array}$ & $\begin{array}{c}-0.034 * * * \\
(0.010)\end{array}$ & $\begin{array}{l}-0.028^{*} \\
(0.015)\end{array}$ & $\begin{array}{c}-0.031 * * * \\
(0.010)\end{array}$ \\
\hline $\begin{array}{l}\text { Very good or good } \\
\text { health }\end{array}$ & $\begin{array}{l}0.143 * \\
(0.082)\end{array}$ & $\begin{array}{c}0.149 * * * \\
(0.052)\end{array}$ & $\begin{array}{l}0.131 * \\
(0.079)\end{array}$ & $\begin{array}{c}0.142 * * * \\
(0.051)\end{array}$ \\
\hline Fair or poor health & $\begin{array}{l}-0.117 \\
(0.346)\end{array}$ & $\begin{array}{c}0.142 \\
(0.204)\end{array}$ & $\begin{array}{l}-0.352 \\
(0.333)\end{array}$ & $\begin{array}{c}0.047 \\
(0.206)\end{array}$ \\
\hline $\begin{array}{l}\text { Annual household } \\
\text { income }<20,000\end{array}$ & $\begin{array}{l}0.271 * \\
(0.155)\end{array}$ & $\begin{array}{l}0.193 * * \\
(0.093)\end{array}$ & $\begin{array}{l}0.376 * * \\
(0.154)\end{array}$ & $\begin{array}{c}0.240 * * * \\
(0.092)\end{array}$ \\
\hline $\begin{array}{l}\text { Annual household } \\
\text { income }>40,000\end{array}$ & $\begin{array}{l}-0.143 \\
(0.097)\end{array}$ & $\begin{array}{c}-0.223 * * * \\
(0.061)\end{array}$ & $\begin{array}{l}-0.129 \\
(0.094)\end{array}$ & $\begin{array}{c}-0.233 * * * \\
(0.060)\end{array}$ \\
\hline Number of siblings & $\begin{array}{c}0.209 * * * \\
(0.043)\end{array}$ & $\begin{array}{c}0.170 * * * \\
(0.026)\end{array}$ & $\begin{array}{c}0.227 * * * \\
(0.042)\end{array}$ & $\begin{array}{c}0.182 * * * \\
(0.026)\end{array}$ \\
\hline Violence Dummy & $\begin{array}{c}0.628 * * * \\
(0.247)\end{array}$ & $\begin{array}{c}0.540 * * * \\
(0.132)\end{array}$ & $\begin{array}{c}0.660 * * * \\
(0.225)\end{array}$ & $\begin{array}{c}0.589 * * * \\
(0.129)\end{array}$ \\
\hline \multirow[t]{2}{*}{$\begin{array}{l}\text { Dummy indicating the } \\
\text { child is religious }\end{array}$} & $\begin{array}{l}-0.183^{*} \\
(0.108)\end{array}$ & $\begin{array}{c}-0.161 * * \\
(0.066)\end{array}$ & $\begin{array}{l}-0.197^{*} \\
(0.106)\end{array}$ & $\begin{array}{c}-0.157 * * \\
(0.065)\end{array}$ \\
\hline & Often bullying & Often bullying & & \\
\hline $\begin{array}{l}\text { Parental bullying control } \\
\text { (punitive score) }\end{array}$ & $\begin{array}{c}0.002 \\
(0.066)\end{array}$ & $\begin{array}{c}0.021 \\
(0.050)\end{array}$ & & \\
\hline $\begin{array}{l}\text { Parental strategy } \\
\text { (hostile score) }\end{array}$ & $\begin{array}{c}0.421 * * * \\
(0.049)\end{array}$ & $\begin{array}{l}0.351 * * * \\
(0.033)\end{array}$ & & \\
\hline $\begin{array}{c}\text { Parental strategy } \\
\text { (consistency score) }\end{array}$ & $\begin{array}{c}0.009 \\
(0.046)\end{array}$ & $\begin{array}{c}0.030 \\
(0.035) \\
\end{array}$ & & \\
\hline $\begin{array}{c}\text { Parental strategy } \\
\text { (positive interaction }\end{array}$ & $\begin{array}{l}-0.009 \\
(0.072)\end{array}$ & $\begin{array}{c}0.017 \\
(0.048)\end{array}$ & & \\
\hline
\end{tabular}




\begin{tabular}{|c|c|c|c|c|}
\hline score) & & & & \\
\hline Very good or good & -0.047 & 0.0005 & & \\
health & $(0.322)$ & $(0.232)$ & & \\
\hline Fair or poor health & -2.367 & -1.059 & & \\
& $(1.583)$ & $(0.929)$ & & \\
\hline Annual household & $1.405^{* * *}$ & $0.918^{* * *}$ & & \\
income <20,000 & $(0.463)$ & $(0.333)$ & & \\
\hline Annual household & -0.027 & -0.399 & & \\
income $>40,000$ & $(0.366)$ & $(0.271)$ & & \\
\hline Number of siblings & $0.616^{* * *}$ & $0.431^{* * *}$ & & \\
& $(0.134)$ & $(0.102)$ & & \\
\hline Violence Dummy & $1.109^{* *}$ & $0.859 * *$ & & \\
& $(0.499)$ & $(0.383)$ & & \\
\hline Dummy indicating the & -0.462 & -0.087 & & \\
child is religious & $(0.368)$ & $(0.274)$ & & \\
\hline $\mathrm{N}$ & 3370 & 17759 & 3370 & \\
\hline
\end{tabular}

Notes.

1. The samples are from Cycle 1 to Cycle 6 of National Longitudinal Survey of Children and Youth.

2. Age $^{2}$ and lagged academic grades dummies are also included in all the regressions. Age, psychological problem dummy, obese/overweight dummy, and often and sometimes cannot concentrate dummies are also included in the regressions.

3. Standard errors are included in the bracket.

4. Significance level is represented by $* * * 1 \%, * * 5 \%, * 10 \%$.

5. The violence dummy is equal to one if there is often and sometimes violence at home, and is equal to zero if the violence has never or seldom happened at home.

6 . The default annual household income dummy is between $(\$ 20,000, \$ 40,000)$.

\subsubsection{Bullying among school-aged children}

So far, the analysis is focused on four-year to 11-year old children. During this period, children will transfer from kindergarten to primary school and will experience dramatic changes due to their natural growth from one phase to another. Similar argument could be applied to parents. Parents might implement different parenting strategies to children at different ages. Moreover, the recognition, definition and attitude towards school-aged children's bullying behavior could differ from that towards to their four to six-year old children. For example, many people believe that children in kindergarten are too little to bully. Although sometimes we do observe bullying 
among young children in kindergarten, parents generally do not take it seriously because they might think that young children's behavior has no intention and the bullying just happens unconsciously. We then restrict our estimations on the school-aged children to reduce the bias due to potential structural change.

The results of fixed-effects estimation on all school-aged children and separately on girls and boys are shown in Table 13 with the same model specification as that in column (5) of Table 9. Qualitatively, all the estimated coefficients are consistent with the ones derived from the original estimations on the overall children, which supports our main conclusions that strictly disciplining children by parents when detecting child bullying could contribute to the inhibition of bullying, while the hostile parenting behavior is positively associated with child bullying and positive parenting style is negatively linked with child bullying. Generally, the magnitudes of all the significant estimates are larger than the original ones with similar significance level. One noticeable evidence is that the very good/good health dummy becomes statistically significant at the ten percent level for the school-aged children. However, one exception is the vanishing effect of religious belief on the inhibition of children's bullying behavior.

Table 13 - The estimated coefficients of regressions of PMK- reported school-aged child bullies

\begin{tabular}{|c|c|c|c|}
\hline & $\begin{array}{c}(1) \\
\text { Fixed-effects on } \\
\text { school-aged } \\
\text { children }\end{array}$ & $\begin{array}{c}(2) \\
\text { Fixed-effects on } \\
\text { school-aged } \\
\text { girls }\end{array}$ & $\begin{array}{c}\text { Fixed-effects on } \\
\text { School-aged } \\
\text { boys }\end{array}$ \\
\hline $\begin{array}{c}\text { Parental bullying control } \\
\text { (punitive score) }\end{array}$ & $-0.041^{* *}$ & $-0.043^{*}$ & -0.037 \\
\hline Parental strategy & $(0.019)$ & $(0.025)$ & $(0.027)$ \\
\hline (hostile score) & $0.243^{* * *}$ & $0.236^{* * *}$ & $0.257^{* * *}$ \\
\hline Parental strategy & $(0.017)$ & $(0.023)$ & $(0.026)$ \\
\hline (consistency score) & -0.016 & -0.003 & -0.030 \\
(parental strategy & $(0.017)$ & $(0.024)$ & $(0.025)$ \\
\hline Veritive interaction score) & $-0.040^{* *}$ & -0.030 & $-0.050^{*}$ \\
& $(0.019)$ & $(0.027)$ & $(0.028)$ \\
\hline good or good health & $0.179^{*}$ & $0.320^{* *}$ & 0.038 \\
& $(0.101)$ & $(0.146)$ & $(0.146)$ \\
\hline
\end{tabular}




\begin{tabular}{|c|c|c|c|}
\hline Fair or Poor health & -0.033 & -0.293 & 0.169 \\
& $(0.420)$ & $(0.641)$ & $(0.553)$ \\
\hline Psychological problem & 0.367 & 0.337 & 0.549 \\
& $(0.325)$ & $(0.448)$ & $(0.485)$ \\
\hline Often cannot concentrate & $0.833^{* * *}$ & $0.587^{* *}$ & $1.093^{* * *}$ \\
& $(0.193)$ & $(0.284)$ & $(0.272)$ \\
\hline Sometimes cannot concentrate & $0.785^{* * *}$ & $0.812^{* * *}$ & $0.785^{* * *}$ \\
& $(0.109)$ & $(0.152)$ & $(0.160)$ \\
\hline Annual household income & $0.420^{* *}$ & 0.321 & $0.484^{*}$ \\
$<\$ 20,000$ & $(0.193)$ & $(0.279)$ & $(0.274)$ \\
\hline Annual household income $>\$ 40,000$ & -0.114 & -0.138 & -0.131 \\
& $(0.119)$ & $(0.168)$ & $(0.174)$ \\
\hline Number of siblings & $0.278^{* * *}$ & $0.215^{* * *}$ & $0.358^{* * *}$ \\
& $(0.054)$ & $(0.072)$ & $(0.081)$ \\
\hline Violence Dummy & 0.264 & 0.089 & 0.472 \\
& $(0.286)$ & $(0.396)$ & $(0.439)$ \\
\hline Dummy indicating the child is & -0.137 & -0.004 & -0.265 \\
religious & $(0.139)$ & $(0.203)$ & $(0.199)$ \\
\hline $\mathrm{N}$ & 2795 & 1406 & 1389 \\
\hline
\end{tabular}

Notes.

1. The samples include children aged six year above from Cycle 1 to Cycle 6 of National Longitudinal Survey of Children and Youth.

2. Age $^{2}$ and lagged academic grades dummies are also included in all the regressions. Age and obese/overweight variables are also included in all the regressions.

3. Standard errors are included in the bracket.

4. Significance level is represented by $* * * 1 \%, * * 5 \%, * 10 \%$.

5. The dummy variable obese \& overweight takes value 1 indicating the child is either obese or overweight, and 0 for normal weight. The obese \& overweight dummy is based on the kids Body Mass Index Charts which take age, gender, height and weight into consideration.

6. The default health dummy is the excellent health dummy.

7. The violence dummy is equal to one if there is often and sometimes violence at home, and is equal to zero if the violence has never or seldom happened at home.

8. The default dummy is never cannot concentrate for the dummies often cannot concentrate and sometimes cannot concentrate.

9. The default annual household income dummy is between $(\$ 20,000, \$ 40,000)$.

\subsubsection{Estimation with all the relevant controls and the fixed effects sample selection bias}

One of the main costs related to any conditional fixed-effect logit estimation is the exclusion of all the time-invariant determinants, which could not be identified through the over-time-variation. We include them in the following cross-sectional logit estimations listed in Table 14 respectively on the 
overall sample and the longitudinal sample of "switchers" whose bullying statuses change over time $^{53}$. Column (1) of Table 14 reports the estimated coefficients from the logit model on the pooled sample from cycle 1 to cycle 6 of NLSCY data, while column (2) lists those estimates from the logit estimation on the pooled "switchers" whose bullying statuses vary through panels.

The estimated coefficients on the originally-included time-variant variables in column (1) of Table 14 are generally in line with those in the regression without time-invariant controls listed in column (7) of Table 9. In addition, some interesting associations between the children's bullying behavior and their family-related/parental characteristics and demographical factors are revealed. Children living in a single-parent family are related with the higher probability of developing bullying behavior, while children with an immigrant family background are less likely to bully other children. Having a student parent and having a parent with a university degree relative to high school completion is linked with the likelihood of children's bullying. Finally, in comparison with children living in Ontario, children from Alberta have higher propensity to bully.

After controlling for the additional time-invariant variables in the cross-sectional model on the "switchers" in column (2) of Table 14, the results are generally similar to those from the regression without the time-invariant controls in column (6) of Table 9. One exception is the estimated significantly negative effect of parental bullying control on stopping child bullying in the logit model with additional time-invariant controls. This estimated coefficient on the bullying control from the cross-sectional logit estimation on the longitudinal sample of "switchers" is surprisingly consistent with that from the fixed-effects logit estimation in column (5) of Table 9 , however, the magnitude is smaller. The results support the prediction of our theoretical model, which states that stricter bullying control will lead to the inhibition of child's bullying. Outlining potential sources which lead to the convergence of fixed-effects results with those of cross-sectional

\footnotetext{
${ }^{53}$ The detailed explanation for the sample of "switchers" has been provided in the previous sections.
} 
estimation on the longitudinal sample will contribute to a better understanding of our results and the model identification. Here, we provide the following two explanations.

First, to certain extent, the inclusion of more relevant covariates serves as a way of controlling for the fixed individual heterogeneity, which could potentially make the cross-sectional estimation results closer to those of fixed-effects estimation. Second, it could be due to the sample selection (switchers) resulted from the fixed effects logit estimation. In particular, the revealed differences in the results between columns (1) and (2) in Table 14 continue telling the story of sample selection caused by fixed effects analysis because only those "switchers" whose bullying behavior varies through time contribute to the fixed effects estimation. Overall, the coefficients are less precisely estimated on the "switchers" due to the largely reduced sample size. The parental bullying control and the university level obtained by the PMK differ significantly in terms of the estimated relationship with children's bullying behavior. Thus, we will generalize our conclusions from the longitudinal analysis carefully to those children who compose the longitudinal sample and whose bullying behavior changes overtime. Who might be in the longitudinal sample? In comparison to children who continuously bully across time, children whose bullying behavior varies through time could be those early bullies who have not bullied for a long time and might have lower bullying intensity (causing less severe harm to other children). Children who consistently bully over years could be at a different phase/point along their bullying evolvement path. However, we are unable to control for the dynamic evolvement of children's bullying behavior in our model, this missing element could be one source for sample selection which makes the longitudinal "switchers" differ from the pooled cross-sectional children. This paper also provides evidence on the necessity of examining the dynamic evolvement/development of children's bullying behavior. 
Table 14 - The estimated coefficients of regressions with all the possible determinants on bullying

\begin{tabular}{|c|c|c|}
\hline & $\begin{array}{l}\text { Logit on the overall } \\
\text { sample } \\
\text { (1) }\end{array}$ & $\begin{array}{l}\text { Logit on the longitudinal } \\
\text { subsample } \\
\text { (2) }\end{array}$ \\
\hline $\begin{array}{l}\text { Parental bullying control } \\
\text { (punitive score) }\end{array}$ & $\begin{array}{c}0.002 \\
(0.011)\end{array}$ & $\begin{array}{l}-0.029^{*} \\
(0.017)\end{array}$ \\
\hline $\begin{array}{l}\text { Parental strategy } \\
\text { (hostile score) }\end{array}$ & $\begin{array}{c}0.210^{* * * *} \\
(0.008)\end{array}$ & $\begin{array}{c}0.231^{* * *} \\
(0.014)\end{array}$ \\
\hline $\begin{array}{l}\text { Parental strategy } \\
\text { (consistency score) }\end{array}$ & $\begin{array}{c}0.008 \\
(0.009)\end{array}$ & $\begin{array}{l}-0.003 \\
(0.014)\end{array}$ \\
\hline $\begin{array}{c}\text { Parental strategy } \\
\text { (positive interaction score) }\end{array}$ & $\begin{array}{c}-0.032^{* * *} \\
(0.010)\end{array}$ & $\begin{array}{l}-0.031^{*} \\
(0.016)\end{array}$ \\
\hline Obese or Overweight & $\begin{array}{c}0.061 \\
(0.053)\end{array}$ & $\begin{array}{c}0.049 \\
(0.083)\end{array}$ \\
\hline Very good or good health & $\begin{array}{l}0.125^{* *} \\
(0.053)\end{array}$ & $\begin{array}{c}0.123 \\
(0.085)\end{array}$ \\
\hline Fair or Poor health & $\begin{array}{c}0.122 \\
(0.209)\end{array}$ & $\begin{array}{l}-0.141 \\
(0.348)\end{array}$ \\
\hline Psychological problem & $\begin{array}{c}0.594 * * * \\
(0.153) \\
\end{array}$ & $\begin{array}{c}0.393 \\
(0.278) \\
\end{array}$ \\
\hline Often cannot concentrate & $\begin{array}{c}0.669^{* * * *} \\
(0.092)\end{array}$ & $\begin{array}{c}0.716^{* * * *} \\
(0.157)\end{array}$ \\
\hline Sometimes cannot concentrate & $\begin{array}{c}0.669^{* * *} \\
(0.056)\end{array}$ & $\begin{array}{c}0.694^{* * * *} \\
(0.088)\end{array}$ \\
\hline Annual household income $<\$ 20,000$ & $\begin{array}{c}0.209^{* * *} \\
(0.104)\end{array}$ & $\begin{array}{l}0.381^{* *} \\
(0.178)\end{array}$ \\
\hline Annual household income $>\$ 40,000$ & $\begin{array}{c}-0.142^{* *} \\
(0.069)\end{array}$ & $\begin{array}{l}-0.077 \\
(0.110)\end{array}$ \\
\hline Number of siblings & $\begin{array}{l}0.188^{* *} \\
(0.027)\end{array}$ & $\begin{array}{c}0.206^{* * *} \\
(0.044)\end{array}$ \\
\hline Violence Dummy & $\begin{array}{c}0.497^{* * *} \\
(0.133)\end{array}$ & $\begin{array}{l}0.605^{* *} \\
(0.271)\end{array}$ \\
\hline Religion Dummy & $\begin{array}{c}-0.153^{* *} \\
(0.070)\end{array}$ & $\begin{array}{l}-0.169^{*} \\
(0.091)\end{array}$ \\
\hline \multicolumn{3}{|l|}{ Time invariant variables } \\
\hline $\begin{array}{l}\text { Very well /Vell lagged academic grade (in } \\
\text { the previous cycle) }\end{array}$ & $\begin{array}{l}-0.018 \\
(0.063)\end{array}$ & $\begin{array}{c}0.159 \\
(0.098)\end{array}$ \\
\hline $\begin{array}{l}\text { Poorly /very poor lagged academic grade (in } \\
\text { the previous cycle) }\end{array}$ & $\begin{array}{c}0.004 \\
(0.145)\end{array}$ & $\begin{array}{l}-0.049 \\
(0.234)\end{array}$ \\
\hline Single parent family & $\begin{array}{l}0.169^{* *} \\
(0.081)\end{array}$ & $\begin{array}{c}0.103 \\
(0.133)\end{array}$ \\
\hline PMK is an immigrant & $\begin{array}{c}-0.334^{* * *} \\
(0.115)\end{array}$ & $\begin{array}{c}-0.409^{* * *} \\
(0.182)\end{array}$ \\
\hline
\end{tabular}




\begin{tabular}{|c|c|c|}
\hline PMK is a student & $0.186^{*}$ & 0.196 \\
& $(0.101)$ & $(0.169)$ \\
\hline PMK is not working & -0.020 & 0.083 \\
& $(0.066)$ & $(0.105)$ \\
\hline PMK's highest education: Elementary & -0.211 & -0.379 \\
& $(0.183)$ & $(0.269)$ \\
\hline PMK's highest education: Secondary & -0.004 & -0.014 \\
without graduation & $(0.018)$ & $(0.152)$ \\
\hline PMK's highest education: Postsecondary & -0.075 & -0.108 \\
below university & $(0.065)$ & $(0.106)$ \\
\hline PMK's highest education: University & $\mathbf{0 . 1 9 1 * *}$ & $\mathbf{- 0 . 1 7 9}$ \\
& $\mathbf{( 0 . 0 9 2 )}$ & $\mathbf{( 0 . 1 4 5}$ \\
\hline Residence province: Atlantic & -0.090 & -0.188 \\
& $(0.058)$ & $(0.125)$ \\
\hline Residence province: Quebec & -0.047 & -0.180 \\
& $(0.061)$ & $(0.129)$ \\
\hline Residence province: Manitoba and & 0.074 & -0.069 \\
Saskatchewan & $(0.058)$ & $(0.134)$ \\
\hline Residence province: Alberta & $0.141^{* *}$ & 0.123 \\
& $(0.069)$ & $(0.163)$ \\
\hline Residence province: B.C. & -0.028 & -0.011 \\
& $(0.075)$ & $(0.163)$ \\
\hline N & 16876 & 3186 \\
\hline
\end{tabular}

Notes.

1. The samples are from Cycle 1 to Cycle 6 of National Longitudinal Survey of Children and Youth.

2. The Age, Age $^{2}$, and the size of residence variables are also included in all the regressions.

3. Standard errors are included in the bracket.

4. Significance level is represented by *** $1 \%, * * 5 \%, * 10 \%$.

5. The dummy variable obese $\&$ overweight takes value 1 indicating the child is either obese or overweight, and 0 for normal weight. The obese \& overweight dummy is based on the kids Body Mass Index Charts which take age, gender, height and weight into consideration.

6. The default health dummy is the excellent health dummy.

7. The violence dummy is equal to one if there is often and sometimes violence at home, and is equal to zero if the violence has never or seldom happened at home.

8. The default dummy is never cannot concentrate for the dummies often cannot concentrate and sometimes cannot concentrate.

9. The default annual household income dummy is between $(\$ 20,000, \$ 40,000)$.

10. The constant is also included in the logit regression and not shown here.

11. The default dummy for the highest education of PMK is the high school completion.

12. The Atlantic provinces include Newfoundland and Labrador, Nova Scotia, P.E.I. and New Brunswick. The default province is Ontario and the children living in Yukon, Northwest Territories and Nunavut are not included in the NLSCY. 


\subsubsection{A note on the instrumental variable estimation}

We also employed a simple two-stage least-squares model by instrumenting the parental bullying control $\boldsymbol{P}$ with two instrumental variables (IVs) proposed by Burton et. al (2002) to reduce the endogenous issue. The first IV is an indicator of whether or not the PMK is currently attending school and the other IV is the percentage of people without graduating from high school in the census tract area where the child is living. However, the F statistic for the joint significance of the coefficients on the instruments is 2.85 at the first stage, which is below the suggested level of ten by Stock et.al (2002) to make the instrumental-variable estimators reliable. The test result shows that the IVs are weak instruments. Additionally, the $\mathrm{Wu}-$ Hausman test of endogeneity is barely significant at the ten percent level with a $p$ value being equal to 0.092 , which indicates that the parental bullying control $\boldsymbol{P}$ barely suffers from the endogenous problem if the IVs we have chosen are valid instruments. Furthermore, the untestable assumption about the validity of the IVs, which have to be highly correlated with the endogenous variable and also have to be uncorrelated with the error term, makes the instrumental-variable estimators doubtful ${ }^{54}$.

\subsection{Conclusions}

In this paper, we have developed a model to capture the interaction between children's bullying behavior and the corresponding parental control. Two assumptions are made whereby the child tends to bully for utility and the bullying is inhibited by the disutility resulted from the interactions between the child and his/her parent. The model also accounts for the imperfect perceiving of bullying by parents. Simultaneously, the parent decides the parental bullying control/punishment to maximize his/her utility, which is comprised of three components: 1) the

\footnotetext{
${ }^{54}$ Although we do have concerns about the validity of the two IVs Burton et. al (2002) have chosen, it is not of our interest to further explore this issue. Here, we argue that our fixed effects estimation is more suitable and produces more robust results for our research question in this paper.
} 
parent's current utility; 2) the child's current utility; and 3) the child's future utility. In equilibrium, two propositions are derived from the model. One important conclusion is that higher disutility generated from parental controls/punishments to the child bullying will contribute to stop bullying when all the other variables are held constant. The other one is related to the empirical estimation that reveals the challenge associated with correctly identifying the causal relationship between the parental disciplinary measures on the child and the child's bullying behavior.

According to the theoretical results, an empirical analysis is conducted by employing data of National Longitudinal Survey of Children and Youth (NLSCY) in Canada. There are four parenting behavior scores available in the NLSCY. The punitive score differs from the other three because it mainly measures the specific action taken by the parent when facing the child's bad behavior which includes bullying, while the other three scores capture the general parenting strategy on the parent-child interaction. After controlling for the unobserved heterogeneity and the three general parental strategy/style variables (hostile, consistency and positive interaction parenting score), the regression shows the significant effect of higher parental disciplinary measures (punitive score) on the inhibition of bullying. This could be due to the higher disutility generated by the higher parental controls, which is consistent with the model's prediction. In addition, the hostile parental behavior is found to be significantly connected to higher probability of child's bullying, while the positive parental interaction strategy is correlated with the lower odds of the child's bullying behavior.

This study also provides empirical evidence on the gender difference in terms of the parental control on child bullying. One of the major differences is that girl bullying could be reduced by higher parental control, which is not true for boy bullying. At this preliminary 
investigation phase, we could not provide any valid speculation to explain this phenomenon. Further investigation is still needed.

In terms of generalizing our conclusions to all the relevant children ${ }^{55}$, we are aware of two potential barriers which might halt the generalization. The first barrier is related to the unobserved genetic factor and the second one is linked with the dynamic evolvement trend of the child bullying. Specifically, if the genetic attributes do not alter the way how the parenting control deters the child bullying dramatically across different groups of children, our conclusions generated by analyzing the longitudinal sample of children whose bullying behavior varies over time could be applied to the overall relevant children. In addition, considering the possible existence of a dynamic trajectory for children's bullying behavior, the parenting control might be effective to stop bullying only at a given time point in the process of the bullying formation and development. The paper also calls for research on the dynamic evolvement of bullying in the future.

This paper highlights the significant roles the parent (mainly the mother) plays in stopping bullying among children. Society often has blamed school systems for failing to prevent bullying among children. It is time to avert our attention to take a closer look at parents' side. Tougher parental control (higher punitive parenting score) might be bad for the children's overall well-being ${ }^{56}$. However, a lack of tough controls on the child's bullying could potentially enable the bullying behavior. The focus of this paper is to reveal the evidence of the inhibition effect of parental controls on the child's bullying. It is beyond the power of this paper to specifically imply how parents should deal with bullying given that the interactions between parents and

\footnotetext{
${ }^{55}$ We exclude children who never bully.

${ }^{56}$ Currie (2006) showed that the children will be less likely to be satisfied with life if they have difficulties in communicating with their parents.
} 
children are very complicated and unique. This research just provides a preliminary result about the parenting behavior against bullying. Future studies on this topic are still necessary.

Considering the revealed adverse effects of children's bullying behavior and bullying experience on their human capital accumulation at school and future labour market performance, this study sheds light on the academic achievement of children and subsequent improvements on their labour market performance in the future. This paper has the following policy implications. First, the significant role played by parents in the prevention of bullying among children needs to be recognized. For example, the government could launch an awareness campaign to highlight the responsibility of the parents in stopping child bullying. Second, the parental bullying controls could be recognized as a potential channel through which the bullying among children is controlled. Once this channel is recognized, more researchers could continue investigating what is an efficient parental interaction measure once the child's bullying is detected. Also, the parental control on bullying could be compared with the anti-bullying program implemented at school. Should the two mechanisms be coordinated to reduce child bullying? and how?

\subsection{Reference}

Aakvik, A. 2001. "Bounding a Matching Estimator: The Case of A Norwegian Training Program. Oxford Bulletin of Economics and Statistics 63: 115-143

Abadie, A. and Imbens, G. 2006."Large sample properties of matching estimators for average treatment effects." Econometrica 74(1), 235-267.

Abel, Andrew B. 1990. "Asset prices under habit formation and catching up with the Joneses." American Economic Review, May 1990, vol. 80(2), 38-42.

Allen, Kathleen P. "A Bullying Intervention System in High School: A Two-Year School-Wide Follow-Up." Studies in Educational Evaluation 36 (3): 83-92.

Ando, Mikayo, Asakura, Takashi and Simons-Morton, Bruce. 2005. "Psychosocial Influences on Physical, Verbal, and Indirect Bullying Among Japanese Early Adolescents." The Journal of Early Adolescence 25 (3): 268-297. 
Baltagi, Badi H. 2008. Econometric Analysis of Panel data, Jonn Wiley \&Son, Ltd.

Becker, Sascha O. and Caliendo, Marco. 2007. "Sensitivity analysis for average treatment effects." The Stata Journal , electronic version (ISSN 1536-8734).

Beran, Tanya, Tutty, Leslie and Steinrath, Greg. 2004. "An Evaluation of a Bullying Prevention Program for Elementary Schools." Canadian Journal of School Psychology 19 (1-2): 99-116.

Brown, S., and Taylor, Karl. 2008. "Bullying, Education and Earnings: Evidence from the National Child Development Study.” Economics of Education Review 27 (2008): 387401.

Burton, P., Phipps, S., and Curtis, L. 2002. "All in the Family: A Simultaneous Model of Parenting Style and Child Conduct.” American Economic Review, 92. 2, 368-372.

Caliendo, M., Hujer, R. and Thomsen, S. 2005. "The Employment Effects of Job Creation Schemes in Germany." IZA-Discussion Paper No. 1512.

Chamberlain, G. 1980. "Analysis of covariance with qualitative data." Review of Economic Studies 47: 225-238.

Christie-Mizell, C., Keil, Jacqueline, Laske, Mary and Stewart, Jennifer. 2011. "Bullying Behavior, Parents' Work Hours and Early Adolescents' Perceptions of Time Spent With Parents." Youth \& Society 43 (4): 1570-1595.

Chua, Amy. 2011. Battle Hymn of the Tiger Mother. New York: Penguin Group.

Constantinides, George M. 1990. "Habit Formation: A Resolution of the Equity Premium Puzzle." Journal of Political Economy, June 1990, vol. 98(3), 519-43.

Craig, Wendy, Pepler, Debra and Atlas, Rona. 2000. "Observations of Bullying in the Playground and in the Classroom." School Psychology International 21 (1): 22-36.

Cross, Donna, Monks, Helen, Hall, Marg, Shaw, Therese, Pintabona, Yolanda, Erceg, Erin, Hamilton, Greg, Roberts, Clare, Waters, Stacey and Lester, Leanne. 2011. "Three-year Results of the Friendly Schools Whole-of School Intervention on Children's Bullying Behavior." British Educational Research Journal 37 (1): 105-129.

Dake, Joseph, Price, James, Telljohann, Susan and Funk, Jeanne. 2004. "Principals' Perceptions and Practices of School Bullying Prevention Activities." Health Education \& Behavior 31(3):372-387. 
Dehejia, R.H and Wahba, S. 1999. "Causal Effects in Non-Experimental Studies: Re-Evaluating the Evaluation of Training Programmes." Journal of the American Statistical Association 94, 1053-1062.

Dinkes, R., Kemp, J., Baum, K., and Snyder, T. 2009. "Indicators of school crime and safety: 2009 (NCES 2010-012/NCJ228478)." Washington, DC: National Center for Education Statistics, Institute of Education Sciences, U.S. Department of Education, and Bureau of Justice Statistics, Office of Justice Programs, U.S. Department of Justice.

DiPrete, Thomas A. and Gangl, Markus. 2004. "Assessing Bias in the Estimation of Causal Effects: Rosenbaum Bounds on Matching Estimators and Instrumental Variables Estimation with Imperfect Instruments.” Sociology Methodology 34 (1):271-310.

Martin, D. and Stewart, J. 2009. "Family income, parenting styles and child behaviouralemotional outcomes." Health Economics, 16 (2), pg. 145-162.

Dynan, Karen E.. 1999. "Habit Formation in Consumer Preferences: Evidence from Panel Data." The American Economic Review Vol. 90, No. 3 (Jun., 2000), pp. 391-406.

Farhat, T., Iannotti, R. J. and Simons-Morton, B. G.2010. “Overweight, Obesity, Youth, and Health-Risk Behaviors." American Journal of Preventive medicine (March 2010), 38 (3), pg. 258-267.

Fuhrer, Jeffrey C. 2000. "Habit Formation in Consumption and its Implications for MonetaryPolicy Models." The American Economic Review Vol. 90, No. 3 (Jun., 2000), pp.367390.

Georgiou, Stelios N. 2008. "Parental Style and Child Bullying and Victimization Experiences at School." Social Psychology Education 11:213-227

Griffiths, L. J., Wolke, D., Page, A. S., Horwood, J. P., and the ALSPAC Study Team 2006. "Obesity and bullying: different effects for boys and girls." Arch Dis Child 91:121-125 doi:10.1136/adc.2005.072314

Greeff, P. and Grobler A.A. 2008. "Bullying During the Intermediate School Phase: A South African Study." Childhook 15 (1): 127-144.

Guerin, Suzanne and Hennessy, Eilis. 2002. "Pupils' definitions of bullying." European Journal of Psychology of Education September 2002, Volume 17, Issue 3, pp 249-261.

Hausman, J. A. 1978. "Specification tests in econometrics.” Econometrica 46: 1251-1271.

Hay, C. and Meldrum, R. 2010. "Bullying Victimization and Adolescent Self-Harm: Testing Hypotheses from General Strain Theory." Journal of Youth and Adolescence Volume 39, Number 5, 446-459. DOI: 10.1007/s10964-009-9502-0. 
Heckman, J.J., Ichimura, H. and Todd, P.E. 1997. "Matching as an Econometric Evaluation Estimator: Evidence from Evaluating a Job Training Programme." Review of Economic Studies 64, 605-654.

Heckman, J.J., Ichimura, H. and Todd, P.E. 1998. "Matching as an Econometric Evaluation Estimator." Review of Economic Studies 65, 261-294.

Holt, Melissa K., Kantor, G.K. and Finkelhor, David. 2008. "Parent/Child Concordance about Bullying Involvement and Family Characteristics Related to Bullying and Peer Victimization." Journal of School Violence 8 (1): 42-63.

Hong, Jun S. 2008. "Feasibility of the Olweus Bullying Prevention Program in Low-Income Schools." Journal of School Violence 8 (1): 81-97.

Janssen,Iran, Craig, Wendy M., Boyce, William F., Pickett, William. 2004. "Associations Between Overweight and Obesity With Bullying Behaviors in School-Aged Children." Pediatrics Vol. 113, No. 5, pp. 1187 -1194.

Jolliffe, Darrick and Farrington, David P. 2011. "Is Low Empathy Related to Bullying after Controlling for Individual and Social Background Variables?" Journal of Adolescence 34 (1): 59-71.

Kaminski, J.and Fang, X. (2009). "Victimization by peers and adolescent suicide in three U.S. samples." Journal of Pediatrics, 155(5), 683-688.

Kim, Y.S., Boyce, T., Koh, Y.J. and Leventhal, B. L. 2009. "Time Trends, Trajectories, and Demographic Predictors of Bullying: A Prospective Study in Korean Adolescents." Journal of Adolescents Health 45 (4): 360-367.

Kim, Y.S. and Leventhal, B. L. 2008. "Bullying and Suicide. A Review." International Journal of Adolescent Medicine and Health. 20(2):133-54.

Lee, Chang-Hun. 2011. "An Ecological Systems Approach to Bullying Behaviors Among Middle School Students in the United States." Journal of Interpersonal Violence 26 (8): 1664-1693.

Lee,Chang-Hun. 2010. "Personal and Interpersonal Correlates of Bullying Behaviors Among Korean Middle School Students." Journal of Interpersonal Violence 25 (1):152-176.

Larochette, Anne-Claire, Murphy, Ashley and Craig, Wendy. 2010. "Racial Bullying and Victimization in Canadian School-Aged Children: Individual and School Level Effects." School Psychology International 31 (4): 389-408.

Levin, K., Dallago, L., Currie, C.. (2012) "The Association between Adolescent Life Satisfaction, Family Structure, Family Affluence and Gender Differences in Parent-Child Communication." Social Indicators Research, 106 (2), pg. 287-305

Ma, Lang, Phelps, Erin, Lerner, J. and Lerner Richard. 2009. “Academic Competence for Adolescents Who Bully and Who are Bullied: Findings from the 4-H Study of Positive Youth Development." The Journal of Early Adolescence 29 (6): 862-897. 
Malcomson, J. 1984. "Working incentives, hierarchy and internal labor market," Journal of Political Economy, 92, pp. 486-507.

Marées, N. V. and Petermann, F. 2010. "Bullying in German Primary Schools: Gender Differences, Age Trends and Influence of Parents' Migration and Educational Backgrounds." School Psychology International (April 2010), 31 (2), pg. 178-198.

Marshall, Megan L., Varjas, Kris, Meyers, Joel. Graybill, E.C. and Skoczylas, R.B. 2009. "Teacher Responses to Bullying: Self-Reports From the Front Line." Journal of School Violence 8 (2):136-158.

Marees, Nandoli Von and Petermann, Franz. 2010. "Bullying in German Primary Schools: Gender Differences, Age Trends and Influence of Parents'Migration and Educational Backgrounds.” School Psychology International 31 (2): 178-198.

Midthassel, Unni V., Bru, Edvin and Idsoe, Thormod. 2008. "Is the Sustainability of Reduction in Bullying related to Follow-Up Procedures?" Educational Psychology 28 (1): 83-95.

Newey, W. K. 1987." Efficient estimation of limited dependent variable models with endogenous explanatory variables." Journal of Econometrics 36: 231-250.

Novick, Rona Milch and Isaacs Jenny. 2010. "Telling is compelling: the Impact of Student Reports of Bullying on Teacher Intervention.” Educational Psychology 30 (3):283-296.

Peterson, Jean and Ray, Karen. 2006. "Bullying and the Gifted: Victims, Perpetrators, Prevalence, and Effects." Gifted Child Quarterly 50 (2): 148-168.

Powell, Melissa D. and Ladd, Linda D. 2010. "Bullying: A Review of the Literature and Implications for Family Therapists." The American Journal of Family Therapy 38 (3): $189-206$.

Rigby, Ken. 2005. "Why Do Some Children Bully at School?: The Contributions of Negative Attitudes Towards Victims and the Perceived Expectations of Friends, Parents and Teachers." School Psychology International 26 (2): 147-161.

Rawana,Jennine, Norwood, Sarah and Whitley, Jessica. 2011. "A Mixed-Method Evaluation of a Strength-Based Bullying Prevention Program." Canadian Journal of School Psychology 26 (4):283-300.

Rosenbaum, P.R. and Rubin, D.B. 1983. "The Central Role of the Propensity Score in Observational Studies for Causal Effects." Biometrika 70, 1, 41-55.

Rosenbaum, P.R. and Rubin, D.B. 1985. "Constructing a Control Group Using Multivariate Matched Sampling Methods that Incorporate the Propensity Score." The American Statistician 39(1), 33-38.

Rosenbaum, P.R. 2002. Observational Studies. 2nd ed. New York: Springer.

Sairanen, Leena and Pfeffer, Karen. 2011. "Self-reported Handling of Bullying Among Junior High School Teachers in Finland." School Psychology International 32 (3): 330-344. 
Sawyer, J-Leigh, Mishna, Faye, Pepler, Debra and Wiener,Judith. 2011. "The Missing Voice: Parents' Perspectives of Bullying." Children and Youth Services Review 33 (10): 17951803.

Samara, Muthanna and Smith, Peter K. 2008. "How Schools Tackle Bullying, and the Use of Whole School Policies: Changes over the Last Decade." Educational Psychology 28 (6):663-676.

Swearer, Susan, Espelage, Dorothy, Vaillancourt, Tracy and Hymel, Shelley. 2010. "What Can Be Done About School Bullying ?" Linking research to Educational Practice Educational Researcher:39 (1): 38-47.

Stock, J. H., Wright, J. H. and Yogo, M. 2002. "A survey of weak instruments and weak identification in generalized method of moments." Journal of Business and Economic Statistics 20: 518-529.

Totura, Christina W., Mackinnon-Lewis, Carol, Gesten, Ellis, Gadd, Ray, Divine, Katherine, Dunham, Sherri and Kamboukos, Dimitra. 2009. "Bullying and Victimization Among Boys and Girls in Middle School: The Influence of Perceived Family and School Contexts." The Journal of Early Adolescence 29 (4):571-609.

Vaillancourt, Tracy, Brittain, Heather, Bennett, Lindsay, Arnocky, Steven, McDougall, Patricia, Hymel, Shelley, Short, Kathy, Sunderani, Shafik, Scott, Carol, Machenzie, Meredith and Cunningham, Lesley. 2010. "Places to Avoid: Population-Based Study of Student Reports of Unsafe and High Bullying Areas at Schools."Canadian Journal of School Psychology 25 (1): 40-54.

Vaiillancourt, Tracy, McDougal, Patricia, Hymel, Shelley, Krygsam, Amanda, Miller, Jessie, Stiver, Kelley and Davis, Clinton. 2008. "Bullying: Are researchers and children/youth talking about the same thing?" International Journal of Behavioral Development 32 (6):486-495.

Wei, His-sheng, Jonson-Reid, Melissa and Tsao, Hui-ling. 2007. "Bullying and Victimization Among Taiwanese 7th Graders: A Multi-Method Assessment." School Psychology International 28 (4): 479-500.

Wong, Dennis S.W., Lok, David P.P., Lo, Wing and Ma, Stephen. 2008. "School Bullying Among Hong Kong Chinese Primary Schoolchildren.” Youth \& Society 40 (1):35-54.

Wong, Dennis. 2004. "School Bullying and Tackling Strategies in Hong Kong." International Journal of Offender Therapy and Comparative Criminology 48 (5):537-553. 


\section{Appendix I}

\section{A1 - Correlation among the parental scores}

\begin{tabular}{|l|l|l|l|l|}
\hline & Punitive score & Hostile score & Consistency score & $\begin{array}{l}\text { Positive } \\
\text { interaction } \\
\text { score }\end{array}$ \\
\hline Punitive score & 1.000 & & & \\
\hline Hostile score & 0.398 & 1.000 & & \\
\hline Consistency score & -0.204 & -0.284 & 1.000 & \\
\hline $\begin{array}{l}\text { Positive } \\
\text { interaction score }\end{array}$ & -0.126 & -0.210 & 0.098 & 1.000 \\
\hline
\end{tabular}

\section{Appendix II}

\section{Survey questions of the covariates}

Q1. Hostile parenting: this factor score was derived using the following weighted items:

How often do you get annoyed with your child for saying or doing something he/she is not supposed to?

Of all the times you talk to your child about his/her behavior, what proportion is praise?

Of all the times you talk to your child about his/her behavior, what proportion is disapproval?

How often do you get angry when you punish your child?

How often do you think the kind of punishment you give your child depends on your mood?

How often do you feel you have problems managing your child in general?

How often do you have to discipline your child repeatedly for the same thing?

Q2. Consistency parenting: this factor score was derived using the following weighted items:

When you give $\%$ him $/$ her $\%$ a command or order to do something, what proportion of the time do you make sure that $\%$ he/she does it?

If you tell $\%$ him $/$ her $\% \%$ he $/$ she $\%$ will get punished if $\%$ he $/$ she $\%$ doesn't stop doing something, and $\%$ he/she $\%$ keeps doing it, how often will you punish $\%$ him $/$ her $\%$ ?

How often does $\%$ he $/$ she $\%$ get away with things that you feel should have been punished?

How often is $\%$ he $/$ she $\%$ able to get out of a punishment when $\%$ he $/$ she $\%$ really sets $\%$ his $/$ her $\%$ mind to it?

How often when you discipline $\%$ him/her $\%$, does $\%$ he/she $\%$ ignore the punishment?

Q4. Positive interaction score: this factor score was derived using the following weighted items:

How often do you praise \%fname\%, by saying something like "Good for you!" or "What a nice thing you did!" or "That's good going!"?

How often do you and \%he/she $\%$ talk or play with each other, focusing attention on each other for five minutes or more, just for fun?

How often do you and \%he/she\% laugh together? 
How often do you do something special with \%him/her\% that \%he/she\% enjoys?

TEXT FOR AGE 3+ YEARS How often do you play sports, hobbies or games with $\%$ him/her\%?

Q4. Punitive parenting: this factor score was derived using the following weighted items:

[When \%FNAME\% breaks the rules or does things that $\%$ he $/$ she $\%$ is not supposed to, how often do you:] Raise your voice, scold or yell at $\%$ he/her $\%$ ?

[When $\%$ FNAME $\%$ breaks the rules or does things that $\%$ he $/$ she $\%$ is not supposed to, how often do you:] Calmly discuss the problem?

[When \%FNAME $\%$ breaks the rules or does things that $\%$ he/she $\%$ is not supposed to, how often do you:] Use physical punishment?

[When $\%$ FNAME $\%$ breaks the rules or does things that $\%$ he $/$ she $\%$ is not supposed to, how often do you:] Describe alternative ways of behaving that are acceptable? 


\title{
Chapter 3 Timing Matters in Stopping Bullying among Children: an Empirical Study Using a Canadian Dataset
}

\begin{abstract}
3.1 Introduction
Bullying among children is a well-recognized social problem around the world, mainly due to its associated ill effects on children's wellbeing and their families (Brown \& Taylor 2008; Kim \& Leventhal 2008; Hay \& Meldrum 2010; Kamimski \& Fang 2009) and researchers from different countries have carried out a variety of analyses on this topic (Beran et al 2004; Rowana et al 2011; Craig et al 2000; Larochette et al 2010; Greef \& Grobler 2008; Wong et al 2008; Marees \& Peterman 2010). In general, the existing literature analyzes the bullying behavior of children in a static way by exploring the effectiveness of potential anti-bullying techniques used by parents, teachers and society generally for a group of children at given ages. To the best of our knowledge, few studies have tried to answer the question of when the best time is to control bullying for a given anti-bullying method. This paper contributes to the literature by taking into account the dynamic formation/evolution of children's bullying behavior to find out the most efficient timing of controls.
\end{abstract}

By conventional wisdom, it is hard to believe that some children's severe bullying behavior just happens without roots and causes. Indeed, we tend to speculate that every observed serious incident of bullying behavior is most likely to have originated at children's younger ages. For instance, a child might start bullying other children without real intent, and just for fun, when he/she was very young, indeed Lee (2010) has shown that children bully for enjoyment. Without interventions, the child might continue to bully and enjoy the intrinsic happiness that it brings. Although the specific dynamics of the evolution of bullying behavior is a black box for 
researchers, in this paper we have found some evidence that supports a hypothesis that bullying does evolve from low intensity to high intensity ${ }^{57}$. In other words, bullying can potentially develop into a worsening habit for some children under certain environments and conditions.

Although most researchers have agreed on the characteristics of bullying behavior as having intentions, causing harm or distress to victims and repetition, the initial bullying at the beginning of its formation might be difficult to identify according to the usual definition. However, if the dynamic formation of bullying behavior is believed to hold, the early detection and recognition of it is of vital importance to the effectiveness of anti-bullying interventions. This paper tries to empirically answer the question of whether or not the timing of bullying detection and interference matters in deterring the bullying behavior of children.

We employ the data from the National Longitudinal Survey of Children and Youth (NLSCY) in Canada to conduct the analysis. The bullying behavior of 4-year-old to 11 year-old children is reported by both their parents and teachers and the relevant questions regarding the same group of children are surveyed every two years from the first cycle in 1994/95 until 2008. We have found some empirical evidence that is consistent with our preliminary speculation. In particular, bullying detected earlier by either the parent or the teacher has a higher propensity to be reported as no longer existing at the end of the longitudinal window provided by the data.

Ecological factors have been recognized as being significantly relevant in affecting children's bullying behavior (Swearer et al 2010; Lee 2011) and, in addition, gender differences in child bullying have been broadly explored by researchers from different perspectives (Anagnostopoulos et al 2009; O’Brien 2011). The rich data set enables us to control for many bullying-related factors studied by other researchers. The only literature to deal with the dynamic

${ }^{57}$ We have found that the probability of children conducting frequent bullying versus occasional bullying increases with ages by holding all the other characteristics constant. 
characteristics of bullying behavior is by Kim et al (2009), who studied "time trends and trajectories of bullying" among Korean adolescents and concluded that children's "participation in bullying is stable overtime." However, since the longitudinal tracking only lasted for one year and the population they tracked was youths in middle school, they could not relate the timing of bullying control with the outcomes of the control over years.

This paper quantitatively investigates the time effect of bullying control implemented by either the parent or the teacher on the outcomes of the control, an area which has long been neglected in the anti-bullying literature. There are many empirical challenges in correctly disentangling the real effects of the early detection and intervention of bullying from numerous observed and unobserved connected factors. The national longitudinal data, with a relatively longer tracking period and detailed information on children, their parents and teachers, combined with advanced econometric methodologies, allow us to reduce the potential biases in our investigation. Based on the results of this paper, we hope to motivate more research on the dynamic studies of bullying among children.

The paper is organized as follows: In Section 2 we illustrate the theoretical background and some related empirical issues. Section 3 presents detailed information of the data. The empirical investigation is carried out in section 4 and Section 5 includes the checking of the robustness of our results. In section 6, conclusions and policy implications are discussed.

\subsection{Theoretical Background}

Habit formation is not a new concept in the field of economics. In a dynamic consumer model, the utility of an individual at time $t$ depends on the relative consumption at time $t$ over the previous consumption level at time $t-1$ (Fuhrer 2000; Dynan 1999; Abel 1990; Constantinides 1990). In the same fashion, given that children bully for utilities, then without interferences, the 
utility of bullying at $t$ could be dependent on the relative bullying intensity derived by comparing the current bullying intensity $\left(b_{t}\right)$ to that in the previous period $\left(b_{t-1}\right)$. Bullying intensity here refers to the frequency/scale of bullying and it could be measured by the level of severity of the bullying consequences. For example, compared to physical bullying, verbal bullying is an incident of bullying with lower intensity. In addition, bullying incidents that occur less frequently are generally treated as having lower intensity relative to bullying behavior that occurs more frequently.

Under the bullying habit formation assumption, the bullying utility at time $t$ could be modeled as

$$
U_{t}\left(b_{t}, b_{t-1}\right)=\frac{1}{1-a}\left(\frac{b_{t}}{b_{t-1}}\right)^{1-a}
$$

In which we assume that the bullying intensities in all periods are nonnegative, $b_{t}>0, b_{t-1}>0$. In contrast, $U_{t}\left(b_{t}\right)=\frac{1}{1-a} b_{t}{ }^{1-a}$ is the utility function without habit formation (Fuhrer 2000). It is easy to show that in order to achieve a certain utility, $\frac{d b_{t}}{d b_{t-1}}=\frac{b_{t}}{b_{t-1}}>0$, which indicates that bullying intensity increases with time if no anti-bullying actions intervene in the children's behavior. Also, the marginal increase in bullying intensity due to habit formation is determined by the ratio of the bullying intensity in the current period to that in the previous period.

Based on the bullying habit formation theory proposed above, we can question the differences in the effects of stopping bullying in terms of interventions implemented at different points of time along the dynamic evolution process of it. In particular, we try to address the question of whether it is more effective to implement bullying controls when the child starts bullying with lower intensity. Can we stop future bullying in advance? This leads to the next relevant step, which is to illustrate several identification issues and some challenges encountered in our empirical analyses. 
If a child starts bullying and he/she has not been bullying before it is first detected by his/her parents/teachers, then we can treat the detected bullying as an early bullying and the detection as an early detection. However, the detection of early bullying largely depends on the definition of bullying proposed by different educators. When children are young, their initial bullying behavior might not be recognized as real bullying behavior according to the general definition involving characteristics such as intention, causing harm or distress to victims, and repetition. Specifically, some children in kindergarten might unconsciously tease other kids, which will not be treated as real bullying behavior by some educators due to the lack of elements within the general bullying definition. On the other hand, parents and teachers who believe that initial bullying behavior with lower intensity could potentially evolve into a bullying habit later will emphasize the detection of the initial early bullying behavior and make efforts to stop it. Therefore, some children's initial early bullying behavior may not be identified and reported by their educators (parents/teachers) when the educators do not believe the young children's behavior is actually severe enough to be recognized as real bullying behavior based on the general definition. If this positive self-selection by the early detection group of parents and teachers is not influenced by the advanced anti-bullying methods which might be more likely to be implemented by the self-selection of parents/teachers, we can treat the positive self-selection process as a part of the mechanism through which early detection affects the inhibition of bullying.

According to the bullying habit formation hypothesis proposed in this paper, bullying behavior is formed and developed from lower intensity to higher intensity without interruptions from educators. Thus, we have equalized the concept of early bullying with that of bullying just formed with lower intensity. The investigation of the influence of early detection/intervention of 
bullying on stopping bullying is in line with the exploration of the impact of detecting/controlling bullying when it has just developed and correspondingly has lower intensity, which is based on our assumption that the earlier the bullying is observed, the lower its intensity is.

How to isolate the pure effect of the timing of the anti-bullying control from many entangled factors is a main challenge in our analysis. The results could be easily confounded by the correlation between the early detection and many other variables. For instance, parents who have superior parenting styles and strategies may be more likely to detect their children's bullying behavior earlier because these parents might make efforts to learn how to effectively parent their children and they might be more alert to the initial early bullying. In addition, early bullying among children in a school with a stricter disciplinary environment is easier to be observed and intervened by teachers compared to a school with less controls. These possible connections and confounding issues are not limited to the illustrated examples and such factors could easily bias our results. Therefore, thoroughly controlling for all the relevant factors in the investigation is a vital contributor to the identification of the real impact of the early detection and control of bullying. The detailed information included in the national data (NLSCY) employed in the paper combined with the semi-parametric matching method used, however, should be effective in eliminating such issues and thus help to validate the results. .

\subsection{Data}

Data from the National Longitudinal Survey of Children and Youth (NLSCY) is employed in this analysis. The NLSCY is a longitudinal survey which tracks a group of children aged 4 to eleven in 1994/95 (Cycle One) until 2008/09 (Cycle Eight) for up to sixteen years. The data contains abundant variables related to the child, the child's family, the community of the child's 
residence, the person most knowledgeable about the child (PMK), the teacher/principal of the child, and the school at which the child is studying ${ }^{58}$.

The information was collected by conducting three surveys for the child (self-completed file), the child's PMK (primary file), and the child's teacher/principal (education file). Our analysis focuses on the information from the primary file and the education file because the children in the self-completed file are generally in a different age group from those in the other files. There are some identical questions linked to the same child covered by the three files, while there are some questions unique to one or two of the survey files. For the questions we use to identify children's bullying behavior, the PMK and teacher of the same child are both asked to answer the same question. However, since the education file is only available for the first four cycles, in some cases the investigations are carried out by restricting the sample to the first four cycles if variables from the education file are included.

The bullying question is "How often would you say this child: Is cruel, bullies or is mean to others?" The answers are "(1) never or not true; (2) sometimes or somewhat true; (3) often or very true." Only those PMKs and teachers whose children are four to 11 years old are required to answer the bullying question. We then generate a bullying dummy with one indicating a bully and zero as a non-bully. The first response of "never or not true" would correspond to nonbullying behaviour, while the other two answers correspond to bullying.

Table 15 lists the age distributions of the PMK-reported sample and the teacher-reported sample broken down by bullying status. The PMK-reported sample is pooled from cycle 1 to cycle 6 , while the teacher-reported sample is from cycle 1 to cycle 4 since the education file is not available after cycle 4 in the data. Overall, the summary statistics from the two samples are similar, with just a few discrepancies. We find more children aged five and under are included in

\footnotetext{
${ }^{58}$ In about 90 percent of cases, the PMK refers to the child's mother.
} 
the PMK-reported sample compared to the one reported by the teacher. This could be explained by the fact that some children under five may not attend school. Furthermore, the percentage of bullies reported by the PMK is less than that reported by the teacher by three percentage points and, among the bullies, there is a higher percentage of boys in the teacher-reported sample versus the PMK reported sample.

Table 15 - Descriptive statistics of bullying broken down by ages on the PMK-reported sample and teacher-reported sample

\begin{tabular}{|c|c|c|c|c|}
\hline & $\begin{array}{c}\text { PMK reported } \\
\text { total sample }\end{array}$ & $\begin{array}{c}\text { PMK reported } \\
\text { bully }\end{array}$ & $\begin{array}{c}\text { Teacher reported } \\
\text { total sample }\end{array}$ & $\begin{array}{c}\text { Teacher reported } \\
\text { bully }\end{array}$ \\
\hline Age & $(\mathbf{\%})$ & $(\%)$ & $(\%)$ & $(\%)$ \\
\hline 4 & 10.44 & 11.77 & 2.4 & 1.6 \\
\hline 5 & 9.47 & 9.77 & 17.8 & 15.3 \\
\hline 6 & 12.45 & 12.08 & 14.8 & 14.6 \\
\hline 7 & 10.84 & 11.11 & 15.2 & 17.0 \\
\hline 8 & 13.78 & 14.08 & 13.5 & 14.3 \\
\hline 9 & 13.14 & 13.30 & 15.1 & 16.4 \\
\hline 10 & 15.95 & 14.46 & 13.3 & 13.6 \\
\hline 11 & 14.57 & 13.43 & 14.5 & 100 \\
\hline Bully & 11.69 & 100.00 & 49.8 & 40.4 \\
\hline Girls & 49.60 & 45.58 & 17783 & 2574 \\
\hline N & 38,639 & 5,114 & & \\
\hline
\end{tabular}

Notes. The descriptive statistics is based on the pooled sample from cycle 1 to cycle 6 of NLSCY for the PMK -reported sample, and cycle 1 to cycle 4 for the teacher-reported sample due to the drop of the education file after cycle 4.

\subsection{Empirical Strategy}

\subsubsection{The effects of early detection}

In this section, we will illustrate methodologies employed to investigate the potential impacts of early detection and intervention in bullying among children. One challenge for this task is that there is no variable available in the data that directly captures the timing of the bullying detection; specifically, whether or not it is observed and intervened upon early in the process. Within a loose definition, we can call it early bullying if it is not long since the child first started 
bullying and the early detection is associated with lower intensity of bullying and fewer bullying incidents.

Our first task therefore is to justify the proposition that early detection is associated with a lower intensity of bullying and that therefore the habit of bullying is formed gradually, with bullying intensity developing from low to high levels. By carrying out a multinomial logit estimation, we find that the relative log odds of the higher-intensity-bullying (frequent bullying) versus the lower-intensity-bullying (occasional bullying) increases as the child grows up ${ }^{59}$, which is indicated by the significant positive estimator on the child's age. This empirical evidence supports the assumption that bullying intensity evolves from low to high gradually. Therefore, low bullying intensity is a necessary condition for the early detection of bullying.

Given that the same child's bullying behavior is reported separately by his/her PMK and teacher in the NLSCY, the data shows that in some cases for the same child, the reported bullying occurrences do not match from the two parties ${ }^{60}$. It could be the case that the child is detected to have shown bullying behavior by the PMK but not by the teacher, and vice versa. Rationally, the detection of bullying by only one party (either by the parent or by the teacher) could occur under the following hypothesized scenarios.

First, we argue that either the PMK or the teacher may not have told the truth. On the other hand, both of them may have detected the bullying but one of the parties is unwilling to reveal it. Generally, the teacher has no strong incentives to hide the truth but the PMK might do this in order to protect her/his child's self-image. If PMKs indeed try to hide the truth about their children's bullying, they would consistently not report bullying for every cycle. However, we

\footnotetext{
${ }^{59}$ The evidence is shown in Table A.1 of Appendix III.

${ }^{60}$ The statistical results of the discrepancy in the identification of the same child's bullying behavior from the PMK and teacher are in Table A.2 of Appendix III.
} 
find that some PMKs, who did not report the bullying behavior of their children early on, actually report bullying in later cycles ${ }^{61}$, which reduces the possibility of the scenario of not telling the truth, although an initial reluctance may be overcome as the bullying intensifies over time.

Secondly, negligence could be another reason why one of the parties has not identified the bullying and the other has. When the bullying happens with relatively lower intensity and has less severe negative effects on both bullies and victims, the bullying behaviour may not have been detected as such. At the early stage of bullying, the intensity of it is relatively low and thus harder to detect. In other words, the negligence in not detecting bullying by one party could be the result of it being at an early stage. Consequently, the detection of bullying by only one party could be treated as an early detection.

Thirdly, one can also argue that it is the lack of opportunity that leads to the failure of detection by the other party. If the child tends to bully in specific places such as the school playground, classroom, home or residential playground, these restricted places will prevent one party from detecting it. However, if the bullying has severe consequences, the party who has observed it first will inform and communicate with the other party to cooperate in dealing with the bullying. Conversely, an incident of minor bullying with lower intensity enables the party who has detected it to think that he/she could manage to control it so that he/she will not bother to inform the other party. Thus, this scenario also points to the possibility of the bullying developing at an early stage and with lower intensity but only being reported by one party. In sum, we argue that the detection of bullying by only one party is the result of early detection

\footnotetext{
${ }^{61}$ The percentage of PMKs who did not identify the bullying behavior of their children actually reported it in later cycles is listed in Table A.3 of Appendix.
} 
because the bullying has lower intensity, develops from an early stage, and is thus harder to detect.

In this paper, we use three methods to generate the early detection dummy as the treatment indicator, equalling one if the bullying is associated with an early detection/intervention and zero if it is not. ${ }^{62}$ First, we define an early detection variable as taking the value of one if the child is first observed to be a bully by only one party (either his/her PMK or teacher) in any one of the cycles of the NLSCY, and equalling to zero if the child is first reported to bully by both parties together. Secondly, the disadvantage of the first method is that we assume the first-reported bullying observed in the data is actually the first bullying behavior in the child's life. Considering that this is a strong assumption, in the second method, we treat it as an early detection of bullying if the child is first reported to be a non-bully by both parties and then is detected to be a bully by either the PMK or teacher, but not both in later cycles. The potential benefits of using the second method as opposed to the first one is that we guarantee the first-observed bullying in the survey is close to the actual first-bullying behavior in the child's life. The third method is based on the age of children when they are first detected as being a bully. Following on from the second method, if the child is observed to be a non-bully in the first observed cycle of the data, then is reported to be a bully by his/her parent, and is in the age range of 4-7 years old inclusive, then this counts as early detection. ${ }^{63}$ The third method is more

\footnotetext{
${ }^{62} \mathrm{We}$ assume the bullying intervention/control will be implemented at the time of bullying detection.

${ }^{63}$ The third early detection is based on the PMK-reported bullying sample from cycle 1 to cycle 6 to increase the sample size because the teacher-reported bullying is not available after cycle 4 in the NLSCY.
} 
robust if we believe that bullies start bullying when they are young and thus identification of bullying at a younger age indicates early detection. ${ }^{64}$

The outcome variable implying the results of the suppression of bullying is generated as follows. In the first two cases of early detection, we track the bullying over time and assign value one to the change of bullying status from bullying to non-bullying, indicating that the bullying has been stopped successfully ${ }^{65}$. Otherwise, the bullying still exists and has not been stopped, indicated by a value zero. In the third case, the bullying is successfully inhibited if the PMK reports the child to be a non-bully in the last observed cycle of the data. Our interest lies in the effects of the early detection on the effectiveness of the bullying intervention.

Ideally, we need to compare the outcomes of bullies whose bullying behavior was detected early compared to those whose bullying behavior was not in order to find the treatment effects of early detection on the suppression of bullying. The early detection of bullying could suffer from endogeneity, which refers to potential connections with observed or unobserved factors which are associated with the effectiveness of bullying suppression. Thus, normal parametric regressions such as logit and probit, may produce biased results on the effect of early detection on the suppression of bullying. Therefore, we employ the propensity score matching method to estimate the average treatment effect (Rosenbaum \& Rubin 1983, 1985; Heckman et al 1997,1998; Dehejia \& Wahba 1999; Abadie \& Imbens 2006), which relaxes the functional assumptions in logit and probit models and also balances the distributions of the covariates between participants and non-participants (Heckman et al. 1997).

\footnotetext{
${ }^{64}$ The first two early detection methods employed data from cycle 1 to cycle 4 , while the last method is based on cycles 1-6.

${ }^{65}$ We drop those who are tracked in the NLSCY only for one cycle.
} 
A group of cross-sectional bullies are divided into two groups, which are the treatment group with early detection and the control group without early detection. Following this, the treatment group and the control group are matched based on the propensity score calculated from the original characteristics of children in the first observed cycle of the data in order to greatly reduce the selection bias. The bullies in the two groups are tracked through cycles and their bullying behavior in the last observed cycle is treated as the final outcome variable.

First, under the assumption of a logistic distribution, we estimate the propensity score to be

$$
p_{i}=\frac{\exp \left(\boldsymbol{x}_{\boldsymbol{i}}{ }^{\prime} \boldsymbol{\beta}\right)}{1+\exp \left(\boldsymbol{x}_{\boldsymbol{i}}{ }^{\prime} \boldsymbol{\beta}\right)}
$$

in which $\mathrm{p}_{\mathrm{i}}$ is the propensity score of the treatment ( early detection of the child's bullying behavior conditional on $\left.\mathbf{x}_{\mathbf{i}}\right)$. Vector $\mathbf{x}_{\mathbf{i}}$ contains a set of observed variables ${ }^{66}$ listed in Table 16 related to the probability of the treatment assignment. After maximizing the likelihood function, we are able to estimate the coefficient vector, $\widehat{\boldsymbol{\beta}}$. The propensity score is estimated as $\widehat{p}_{\imath}$ for each child. Then, the nearest one-to-one matching within a caliper and kernel matching with common-support is conducted. After randomly ordering the treated and control participants, the nearest one-to-one matching within a caliper matching involves matching the first participant in the treatment group with the one in the control group based on the smallest absolute difference in propensity scores between the two units and also the distance has to be smaller than the predetermined caliper imposed in the matching. Rosenbaum and Rubin (1985) suggested that the caliper size should be one quarter of a standard deviation of the estimated propensity score. Due to the small sample size, the matching techniques with and without replacement are employed. In

\footnotetext{
${ }^{66}$ All the covariates are from the first cycle when the bullying is observed
} 
particular, once a control unit is matched to a treatment participant, it will be placed back to the control group for later matching in the first matching scheme and it will be removed from the control group without replacement in the second matching scheme. The common support is imposed to all the matching by dropping the treated units whose propensity scores are larger than the largest propensity score in the non-treated group. The kernel matching involves assigning the outcome of the treated participant a matched kernel-weighted outcome. The matched kernelweighted outcome for the treated unit $\mathrm{i}$ is given by

$$
\widehat{y}_{\iota}=\frac{\sum_{j \in\{D=0\}} K\left(\frac{p_{i}-p_{j}}{h}\right) y_{j}}{\sum_{j \in\{D=0\}} K\left(\frac{p_{i}-p_{j}}{h}\right)}
$$

Where the outcome of the unit $\mathrm{j}$ in the control group $\mathrm{D}=0$ is represented by $y_{j}$, and the Epanechnikov kernel is employed by treating $K(u)=1-u^{2}$ if $|u|<1$, otherwise $K(u)=0$. The bandwidth $h$ takes the same value as the caliper in each case.

The average treatment effect is calculated based on the following equations.

$$
\begin{aligned}
& \widehat{a t t}=\frac{1}{n^{1}} \sum_{i}\left\{\left(Y_{i} \mid D_{i}=1\right)-\sum_{j} w_{i, j}\left(Y_{j} \mid D_{j}=0\right)\right\} \\
& \widehat{a u t}=\frac{1}{n^{2}} \sum_{j}\left\{\left(Y_{j} \mid D_{j}=0\right)-\sum_{i} w_{j, i}\left(Y_{i} \mid D_{i}=1\right)\right\} \\
& \widehat{a t e}=\left\{\frac{1}{n} \sum_{i} D_{i}\right\} \widehat{a t t}+\left\{1-\left[\frac{1}{n} \sum_{i} D_{i}\right]\right\} \widehat{a u t}
\end{aligned}
$$

where $\widehat{a t t}$ is the average treatment effect on the treated (ATT), $\widehat{a u t}$ is the average treatment effect on the untreated, $\widehat{a t e}$ is the average treatment effect (ATE), $\mathrm{n}^{1}$ is the number of children in the treated group, $\mathrm{n}^{2}$ the number of children in the control group, i represents the treatment cases, $n$ represent the total number of children, $j$ denotes the control cases, $D_{i}=1$ indicates the child $i$ is in the treatment group, $\mathrm{D}_{\mathrm{i}}=0$ implies the child $\mathrm{i}$ is in the control group. $\mathrm{Y}_{\mathrm{i}}$ is the outcome variable for the child $\mathrm{i}$ and indicates whether the bullying behavior was successfully stopped. The weight 
$\mathrm{w}_{\mathrm{i}, \mathrm{j}}=1$ if the control case $\mathrm{j}$ is matched with the treatment case $\mathrm{i}$, otherwise $\mathrm{w}_{\mathrm{i}, \mathrm{j}}=0$; similarly, $\mathrm{w}_{\mathrm{j}, \mathrm{i}}=1$

if the treatment case $\mathrm{i}$ is matched with the control case $\mathrm{j}$, otherwise $\mathrm{w}_{\mathrm{j}, \mathrm{i}}=0$. Estimated positive average treatment effect indicates that the early detection of bullying contributes towards raising the effectiveness of bullying inhibition.

Table 16 - Covariates used to generate the propensity scores before matching

\begin{tabular}{|c|c|c|c|}
\hline $\begin{array}{c}(1) \\
\text { Children's } \\
\text { characteristics }\end{array}$ & $\begin{array}{c}(2) \\
\text { Parent's } \\
\text { characteristics }\end{array}$ & $\begin{array}{c}\text { (3) } \\
\text { Family } \\
\text { background }\end{array}$ & $\begin{array}{c}(4) \\
\text { School related } \\
\text { factors }\end{array}$ \\
\hline Age & $\begin{array}{l}\text { Parental punitive } \\
\text { score }\end{array}$ & Household income & Class size \\
\hline Female & $\begin{array}{l}\text { Parental hostile } \\
\text { score }\end{array}$ & $\begin{array}{l}\text { Single mother } \\
\text { family }\end{array}$ & $\begin{array}{c}\text { Teachers rarely } \\
\text { overlook physical } \\
\text { aggression }\end{array}$ \\
\hline $\begin{array}{c}\text { Obese or } \\
\text { overweight }\end{array}$ & $\begin{array}{l}\text { Parental consistency } \\
\text { score }\end{array}$ & Number of siblings & $\begin{array}{l}\text { Teachers rarely } \\
\text { overlook verbal } \\
\text { aggression }\end{array}$ \\
\hline School grades & $\begin{array}{l}\text { Parental positive } \\
\text { interaction score }\end{array}$ & Size of residence & $\begin{array}{l}\text { Teacher's strictness } \\
\text { on the homework }\end{array}$ \\
\hline $\begin{array}{l}\text { Overall health } \\
\text { condition }\end{array}$ & $\begin{array}{c}\text { Parental education } \\
\text { level }\end{array}$ & & $\begin{array}{l}\text { Misbehaving of the } \\
\text { class }\end{array}$ \\
\hline $\begin{array}{l}\text { Psychological } \\
\text { problem }\end{array}$ & $\begin{array}{c}\text { Parental } \\
\text { involvement with } \\
\text { children }\end{array}$ & & $\begin{array}{c}\text { Frequency of } \\
\text { disciplining verbal } \\
\text { conflicts among } \\
\text { students at school } \\
\text { by principals }\end{array}$ \\
\hline Cannot concentrate & Immigrant parent & & $\begin{array}{c}\text { Frequency of } \\
\text { disciplining physical } \\
\text { conflicts among } \\
\text { students at school } \\
\text { by principals }\end{array}$ \\
\hline & & & $\begin{array}{l}\text { Family income } \\
\text { distribution of } \\
\text { students at school }\end{array}$ \\
\hline
\end{tabular}

Notes. (i).the values of these variables are taken from the first cycles when the early detection variable is generated; (ii) the variables in the first three columns are reported by the child's PMK; the variables in the last column are reported by the child's teacher/principal; (iii) the parental punitive score, hostile score, consistency score and the positive interaction score are continuous variables and each of them was derived using a set of weighted items, higher scores respectively indicate more punitive, hostile, consistent and positive parenting; (iv) the parental involvement with children captures how often the parent plays sports, hobbies or games with the child. 


\subsubsection{Results from the propensity score matching evaluation}

We matched the bullies with early detection to the bullies without early detection based on the predicted propensity score calculated from equation (2). One disadvantage associated with propensity score matching is that it is based on observables and cannot address selection bias caused by the unobserved heterogeneity. However, the rich information available in the data related to the children helps to reduce the hidden biases. In addition, a sensitivity analysis for the treatment effect on the confoundedness of the unobserved variables will be carried out in the next section.

Employing the nearest neighbor with caliper one- to-one matching with and without replacement and the kernel matching using the Epanechnikov kernel function, we estimate the average treatment effects on the treated (ATT) and the average treatment effects (ATE). The matching results are reported in Table 17 respectively according to each of the three methods of defining early detection argued before. The caliper matching results in our analyses are conducted by using caliper sizes of $0.032,0.055$, and 0.031 for each case, which are equal to one fourth of the standard deviation of the estimated propensity score. The sample sizes in the matched sample are presented in Table 17 as well ${ }^{67}$. The propensity score matching is based on the characteristics of the sub-samples when the bullying is first observed in the data.

If a bully is indicated as being a non-bully by his/her PMK and teacher (for methods one and two) and by his/her PMK (for method three) in the last available tracked cycle, the outcome variable is that the bullying has been successfully stopped. In each case, the average treatment effect on the treated (ATT) and the average treatment effect (ATE) are generally estimated to be positive, although not every effect is significantly different from zero at conventional levels. The

${ }^{67}$ The common support restriction leads 84 observations to be dropped in the first two cases and 21 observations to be dropped in the third case. 
positive ATE and ATT estimates suggest that early detection of bullying is associated with a higher successful suppression rate over the panel period than is the case for not detecting bullying at its early phase of its development with the estimates being around 5 percentage points for the first case, 7 to 10 percentage points for the second case, and roughly 4 percentage points for the third case.

Generally, the caliper matching without replacement suffers from the small sample size issue across different early detection methods, which leads to the insignificant estimates for both ATT and ATE. However, the significant positive suppression effects from the early detection of bullying are overall valid regardless of the choice of matching method and the strategy of defining early detection with only one exception - the no longer positive ATE when the caliper matching is conducted without replacement in the second case. The early detection of bullying can increase the probability of stopping bullying for all children by around 5 to 8 percentage points according to the ATE results in the first two cases. This empirical result supports the prediction derived from the theoretical model, which states that the earlier the bullying is detected by his/her parent/educator, the easier it is to suppress.

Table 17 - Average treatment effects of early detection of bullying on the outcome of bullying suppression with common support

\begin{tabular}{|c|c|c|c|}
\hline \multicolumn{4}{|c|}{ Early detection 1 } \\
\hline & $\begin{array}{c}\text { Caliper=0.032 } \\
\text { With replacement }\end{array}$ & $\begin{array}{c}\text { Caliper=0.032 without } \\
\text { replacement }\end{array}$ & Kernel \\
\hline ATT & $0.0577^{* *}$ & 0.0331 & $0.0544^{*}$ \\
$(\%)$ & $(0.0282)$ & $(0.0275)$ & $(0.0283)$ \\
\hline ATE & $0.0524^{*}$ & 0.025 & $0.0516^{* *}$ \\
$(\%)$ & $(0.0299)$ & $(0.027)$ & $(0.0228)$ \\
\hline Sample sizes & {$[2501]$} & {$[720]$} & $(2133]$ \\
& $(2501)$ & $(720)$ & Kernel \\
\hline \multicolumn{4}{|c|}{ Early detection 2 } \\
\hline \multicolumn{5}{|c|}{ Caliper=0.055 } & Caliper=0.055 & $0.084 *$ \\
\hline ATT & With replacement & Without replacement & 0.06977 \\
\hline
\end{tabular}




\begin{tabular}{|c|c|c|c|}
\hline$(\%)$ & $(0.051)$ & $(0.1136)$ & $(0.046)$ \\
\hline $\begin{array}{l}\text { ATE } \\
(\%)\end{array}$ & $\begin{array}{l}0.0769 * \\
(0.041)\end{array}$ & $\begin{array}{c}-0.0116 \\
(0.08318)\end{array}$ & $\begin{array}{c}0.076^{* *} \\
(0.037)\end{array}$ \\
\hline Sample sizes & $\begin{array}{l}{[312]} \\
(312)\end{array}$ & $\begin{array}{l}{[86]} \\
(86)\end{array}$ & $\begin{array}{c}{[259]} \\
(54)\end{array}$ \\
\hline \multicolumn{4}{|c|}{ Early detection 3} \\
\hline & $\begin{array}{c}\text { Caliper }=0.031 \\
\text { with replacement }\end{array}$ & $\begin{array}{c}\text { Caliper }=0.031 \text { without } \\
\text { replacement }\end{array}$ & Kernel \\
\hline $\begin{array}{l}\text { ATT } \\
(\%)\end{array}$ & $\begin{array}{c}0.0152 \\
(0.0377)\end{array}$ & $\begin{array}{c}0.0307 \\
(0.03348)\end{array}$ & $\begin{array}{c}0.04167^{*} \\
(0.024)\end{array}$ \\
\hline $\begin{array}{l}\text { ATE } \\
(\%)\end{array}$ & $\begin{array}{l}0.04468 \\
(0.0307)\end{array}$ & $\begin{array}{c}0.03906 \\
(0.03237)\end{array}$ & $\begin{array}{c}0.039 \\
(0.0305)\end{array}$ \\
\hline Sample sizes & $\begin{array}{l}{[1298]} \\
(1298)\end{array}$ & $\begin{array}{l}640] \\
(640)\end{array}$ & $\begin{array}{l}{[328]} \\
(970)\end{array}$ \\
\hline
\end{tabular}

Notes. (i) $* * *$ representing significant at $1 \%$ level, $* *$ significant at $5 \%, *$ significance at $1 \%$; (ii) Standard errors of ATE and ATT are generated by bootstrapping method and reported in parentheses; (iii)The sample size of the control group is in parentheses and the sample size of the treatment group is in square brackets.

\subsection{Robustness Check}

\subsubsection{Sensitivity analysis of hidden bias in the matching}

The matching method employed in section 4 for identifying the treatment effect of early detection and control of bullying on the probability of stopping bullying is based on the conditional independence assumption. This assumption states that the assignment to the treatment group is not confounded if it is conditional on a set of pre-treatment covariates. It rules out any systematic selection into levels of the treatment based on unobserved characteristics correlated with outcomes. If the assumption is violated, the matching results will not be robust to hidden biases. Although we are unable to identify whether the independence assumption is violated, we can check the sensitivity of the average treatment effect to the potential deviations from the assumption by conducting the test proposed (by Rosenbaum 2002; Aakvik 2001; Caliendo et al 2005; DiPrete \& Gangl 2004), which provides evidence on whether the significant results depend on the untestable assumption. 
Rosenbaum's method should be thought of as a sensitivity analysis that relies on the sensitivity parameter gamma which measures the degree of departure from random assignment of treatment. In a randomized experiment, randomization of the treatment ensures that gamma is equal to 1 . In an observational study, where we do not have a randomized experiment, if gamma is equal to 2 , and two subjects are identical on matched covariates, then one might be twice as likely as the other to receive the treatment because they differ in terms of an unobserved covariate (Rosenbaum 2005). In the sensitivity analysis we are asking how big the gamma needs to be to change our basic inference ${ }^{68}$.

We report the test results in Table 18 for the first two early detection methods. ${ }^{69}$ Based on the evidence shown in Table 18, we see that we need a value of at least 1.29 and 1.80 before we reach the upper bound of significance level of 0.10 respectively for the first and second method of early detection cases. This implies that to attribute a higher probability of stopping bullying due to an unobserved covariate rather than the early detection and intervention of bullying we would need to produce a roughly 29 percent in the odds of being in the early detection group for the first case and 80 percent for the second case. That is, an unobserved covariate should increase the odds ratio of early detection by 29 percent in the first case and 80 percent in the second case in order to challenge our conclusions. We believe that there is no such unobserved factor which could have such high impacts on the assignment into treatment group to bias our results, which is

\footnotetext{
${ }^{68}$ Although Aakvik (2001) suggests using the Mantel and Haenszel (1959) test statistic for a binary outcome in the matching, our sensitivity tests are conducted based on the Wilcoxon signrank test statistic mainly because the MH test statistic is more suitable for testing the matching without replacement which is not the case in our analysis due to the limitation of small sample size.

${ }^{69}$ Since the ATT and ATE estimates in the third case are generally not statistically significant from zero, we only conduct the sensitivity analysis on the first two cases.
} 
especially true for the second method of early detection. Therefore, we are confident that our findings will not be undermined by unobserved selection bias.

Table 18 - Rosenbaum Bounds test for the average treatment effects on the treated of the early detection of bullying

\begin{tabular}{|c|c|c|}
\hline Gamma & p-critical+ & p-critical- \\
\hline \multicolumn{3}{|c|}{ Early detection method 1 } \\
\hline 1.05 & $1.5 \mathrm{e}-06$ & $1.5 \mathrm{e}-06$ \\
\hline 1.1 & 0.000028 & $5.3 \mathrm{e}-08$ \\
\hline 1.15 & 0.00031 & $1.5 \mathrm{e}-09$ \\
\hline 1.2 & 0.002237 & $3.4 \mathrm{e}-11$ \\
\hline 1.25 & 0.011049 & $6.5 \mathrm{e}-13$ \\
\hline 1.29 & 0.03935 & $1.0 \mathrm{e}-14$ \\
\hline 1.3 & 0.088584 & $3.3 \mathrm{e}-16$ \\
\hline & 0.105764 & $1.1 \mathrm{e}-16$ \\
\hline 1 & 0.00032 & 0.00032 \\
\hline 1.1 & 0.001126 & 0.00078 \\
\hline 1.2 & 0.003139 & 0.00019 \\
\hline 1.3 & 0.007314 & $4.4 \mathrm{e}-06$ \\
\hline 1.4 & 0.014812 & $1.0 \mathrm{e}-06$ \\
\hline 1.5 & 0.026816 & $2.3 \mathrm{e}-07$ \\
\hline 1.6 & 0.044337 & $5.3 \mathrm{e}-08$ \\
\hline 1.7 & 0.06805 & $1.2 \mathrm{e}-08$ \\
\hline 1.8 & 0.098199 & $2.7 \mathrm{e}-09$ \\
\hline 1.9 & 0.134577 & $6.1 \mathrm{e}-10$ \\
\hline
\end{tabular}

Notes. (i) Gamma measures the odds of differential assignment due to unobserved factors. (ii) Pcritical + is the significance level under the assumption of overestimation of treatment effect. pcritical- is the significance level under the assumption of underestimation of treatment effect. (iii) The tests are conducted based on the caliper matching with replacement.

\subsection{Conclusions}

In this paper, we employed a national data set to empirically test whether or not the timing of detection and intervention of bullying matters in the outcomes of bullying control. Following the bullying habit formation hypothesis proposed in this paper, we expect that the early detection and control of bullying is important in order to effectively stop it. If a child's bullying behavior 
had been developing without detection and control for a long period, it may be harder to deter it later.

The treatment effect of the earlier detection of bullying is evaluated by employing the propensity score matching strategy of the Canadian Data of National Longitudinal Survey of Children and Youth. According to three different ways of defining the variable of early detection of bullying, the treatment group covers the bullies whose bullying behaviors are detected by educators at an earlier stage along the bullying evolutionary path, while the control group includes those without the early detection of bullying. The percentage of bullies whose bullying behaviors disappear by the end in the treatment group is found to be significantly higher over that in the control group according to most ATT and ATE estimates in the first two cases. This empirical evidence, which is also robust to potential unobserved heterogeneity bias, conforms to our earlier expectation, which is that the earlier the bullying is detected and controlled, the more likely it will to lead to a better suppression outcome.

This paper highlights the timing effect as a significant determinant of stopping bullying which has received less attention from researchers and policy makers. Additionally, it provides empirical evidence that the time of control matters in controlling children's bullying behavior by employing a semi-parametric matching methodology. Society has often blamed school systems for failing to prevent bullying among children. However, no matter where the bullying incident happens, each act of bullying is not a static incident; instead, the child's bullying behavior could potentially have started at some moment in their earlier years and then evolve into a habit. It is not only school but also parents that can suppress the formation of children's bullying habits but educators might be inclined to ignore minor bullying, because it may not yet have severe 
consequences. We argue that the initial neglect of bullying by parents and teachers is detrimental to the eventual control of bullying. Thus, it is more effective to stop bullying at its early stages.

This paper fills a much needed gap in the literature. According to the evidence, policy makers and educators are advised to place emphasis on when to control child bullying. Early prevention action could be taken into account when designing anti-bullying programs and special attention and training could be placed on the careful monitoring of the child's behavior and detecting bullying as early as possible. Parents and schools could cooperate and inform each other in order to closely monitor the child's behavior and effectively interact with children. The most important contribution of this paper to the existing literature is that it calls for more dynamic studies on children's bullying behavior and, in the author's opinion, effective ways of interacting with children to control bullying behavior should be analyzed and developed within a dynamic context rather than by investigating it in a static environment. 


\subsection{References}

Aakvik, A. (2001). Bounding a Matching Estimator: The case of a Norwegian training program. Oxford Bulletin of Economics and Statistics, 63, 115-143.

Abadie, A.,\& Imbens, G. (2006). Large sample properties of matching estimators for average treatment effects. Econometrica, 74(1), 235-267.

Abel, A. B. (1990). Asset prices under habit formation and catching up with the Joneses. American Economic Review, 80(2), 38-42.

Anagnostopoulos, D., Buchanan, N. T., Pereira, C. \& Lichty, L.F. (2009). School staff responses to gender-based bullying as moral interpretation: an exploratory study. Educational Policy, 23 (4), 519-553.

Beran, T., Tutty, L., \& Steinrath, G. (2004). An evaluation of a bullying prevention program for elementary schools. Canadian Journal of School Psychology,19 (1-2),99-116.

Brown, S., \& Taylor, K.(2008). Bullying, education and earnings: evidence from the national child development study. Economics of Education Review, 27, 387-401.

Caliendo, M., Hujer, R.,\& Thomsen, S.L. (2005). The employment effects of job creation schemes in Germany. IZA-Discussion Paper No. 1512.

Constantinides, G. M. (1990). Habit formation: a resolution of the equity premium puzzle. Journal of Political Economy, 98(3), 519-43.

Craig, W.M., Pepler, D., \& Atlas, R. (2000). Observations of bullying in the playground and in the classroom. School Psychology International, 21 (1), 22-36.

Cunningham, L. (2010). Places to avoid: population-based study of student reports of unsafe and high bullying areas at schools. Canadian Journal of School Psychology, 25 (1), 40-54.

Dehejia, R.H., \& Wahba, S. (1999). Causal effects in non-experimental studies: re-evaluating the evaluation of training programs. Journal of the American Statistical Association, 94, 1053-1062.

DiPrete,T. A., \& Gangl, M. (2004). Assessing bias in the estimation of causal effects: rosenbaum bounds on matching estimators and instrumental variables estimation with imperfect instruments. Sociology Methodology, 34 (1), 271-310.

Dynan, K. E. (1999). Habit formation in consumer preferences: evidence from panel data. The American Economic Review, 90(3), 391-406. 
Farhat, T., Iannotti, R. J., \& Simons-Morton, B. G. (2010). Overweight, obesity, youth, and health-risk behaviors. American Journal of Preventive medicine, 38(3), 258-267.

Fuhrer, J. C. (2000). Habit formation in consumption and its implications for monetary-policy models. The American Economic Review, 90(3), 367-390.

Greeff, P., \& Grobler, A.A. (2008). Bullying during the intermediate school phase: a south African study.Childhood, 15 (1), 127-144.

Hay, C., \& Meldrum, R. (2010). Bullying victimization and adolescent self-harm: testing hypotheses from general strain theory. Journal of Youth and Adolescence, 39(5), 446459.

Heckman, J.J., Ichimura, H., \& Todd, P.E. (1997). Matching as an econometric evaluation estimator: evidence from evaluating a job training program. Review of Economic Studies, $64,605-654$.

Heckman, J.J., Ichimura, H., \& Todd, P.E. (1998). Matching as an econometric evaluation estimator. Review of Economic Studies, 65, 261-294.

Kaminski, J., \& Fang, X. (2009). Victimization by peers and adolescent suicide in three U.S. samples. Journal of Pediatrics,155(5), 683-688.

Kim, Y.S., \& Leventhal, B. L. (2008). Bullying and suicide. A review. International Journal of Adolescent Medicine and Health, 20(2), 133-54.

Kim, Y.S., Boyce, T., Koh, Y.J., \& Leventhal, B. L. (2009). Time trends, trajectories, and demographic predictors of bullying: a prospective study in Korean adolescents. Journal of Adolescents Health, 45 (4), 360-367.

Larochette, A. C., Murphy, A., \& Craig, W. (2010). Racial bullying and victimization in Canadian school-aged children: individual and school level effects. School Psychology International, 31 (4),389-408.

Lee, C. H. (2010). Personal and interpersonal correlates of bullying behaviors among Korean middle school students. Journal of Interpersonal Violence, 25 (1), 152-176.

Lee, C. H. (2011). An ecological systems approach to bullying behaviors among middle school students in the United States. Journal of Interpersonal Violence, 26 (8), 1664-1693.

Mantel, N., \& Haenszel, W. (1959). Statistical aspects of the analysis of data from retrospective studies of disease. Journal of the National Cancer Institute, 22(4),719-748.

Marees, N. V. , \& Petermann, F. (2010). Bullying in German primary schools: gender differences, age trends and influence of parents' migration and educational backgrounds. School Psychology International, 31 (2), 178-198. 
O'Brien, C. (2011).Young people's comparisons of cross-gender and same-gender bullying in British secondary schools. Educational Research, 53 (3), 257-301.

Rawana, J., Norwood, S., \& Whitley, J. (2011). A mixed-method evaluation of a strength-based bullying prevention program. Canadian Journal of School Psychology, 26 (4), 283-300.

Rosenbaum, P.R., \& Rubin, D.B. (1983). The central role of the propensity score in observational studies for causal effects. Biometrika, 70 (1), 41-55.

Rosenbaum, P.R., \& Rubin, D.B. (1985). Constructing a control group using multivariate matched sampling methods that incorporate the propensity score. The American Statistician, 39(1), 33-38.

Rosenbaum, P.R. (2002). Observational Studies. (2nd ed). New York: Springer.

Swearer, S., Espelage, D., Vaillancourt, T., \& Hymel, S. (2010). What can be done about school bullying? Linking research to educational practice. Educational Researcher,39 (1), 3847.

Wong, D. S. W., Lok, D. P. P., Lo, T. W., \& Ma, S.K. (2008). School bullying among Hong Kong Chinese primary schoolchildren. Youth \& Society, 40 (1), 35-54. 


\section{Appendix III}

A.1- The estimated coefficients on the age of children

\begin{tabular}{|c|c|c|}
\hline & $\begin{array}{l}\text { Logit model of high intensity } \\
\text { bullying }\end{array}$ & $\begin{array}{c}\text { Multinomial logit model of } \\
\text { high intensity bullying }\end{array}$ \\
\hline Dependent variable & $\begin{array}{c}1=\text { often bullying } \\
0=\text { sometimes bullying }\end{array}$ & $\begin{array}{c}1=\text { never bullying } \\
2=\text { sometimes bullying } \\
\text { (default) } \\
3=\text { often bullying }\end{array}$ \\
\hline Age & $\begin{array}{l}0.18^{*} \\
(0.10)\end{array}$ & $\begin{array}{l}0.17 * \\
(0.097)\end{array}$ \\
\hline Sample size & 1972 & 16857 \\
\hline
\end{tabular}

Notes. (i)The sample is from the cycle 1 to cycle 6 of NLSCY; (ii) The variables of household income, psychological problems of the child, overweight/obese of the child, number of siblings, health condition, parenting scores (punitive, hostile, and consistency), religious belief of the child, the academic grade of the child and the concentration situation of the child are all included in the two models; (iii) The robust standard errors are included in the bracket below the coefficients. * indicates the significance at the 10 percent level.

A.2-Discrepancies in the identification of bullying by the PMK and the teacher

\begin{tabular}{|c|c|c|c|}
\hline Age & $\begin{array}{c}\text { Both-reported bully } \\
(\%)\end{array}$ & $\begin{array}{c}\text { Reported bully by } \\
\text { PMK, non-bully by } \\
\text { teacher } \\
(\%)\end{array}$ & $\begin{array}{c}\text { Reported non-bully by } \\
\text { PMK, bully by } \\
\text { teacher } \\
(\%)\end{array}$ \\
\hline Under 6 & 8.29 & 10.40 & 7.71 \\
\hline 6 & 14.00 & 16.11 & 14.29 \\
\hline 7 & 17.14 & 15.31 & 13.80 \\
\hline 8 & 18.29 & 16.11 & 17.21 \\
\hline 9 & 13.71 & 14.74 & 15.18 \\
\hline 10 & 14.57 & 14.97 & 17.53 \\
\hline 11 & 14.00 & 12.34 & 14.29 \\
\hline Total observations & 350 & 875 & 1232 \\
\hline
\end{tabular}

Notes. (i) The results are based on the sample from cycle 1 to cycle 4 of children who were firstly reported to bully by either PMK or teacher or both. 


\section{A.3- The percentage of PMKs who did not identify the bullying behavior of their children}

actually reported it in later cycles

\begin{tabular}{|c|c|c|c|c|}
\hline $\begin{array}{c}\text { Only PMK not } \\
\text { reported bully } \\
\text { (\%) }\end{array}$ & 28.63 & Cycle 2 & Cycle 3 & Cycle 4 \\
\hline $\begin{array}{c}\text { Bully reported by } \\
\text { the PMK later } \\
\text { (\%) }\end{array}$ & 16.51 & 9.75 & 9.30 & 18.46 \\
\hline $\begin{array}{c}\text { Only teacher not } \\
\text { reported bullying } \\
(\%)\end{array}$ & 24.59 & 21.14 & 14.40 & n.a. \\
\hline $\begin{array}{c}\text { Bully reported by } \\
\text { the teacher later } \\
(\%)\end{array}$ & 22.84 & 5.11 & 2.27 & n.a. \\
\hline
\end{tabular}

${ }^{70}$ Children were reported to bully only by their teachers, but not by their PMKs. The percentage is the ratio of the number of children reported only by teachers over all the identified bullies in the same cycle.

${ }^{71}$ Children were reported to bully only by their teachers in the current cycle, but they were reported to bully in later cycles by their PMKs. The percentage is measured by the ratio of those children whose PMKs started to report their bullying behavior in later cycles but not in the current survey over all the children currently reported to be bullies only by their teachers not by PMKs. 


\title{
Chapter 4 Who Entered and Who Left?
}

\section{School Program Streaming and Attrition: \\ Evidence from French Immersion Programs ${ }^{72}$}

\begin{abstract}
4.1 Introduction
Allowing parents to choose the type of education that their children will receive has great appeal to many parents and educators. Parents often understand their children's strengths, as well as the areas in which remedial help is needed, and incorporating the parents into the decision making could be helpful in terms of developing a successful, child-specific education program. In order to facilitate this, many school districts have introduced heterogeneity in the school programs on offer in order to allow parents to choose the program that is best suited to their children.

One of the challenges related to testing for the relationships between school program choice and educational outcomes is the lack of data on these programs. Many programs either have low enrollment making the children difficult to identify in national data sets or the programs are relatively new making them also difficult to analyze thoroughly. One exception is French Immersion which is a program that is offered by many English language school boards in Canada. In French Immersion, children can choose to be immersed in French as a form of second language training at a relatively early age with the goal of generating fluency in French.

Typically, the child's mother-tongue is not French and the children must adjust quickly to the new language or face switching out of the program - usually back into the English program. These French Immersion programs were introduced starting in the 1970 s as a way to try to increase the overall bilingualism of the country. Therefore, the origins of the program are not so

\footnotetext{
${ }^{72}$ This is a joint paper with Christopher Worswick. My contribution to this paper is more than half of the work.
} 
much driven by a commitment to school choice as by the desire to increase the number of Anglophones who are fluent in French. Nevertheless, the creation of these French Immersion programs, operating in parallel with (primarily) English programs, has been one of the main dimensions along which parents can exercise choice over the education of their children ${ }^{73}$.

However, a concern related to school program choice is that this may lead to inequities in the school opportunities of different children. For example, if children from lower income families or from less educated backgrounds are less likely to choose French immersion perhaps due to the lack of familiarity and recognition of the potential benefits of the program on the part of their parents or because of added non-financial or financial costs associated with the programs, then it may be that differential educational opportunities will be generated due to the availability of program choice and the self-selection process. The inequity could be worsened if children with certain behavioral problems are at higher risk of dropping out of the program. One direct significant consequence of this inequity is the biased evaluation of the real effects of the French immersion program on the school performance of children if the selection has been done at the beginning of and also through the program. Also, Christofides and Swidinsky (2010) show that being able to use French as a second language at work is beneficial to workers' earnings in certain areas of Canada. Depriving the educational choice from children leads to the relative disadvantage in their future job market performance. Therefore, it is important for educational policy to make sure that every child can have access to French immersion program and also, the bilingualism could be promoted through participation in French immersion. Recognition of the possible selection issues related to the French immersion program is of importance to create a fair school environment for students. Only when the program functions on the basis of fairness, these programs could start producing desired results that educators originally designed them for.

\footnotetext{
${ }^{73}$ J. Markropoulos (2009); E.-S. Yoon and K.N. Gulson (2010);
} 
An important feature of French Immersion programs is that they are academically demanding. The children are expected to achieve the same minimum level of performance over the same curriculum as children in other programs while also having to master a second language, French. Consequently, school officials often warn parents not to enroll children in French Immersion programs if the child is struggling in school, if the child has learning disabilities or emotional/behavioral difficulties. Therefore, it is reasonable to expect that children in French Immersion programs will have higher performance on academic tests such as mathematics and reading tests as well as having lower scores on measures of emotional and behavioral problems. Due to the nature of the French immersion programs, the selection, which is based on the academic ability of children, might not be a bad thing; however, selections according to the children's socioeconomic background or pure non-academic behavioral problems could lead to inequity and is opposite to the original purpose of French immersion for promoting bilingualism for every child. One of the goals of this study is to provide nationally representative estimates of the nature and magnitudes of any differences across children who enter in French Immersion programs and those in English programs. The other goal is to investigate attrition of the program and examine whether or not the attrition is really based on the academic incapacity for the program.

An extensive literature in education research exists on second language training and on language immersion programs. For a good review of the literature on French Immersion in Canada see Swain (2000). Many studies have tried to investigate the impacts of the French immersion program on children's school performance. Generally, they found significant positive associations. Allen (2004) provides basic statistics in Canada to show that French immersion 15year-old students achieve significantly higher PISA reading scores in every province than those 
in non-immersion programs except Manitoba. Based on a survey of research, Lazaruk (2007) suggests that French immersion programs contribute to language proficiency in both English and French and a cognitive advantage of students at no cost of academic success. The strong benefits of French immersion programs concluded by the author could be easily biased by the selection issues. However, researchers had difficulties to identify that the connections revealed from the data is the unbiased causal effects rather than the one confounded with individual-specific endogeneity. A well-known concern is over the possibility that a French Immersion program running in parallel to a traditional English program will lead to the "streaming effect" where the higher ability/higher socio-economic status children enter the more demanding French Immersion program. The streaming issue is frequently mentioned in the literature (see, for example, Lawton, 2001). However, this paper fills a void in the literature by comparing the characteristics of children in the program using nationally representative data.

The causal links between social and community backgrounds of individuals and their second language learning and bilingualism are found by Cardner, Masgoret and Tremblay (1999). Muircheartaigh and Hickey (2008) investigate the differential outcomes between the early and late immersion programs in Ireland. A growing literature on the economics of school choice exists. Hoxby (2000) analyzes the impact of greater choice in terms of number of school districts within a metropolitan area on school performance based on the argument that greater choice leads to increased competition among schools and better educational services provided to students. She finds evidence in support of greater school choice leading to better outcomes for students. $^{74}$

\footnotetext{
${ }^{74}$ See also Epple and Romano (1998) and Hoxby (1999).
} 
This study contributes to the literature on the economics of school choice by analyzing the factors that affect a family's decision to place a child in a "specialty" program. The first part of the paper contains an analysis of a popular, long-standing program (French Immersion), and analyzes the extent to which its existence has led to the "streaming" of students by program type along the dimensions of the child's ability and socio-economic status. In the second part, we argue that the program "streaming" effect exists not only at the time when the children/parents self-selected themselves into a program; it could also happen when the children decide to drop out it. Further investigation in program attrition contributes to a better understanding of who entered the program and who actually stayed in the program through time, which outlines a more comprehensive picture of French immersion "streaming".

\subsection{Data and Sample Selection}

The data employed are taken from the National Longitudinal Survey of Children and Youth (NLSCY) of Statistics Canada. The Survey was originally conducted on a group of 0 to 11 year-old children in 1994/95 and has been repeated every second year until Cycle 8 in 2008/09. Cycle 3 of NLSCY includes children aged 0 to 15 living in ten provinces of Canada in 1998/99, which includes both longitudinal and cross-sectional children. The cross-sectional sample of Cycle 3 is used to examine streaming effects of French immersion programs, whereas the longitudinal sample of Cycle 3 to Cycle 8 is suitable for investigation of program attrition. Cycle 3 includes detailed information on children, their families, their schools and neighborhoods.

Cycle 3 is selected in this study since it is the first cycle of the NLSCY data to contain questions on enrollment in language immersion programs. Cycle 3 of NLSCY data contains a set of crosssectional and longitudinal weights and these are employed in corresponding analysis. 
At the time of interview, one adult in the child's household is identified (by the family) as the "Person-Most-Knowledgeable" (PMK) about the child. For over 90 percent of the children, this person is the child's biological mother. Detailed demographic information is collected on the PMK and the PMK's spouse. This information is used in the analysis to capture parental information for the child. ${ }^{75}$

The sample employed in this paper is comprised of children (4-15), whose PMKs are surveyed with the immersion program question. The PMK is asked a series of questions on the type of education that the child is receiving. From the answers to these questions, it is possible to identify whether the child is in a publicly funded school. Only children currently enrolled in publicly funded schools (both Catholic and non-Catholic) are included in the sample. Children are treated as French immersion students if they are reported by their PMKs to be in language immersion programs of public schools and the main language of instruction at school is either French or half French and half English. In order to justify this French immersion identification method employed in this study, evidence is established through comparing answers to the direct French immersion question in the education file of Cycle 4 reported by teachers of students ${ }^{76}$ with the same cycle's French immersion identification results by PMKs as being in language immersion programs of public schools with French or both English and French as main

\footnotetext{
${ }^{75}$ Information exists for the PMK and the PMK's spouse if present. In order to allow for differences in effects of variables in the analysis according to the gender of the parents, PMKs and spouses were assigned as mother or father of the child in the following way. In terms of the definitions used in the analysis, the child's mother is defined to be the child's PMK if the PMK is female or the PMK's spouse if the spouse is present and female. The child's father is defined to be the child's PMK if the PMK is male or the PMK's spouse if the spouse is present and male. If the PMK's gender was the same as the PMK's spouse's gender, the child was excluded from the analysis. The very small number of children in this category makes it prohibitively difficult to analyze this group separately.

${ }^{76}$ In NLSCY, teachers were only asked to indicate whether the child is in French immersion program in Cycle 4.
} 
instruction languages. The two different methods of identifying French immersion students should produce very similar results.

Table 19 lists the cross tabulation of the two types of French immersion identification methods. Overall, the two samples match quite well with the exception of 19 students being reported to be in French immersion programs (FIPs) by their teachers but not by PMKs and 43 students being identified in FIPs by PMKs but not by teachers. The mismatched sample totally accounts for only $11 \%$ of total observations. Specifically, in comparison to teacher- reported French immersion enrolment, only around 3\% of students are underrepresented by PMKs, while roughly $8 \%$ of students are overrepresented to be reported in FIPs by PMKs. It is noted that the overrepresentation outnumbers the underrepresentation by parents, which could be attributable to either incomplete information possessed by parents on school systems or potential sample errors.

Table 19 - Cross tabulation of French immersion children by teachers and PMKs

\begin{tabular}{|c|c|c|c|}
\hline & $\begin{array}{c}\text { In (identified by } \\
\text { teachers) }\end{array}$ & $\begin{array}{c}\text { Not (identified by } \\
\text { teachers) }\end{array}$ & Total \\
\hline $\begin{array}{c}\text { In (identified by } \\
\text { PMKs) }\end{array}$ & 268 & $\mathbf{4 3}$ & 311 \\
\hline $\begin{array}{c}\text { Not (identified by } \\
\text { PMKs) }\end{array}$ & $\mathbf{1 9}$ & 234 & 253 \\
\hline Total & 287 & 277 & 564 \\
\hline
\end{tabular}

Note.

1. Data are from the education file and primary file in Cycle 4 of NLSCY.

2. Children are identified "In" French immersion programs by teachers if the answer to the French immersion question is "yes" in the education file of Cycle 4, while children are identified "In" French immersion programs by PMKs if PMKs reported them to be in language immersion programs of public schools plus the main instruction language is either French or both English and French. 


\subsection{Preliminary evidence on Streaming by School Program Type}

In Cycle 3, the PMK was asked whether the child is in a language Immersion program, from which the child's participation in French immersion programs is derived ${ }^{77}$. In this paper, students from Yukon, Northwest Territories and Nunavut are not included in the sample. In order to focus on the implications of school choice (in the form of access to a parallel French Immersion program) on streaming of students in programs according to ability and socio-economic background, children in French-language schools who are not in French Immersion programs are excluded from the sample. Table 20 contains mean characteristics of children broken down by whether they are enrolled in French Immersion. The sample size listed in Table 20 indicates that there is roughly eight percent French immersion students among all the Canadian students aged four to 15 years old enrolled in English programs in the survey year of 1994/1995. This statistics are reasonable when compared to the number reported by Statistics Canada in 2000 showing that the percentage of 15-year-olds enrolled in French immersion programs in Canada is around 11 percent across the ten Canadian provinces ${ }^{78}$. The proportion of French Immersion students who are female is 56.2 percent compared with 48.4 percent for the English program children. Given that a child's capacity to learn a new language in an immersion environment relies heavily on language ability, it may be that girls are more able to handle this extra demand associated with the French Immersion program.

Children in French Immersion have parents who are generally more educated than children not in French Immersion. This is most pronounced at the university degree level where 28 percent of children in French Immersion have mothers with university degrees compared with

\footnotetext{
${ }^{77}$ As discussed in the previous section, those in language immersion programs at public or Catholic schools are treated as French immersion students if the main instruction of language in classes is French or both English and French.

${ }^{78}$ http://www.statcan.gc.ca/pub/81-004-x/200406/6923-eng.htm\#a
} 
13 percent for children in English Programs. A similar pattern exists for father's education. This is preliminary evidence of an endogenous selection of children of high socio-economic status into French Immersion.

Table 20 - Sample means of demographic variables by school program type

\begin{tabular}{|c|c|c|}
\hline & French language immersion & English program \\
\hline Female & $0.5618^{* * *}$ & 0.4841 \\
& $(0.4964)$ & $(0.4998)$ \\
\hline Mother's education & & 0.0223 \\
& $0.0099^{* * *}$ & $(0.1475)$ \\
\hline Elementary of less & $(0.0990)$ & 0.1002 \\
& $0.0573^{* * *}$ & $(0.3003)$ \\
\hline Secondary without & $(0.2326)$ & 0.2033 \\
graduation & $0.1542^{* * *}$ & $(0.4024)$ \\
\hline Secondary with graduation & $(0.3613)$ & 0.5436 \\
& $0.5010^{* * *}$ & $(0.4981)$ \\
\hline Post-secondary ( some or & $(0.5002)$ & 0.1306 \\
certificate) & $0.2777^{* * *}$ & $(0.3370)$ \\
\hline University and higher & $(0.4481)$ & 0.0343 \\
& & $(0.1820)$ \\
\hline Father's education & $0.0139^{* * *}$ & 0.1266 \\
& $(0.1172)$ & $(0.3325)$ \\
\hline Elementary of less & $0.0660^{* * *}$ & 0.1830 \\
& $(0.2485)$ & $(0.3867)$ \\
\hline Secondary without & 0.1727 & 0.5057 \\
graduation & $(0.3782)$ & $(0.5000)$ \\
\hline Secondary with graduation & $0.4542^{* * *}$ & 0.1505 \\
& $(0.4982)$ & $(0.3575)$ \\
\hline Post-secondary (some or & $0.2932^{* * *}$ & 11782 \\
\hline certificate) & $(0.4555)$ & \\
\hline University and higher & 1027 & \\
\hline Sample size & & \\
\hline
\end{tabular}

Note.

1. The data is from cycle 3 of NLSCY.

2. A child is identified to be in a French immersion program if he/she is in a language immersion program and the main instruction language is French or both English and French.

3. Standard deviations are in round brackets.

4. Children in French language schools who are not in language immersion programs are excluded from the sample.

5. Tests of differences in means are performed between the immersion and English program samples: $* * *, * *$ and $*$ denote significance at the one, five and ten percent levels, respectively. 
Table 21 contains mean characteristics of children's parents based on mother tongue. ${ }^{79}$ It is likely that parents whose mother tongue is French find French Immersion relatively more attractive since they may wish to ensure that their children develop fluency in French. This is especially likely in families where one parent has English as a mother tongue and one parent has French as a mother tongue. For at least some of these families, it will be the case that they choose to send their children to a school in an English language school board. However, they may also choose to place the child in a French Immersion program at the local English language school board in order to ensure that the child develops fluency in French. Children in French Immersion programs are more likely to have a mother whose mother tongue is French (21 percent compared with 2.8 percent). A similar difference exists for the father's mother tongue. It is worth noting that a significantly lower percentage of children are in French immersion programs whose mother's mother tongue includes a language rather than English and French. The similar pattern exists for the father's mother tongue containing a non-English and nonFrench language between French immersion and non-French immersion students. This indicates that children in immigrant families from non-traditional source countries may be less likely to be in French Immersion as in an English Program.

Table 21 - Sample means of parents' linguistic background by school program type

\begin{tabular}{|c|c|c|}
\hline & French Immersion & English Program \\
\hline Mother's mother tongue- & $0.2098^{* * *}$ & 0.0278 \\
French & $(0.4000)$ & $(0.1511)$ \\
\hline Mother's mother tongue- & $0.7063^{* * *}$ & 0.8447 \\
English & $(0.4557)$ & $(0.3622)$ \\
\hline Mother's mother tongue- & $0.0839 * * *$ & 0.1276 \\
other & $(0.2774)$ & $(0.3337)$ \\
\hline Sample size & 1001 & 11472 \\
\hline
\end{tabular}

\footnotetext{
${ }^{79}$ If the mother tongue of parents is identified to include a language other than French and English, it will be treated as other mother tongue.
} 


\begin{tabular}{|c|c|c|}
\hline Father's mother tongue- & $0.1953 * * *$ & 0.0315 \\
French & $(0.3874)$ & $(0.1561)$ \\
\hline Father's mother tongue- & $0.7181^{* * *}$ & 0.8286 \\
English & $(0.4502)$ & $(0.3769)$ \\
\hline Father's mother tongue- & 0.0865 & 0.1399 \\
other & $(0.2813)$ & $(0.3469)$ \\
\hline
\end{tabular}

Note.

1. The data is from cycle 3 of NLSCY.

2. A child is identified to be in a French immersion program if he/she is in a language immersion program and the main instruction language is French or both English and French.

3. Standard deviations are in round brackets.

4. Children in French language schools who are not in language immersion programs are excluded from the sample.

5. Tests of differences in means are performed between the immersion and English program samples: $* * *, * *$ and $*$ denote significance at the one, five and ten percent levels, respectively.

Table 22 contains mean characteristics of the children's parents in terms of income of the mother, income of the father and whether either parent received social assistance and employment insurance benefits. The higher percentage of mothers of children in French Immersion is in higher income categories than are mothers of children in English programs. The equivalent differences in father's incomes also exist between French immersion and English program students; however, the magnitudes of the differences are smaller. Parents of children in French Immersion are less likely to be receiving social assistance (6.2 percent compared with 9.8 percent for the children in the English Program). Also, it is less likely for French immersion students' parents to receive Employment Insurance with 15.9 percent compared to 18.4 percent for English Program children.

The results to this point indicate that children in French Immersion programs differ on average from children in English programs along a number of dimensions of parental characteristics. Preference factors - or factors likely to be related to parents' preferences over enrollment in French Immersion - such as having French as a mother tongue are associated with 
children being enrolled in French Immersion. In addition, the family's economic situation is also correlated with French Immersion enrollment. Children in French Immersion have parents with higher incomes and lower probability of collecting employment insurance and lower likelihood to be social assistance recipients.

Table 22 - Sample means of parental income, receipt of employment insurance income and social welfare assistance by school program type

\begin{tabular}{|c|c|c|}
\hline & French Immersion & English Program \\
\hline \multicolumn{3}{|c|}{ Mother's income (in thousands of 1998 dollars) } \\
\hline $10,000-14,999$ & $\begin{array}{c}0.105^{* * *} \\
(0.307)\end{array}$ & $\begin{array}{c}0.141 \\
(0.348)\end{array}$ \\
\hline $15,000-19,999$ & $\begin{array}{c}0.114 \\
(0.318)\end{array}$ & $\begin{array}{c}0.116 \\
(0.320)\end{array}$ \\
\hline $20,000-29,999$ & $\begin{array}{c}0.149^{* * *} \\
(0.356)\end{array}$ & $\begin{array}{c}0.177 \\
(0.382)\end{array}$ \\
\hline $30,000-39,999$ & $\begin{array}{c}0.151^{* * *} \\
(0.358)\end{array}$ & $\begin{array}{c}0.123 \\
(0.329)\end{array}$ \\
\hline 40,000 or more & $\begin{array}{c}0.259 * * * \\
(0.438) \\
\end{array}$ & $\begin{array}{c}0.148 \\
(0.355)\end{array}$ \\
\hline \multicolumn{3}{|c|}{ Father's income (in thousands of 1998 dollars) } \\
\hline $10,000-14,999$ & $\begin{array}{c}0.028^{* *} \\
(0.166)\end{array}$ & $\begin{array}{c}0.039 \\
(0.194)\end{array}$ \\
\hline $15,000-19,999$ & $\begin{array}{c}0.034^{* * * *} \\
(0.182)\end{array}$ & $\begin{array}{c}0.049 \\
(0.216)\end{array}$ \\
\hline $20,000-29,999$ & $\begin{array}{c}0.120 \\
(0.325)\end{array}$ & $\begin{array}{c}0.133 \\
(0.339)\end{array}$ \\
\hline $30,000-39,999$ & $\begin{array}{l}0.138^{* *} \\
(0.345)\end{array}$ & $\begin{array}{c}0.158 \\
(0.365)\end{array}$ \\
\hline 40,000 or more & $\begin{array}{c}0.470 * * * \\
(0.499)\end{array}$ & $\begin{array}{c}0.403 \\
(0.491)\end{array}$ \\
\hline Sample size & 883 & 10003 \\
\hline $\begin{array}{l}\text { Parental receipt of } \\
\text { employment insurance } \\
\text { benefits }\end{array}$ & $\begin{array}{c}0.1585^{* *} \\
(0.3654) \\
{[902]}\end{array}$ & $\begin{array}{l}0.1840 \\
(.3875) \\
{[10178]}\end{array}$ \\
\hline $\begin{array}{l}\text { Parental receipt of social } \\
\text { welfare assistance }\end{array}$ & $\begin{array}{c}0.0623^{* * *} \\
(0.2418)\end{array}$ & $\begin{array}{c}0.0982 \\
(0.0027)\end{array}$ \\
\hline
\end{tabular}

Note.

1. The data is from cycle 3 of NLSCY.

2. A child is identified to be in a French immersion program if he/she is in a language immersion program and the main instruction language is French or both English and French. 
3. Standard deviations are in round brackets, sample sizes are in square brackets.

4. Children in French language schools who are not in language immersion programs are excluded from the sample.

One final area in which a comparison of children in French Immersion and English programs can be made is in terms of the children's academic test scores and other characteristics. In particular, the NLSCY data contains detailed information on the children's school performance defined in terms of scores on formal tests in mathematics and reading. Additionally, we use the hyperactivity score available in NLSCY to measure the behavioral wellbeing of children. Table 23 lists means of children's academic and behavioral scores. For each of the academic test scores, the scores are re-scaled to have a mean of 50 and a standard deviation of 10. The first two scores are for reading and mathematics. These tests were administered to children in grade 2 or higher if the parent gave permission for the tests to be conducted. For both tests, the mean scores are higher for the children in French Immersion (51.84 for mathematics and 50.88 for reading) compared with the children in the English Program (49.84 for mathematics and 49.92 for reading). These differences (approximately one fifth of a standard deviation for mathematics and one tenth of a standard deviation for reading) in each of the test scores between the two groups of students are consistent with the predictions of the model that higher ability children select themselves (or are selected by their parents) into French Immersion. It is interesting that the difference is larger in the mathematics test score relative to that of reading test score. One would expect that any ability advantage on the part of the French Immersion students might be larger in the area of reading given the need for strong reading skills in a second language immersion program. The fact that the opposite is true could be speculated by the assumption that French immersion selection might be based on the children's overall academic capacity rather than only on their language skill. Especially, when children are at an 
earlier stage of academic development and thus their advantages in learning areas could not be fully revealed, overall academic achievement might be more likely to be treated as a valuable criteria for selection into French immersion programs.

An important issue related to interpreting these differences is that the children's performance in reading and mathematics on the tests will be in general a function of the quality of the past instruction, children's intrinsic ability and the quality of the learning environment. For example, it may be that the French Immersion children are having higher tests scores in reading and mathematics because of higher quality teaching, effective education style, higher innate ability, or possibly a better family and classroom environment. It is difficult to control for these determinants of test score performance.

Table 23 also lists mean scores of hyperactivity behavior by school program type. This score is described in detail in the NLSCY documentation and is indexed based on a series of specific qualitative questions asked of the PMK related to the child's behavior. Children in French immersion programs are found to have a significantly lower hyperactivity mean score compared with their peers in normal English programs by 0.21 points. This is somewhat consistent with general speculation that children with learning disabilities and behavioral problems are often thought to have difficulty adjusting to the French Immersion curriculum.

The results to this point indicate that factors likely to impact on preferences for French Immersion on the part of families differ between children in French Immersion programs and children in English programs. Children in French Immersion programs are more likely to have a father or a mother who report French as a mother tongue. This is consistent with the idea that there exists heterogeneity in the Canadian population of families in terms of preferences for different types of education. As was stated above, the existence of school choice raises the 
possibility of "streaming" by ability and/or socio-economic status. The results indicate that children in French Immersion programs are typically from higher income families, with mothers and fathers who are more likely to have university degrees. In addition, children in French Immersion families are less likely to be receiving social assistance and employment insurance income. These mean differences are preliminary evidence in favour of the "streaming" hypothesis.

Table 23 - Sample means of test scores, behavior scores, and school achievement expectations by school program type

\begin{tabular}{|c|c|c|}
\hline & French Immersion & English Program \\
\hline Mathematics scores & $51.84^{* * *}$ & 49.84 \\
& $(10.05)$ & $(9.98)$ \\
\hline Reading scores & $50.88^{*}$ & 49.92 \\
& $(10.91)$ & $(9.91)$ \\
\hline Hyperactivity/Inattention & $4.37^{* *}$ & 4.58 \\
score & $(3.30)$ & $(3.45)$ \\
\hline
\end{tabular}

Note.

1. The data is from cycle 3 of NLSCY.

2. A child is identified to be in a French immersion program if he/she is in a language immersion program and the main instruction language is French or both English and French.

3. The mathematics and reading test scores are standardized to have a mean of 50 and a standard deviation of 10 .

4. Standard deviations are in round brackets, sample sizes are in square brackets.

5. Children in French language schools who are not in language immersion programs are excluded from the sample.

6. Tests of differences in means are performed between the immersion and English program samples: $* * *, * *$ and $*$ denote significance at the one, five and ten percent levels, respectively.

\subsection{Estimation of Models of French Immersion Enrollment}

The results to this point are generally consistent with the "streaming" hypothesis, which argues that children with higher intellectual ability and those from families with higher socio-economic 
status are more likely to be placed in French Immersion compared with other children.

However, given that many of these family characteristics have a positive correlation (i.e. parental education and income, parental education and academic scores of children) it is not clear which factors are most important in terms of the selection into French Immersion. It is also unclear how important the child's academic ability is in terms of determining French Immersion enrollment. In order to explore these issues, the next stage of the analysis involves the estimation of models of the decision to enroll children in French Immersion.

Firstly, we estimate the following reduced-form linear probability model of participation of French immersion programs and children's social-economic background and demographic characteristics.

$$
Y_{i}=\beta_{0}+L A N_{i} \alpha+E D U_{i} \gamma+I N C_{i} \delta+X_{i} \theta+\varepsilon_{i}
$$

In the regression, $Y$ measures the probability of enrolling in French immersion programs. Vector $L A N$ contains mother tongue language indicators of children's parents, and the children's social-economic background is measured by parental education and income variables, represented by $E D U$ and $I N C$. Additionally, vector $X$ in the model includes a set of covariates concerning children's demographic characteristics such as gender, age, province of residence, size of residence and whether PMK has a spouse. $\varepsilon$ is a random error with a zero mean. In addition to applying a linear probability regression to examine streaming effects of French immersion programs, a nonlinear logistic model with the same covariates are also employed and results are shown in Table 24.

In order to further expand an inquiry to include the potential academic streaming effects of French immersion program, the reading score of children are added to the present regression. However, the endogenous problem associated with reading score, which could come from the 
simultaneity relationship between children's reading ability and enrollment of French immersion, will lead to biased estimated coefficient on reading ability. A solution to this problem is to instrument for the reading variable. We use four parental income variables (father's income, mother's income, social assistance recipients of parents, and employment insurance recipients of parents) as instrumental variables for the reading score. Given that the French immersion programs in Canada are free to enter and are not subject to economic restrictions, we assume that parental incomes will have impacts on children's enrollment in French immersion programs only through affecting the resources available to support children's reading achievement. Parents with higher incomes will have access to more resources to improve their children's reading ability such as buying more books, subscribing magazines, and hiring tutors. The quality of the instruments and the endogeneity of the reading variable are tested and the results are reported in Table 24. The academic ability streaming effects of French immersion programs are estimated by employing the following estimation specification.

$$
\begin{aligned}
& Y_{i}=\beta_{0}+\beta_{1} \text { Reading }_{i}+L A N_{i} \alpha+E D U_{i} \gamma+X_{i} \theta+\varepsilon_{i} \\
& \text { Reading }_{i}=Z_{i} \rho+u_{i}
\end{aligned}
$$

In which, coefficient $\beta_{1}$ captures the effect of reading ability instrumented with four parental income variables on enrollment in French immersion programs for child $i$. Besides the linear probability regression in equation (2), a non-linear Probit instrumental variable estimation is also employed and the marginal effects are reported in Table 24.

Table 24 presents estimated marginal effects from the linear probability reduced form model in column (1), the logistic model of French Immersion enrollment in column (2), and structural models of two stage least squares and instrumental variables Probit with instrumented reading scores respectively in columns (3) and (4). According to the estimates of the reduced 
models in the first two columns of Table 24, girls are more likely to be enrolled in French Immersion than are boys by roughly three percentage points. A child's probability of enrollment in French Immersion is around 20 to 10 percentage points higher if the child's mother stated that French was her mother tongue and 19 to 8 percentage points higher if the father's mother tongue was French. ${ }^{80}$ Overall, parental education levels have no significant impacts on children's enrollment in French immersion programs. ${ }^{81}$ The child's father having some secondary education without graduation is associated with roughly a two to three percentage points decrease in the probability of the child being in French Immersion. The rest rows contain coefficient estimates on the variables related to family socio-economic status. It is interesting to note that while mother's income is positively associated with enrollment in French Immersion of children, father's earnings almost have no significant connections with children's French immersion statuses. No significant relationship is found between the recipients of welfare or employment insurance income of parents and their children's enrollment in French immersion.

Column (3) of Table 24 contains the estimated marginal effects of the linear two stage least squares estimation, while column (4) reports the marginal effects from the Newey's (1987) minimum chi-squared estimation for the Probit model with a continuous endogenous variable. The reading test score is employed as the measure of the child's human capital. Alternatively, the child's mathematics test score is also used. The reading score was chosen since French immersion aptitude is more likely to be related to language skills than to mathematics skills. However, the analysis is also repeated using the mathematics score instead of the reading score and the results are generally similar. It should be noted that there are many other aspects of a

\footnotetext{
${ }^{80}$ The default category for each set of mother tongue variables is English.

${ }^{81}$ The default category for each set of education variables is secondary education with graduation.
} 
child's human capital (such as knowledge of history, science, literature, etc.) that might be important for learning. The reading test score is used mainly due to availability. However, it is also a measure of the skills that are most likely to have an important impact on a child's success in school.

The reading score is only available for children who were in grade two or higher and underwent the test. Therefore, our sample size drops after the inclusion of reading score in the models. The reading score is instrumented with parental income variables, social assistance and employment insurance receiving status for both parents at the first stage in column (3) of Table 24. At the second stage the regression is carried out on the fitted reading score from the first stage. This procedure for estimating a linear probability model with an endogenous right-handside variable (the test score) is based on the approach suggested by Heckman and MaCurdy (1985). One advantage of this approach is that it greatly reduces the endogenous problems and produces the unbiased estimate on the reading score. Another advantage to this approach is that it removes the effect of differences in school environment and curriculum on the reading score since the predicted reading score model does not contain controls for whether the child is enrolled in French Immersion or not. This means that the resulting reading score is determined by the characteristics of the child's family. Column (4) of Table 24 fits a Probit model with the reading score as the endogenous variable which is instrumented with the same exogenous controls employed in column (3).

According to the estimated marginal effects reported in columns (3) and (4) of Table 24, 2.5 to 3.4 percentage points increase in the probability of being in French Immersion for each one point increase in the reading score. This is a strong relationship given that is implies that a one standard deviation increase in the test score would be associated with 25 to 34 percentage 
points increase in the probability of being in French Immersion. This indicates that academic performance is an important determinant of a family's decision to enroll in French Immersion and is further evidence that school choice of this type is consistent with streaming of high ability/human capital children into the non-traditional school program choice. However, it is worth noting that although the reading score is tested to be endogenous, the quality of our income instruments are low with the F value lower than the minimum suggested threshold (10) by Stock, Wright and Yogo (2002). Better instruments are still needed in future analysis in order to get more robust estimates on the effect of the reading ability on the decision of enrollment in French immersion program. The estimates on the mother tongue language for parents in columns (3) and (4) are similar in magnitude to those of Columns (1) and (2). Families with parents who reported French as a mother tongue have a preference for French Immersion. However, girls are not estimated to have higher probability to enter French immersion programs in the structural models as predicted in the reduced models. It supports our early speculation that female children tend to have higher reading scores so that they are more likely to be sent to French immersion programs based on their higher academic abilities. The parental education levels are statistically insignificant from zero in columns (3) and (4) of Table 24, which is consistent with the findings from the reduced models.

Table 24 - Estimated marginal effects of Reduced Form and Instrumental Variable Models of French Immersion Enrollment

\begin{tabular}{|l|c|c|c|c|}
\hline \multirow{2}{*}{} & \multicolumn{2}{|c|}{ Reduced Form } & Structural Form & $\begin{array}{c}\text { Structural } \\
\text { Form }\end{array}$ \\
\cline { 2 - 5 } & Linear Probit & Logit & 2SLS & IV Probit \\
\cline { 2 - 5 } & $(1)$ & $(2)$ & $(3)$ & $(4)$ \\
\hline Reading & n.a. & n.a. & $0.025^{* *}$ & $0.034^{* * *}$ \\
& & & $(0.010)$ & $(0.007)$ \\
\hline Child is female & $0.029^{* * *}$ & $0.031^{* * *}$ & 0.004 & 0.002 \\
& $(0.008)$ & $(0.008)$ & $(0.015)$ & $(0.018)$ \\
\hline
\end{tabular}




\begin{tabular}{|c|c|c|c|c|}
\hline $\begin{array}{l}\text { Mother's mother tongue } \\
\text { is French }\end{array}$ & $\begin{array}{c}0.198 * * * \\
(0.039)\end{array}$ & $\begin{array}{c}0.098 * * * \\
(0.016)\end{array}$ & $\begin{array}{l}0.215 * * * \\
(0.059)\end{array}$ & $\begin{array}{c}0.133 * * * \\
(0.050)\end{array}$ \\
\hline $\begin{array}{l}\text { Mother's mother tongue } \\
\text { is neither French nor } \\
\text { English }\end{array}$ & $\begin{array}{l}-0.025 \\
(0.017)\end{array}$ & $\begin{array}{l}-0.027 \\
(0.019)\end{array}$ & $\begin{array}{l}-0.022 \\
(0.027)\end{array}$ & $\begin{array}{l}-0.023 \\
(0.038)\end{array}$ \\
\hline $\begin{array}{l}\text { Father's mother tongue } \\
\text { is French }\end{array}$ & $\begin{array}{c}0.186 * * * \\
(0.038)\end{array}$ & $\begin{array}{c}0.079 * * * \\
(0.017)\end{array}$ & $\begin{array}{l}0.126^{* *} \\
(0.063)\end{array}$ & $\begin{array}{l}0.074 * \\
(0.042)\end{array}$ \\
\hline $\begin{array}{l}\text { Father's mother tongue } \\
\text { is neither French nor } \\
\text { English }\end{array}$ & $\begin{array}{l}-0.012 \\
(0.019)\end{array}$ & $\begin{array}{l}-0.011 \\
(0.021)\end{array}$ & $\begin{array}{l}-0.004 \\
(0.029)\end{array}$ & $\begin{array}{l}-0.001 \\
(0.033)\end{array}$ \\
\hline $\begin{array}{l}\text { Mother's education - } \\
\text { Elementary or less }\end{array}$ & $\begin{array}{c}0.014 \\
(0.028)\end{array}$ & $\begin{array}{c}0.013 \\
(0.036)\end{array}$ & $\begin{array}{c}0.077 \\
(0.050) \\
\end{array}$ & $\begin{array}{c}0.086 \\
(0.066)\end{array}$ \\
\hline $\begin{array}{l}\text { Mother's education - } \\
\text { secondary without grad. }\end{array}$ & $\begin{array}{l}-0.0002 \\
(0.013)\end{array}$ & $\begin{array}{l}-0.004 \\
(0.016)\end{array}$ & $\begin{array}{c}0.019 \\
(0.031) \\
\end{array}$ & $\begin{array}{c}0.019 \\
(0.038) \\
\end{array}$ \\
\hline $\begin{array}{l}\text { Mother's education - } \\
\text { post-secondary }\end{array}$ & $\begin{array}{l}0.0002 \\
(0.012)\end{array}$ & $\begin{array}{l}-0.0007 \\
(0.012)\end{array}$ & $\begin{array}{l}0.0001 \\
(0.021)\end{array}$ & $\begin{array}{l}-0.008 \\
(0.023)\end{array}$ \\
\hline $\begin{array}{l}\text { Mother's education - } \\
\text { university }\end{array}$ & $\begin{array}{c}0.027 \\
(0.021)\end{array}$ & $\begin{array}{c}0.021 \\
(0.017)\end{array}$ & $\begin{array}{l}-0.039 \\
(0.044)\end{array}$ & $\begin{array}{l}-0.062 \\
(0.040)\end{array}$ \\
\hline $\begin{array}{l}\text { Father's education - } \\
\text { Elementary or less }\end{array}$ & $\begin{array}{l}-0.030 \\
(0.022)\end{array}$ & $\begin{array}{l}-0.041^{*} \\
(0.024)\end{array}$ & $\begin{array}{l}-0.015 \\
(0.054)\end{array}$ & $\begin{array}{l}-0.0001 \\
(0.066)\end{array}$ \\
\hline $\begin{array}{l}\text { Father's education - } \\
\text { secondary without grad. }\end{array}$ & $\begin{array}{l}-0.024 * \\
(0.014)\end{array}$ & $\begin{array}{l}-0.032 * \\
(0.017)\end{array}$ & $\begin{array}{c}0.014 \\
(0.031)\end{array}$ & $\begin{array}{c}0.018 \\
(0.037)\end{array}$ \\
\hline $\begin{array}{l}\text { Father's education - } \\
\text { post-secondary }\end{array}$ & $\begin{array}{l}-0.003 \\
(0.013) \\
\end{array}$ & $\begin{array}{l}-0.005 \\
(0.013) \\
\end{array}$ & $\begin{array}{l}-0.015 \\
(0.025) \\
\end{array}$ & $\begin{array}{l}-0.019 \\
(0.025) \\
\end{array}$ \\
\hline $\begin{array}{l}\text { Father's education - } \\
\text { university }\end{array}$ & $\begin{array}{c}0.029 \\
(0.021) \\
\end{array}$ & $\begin{array}{c}0.021 \\
(0.016) \\
\end{array}$ & $\begin{array}{c}-0.014 \\
(0.037)\end{array}$ & $\begin{array}{l}-0.033 \\
(0.32) \\
\end{array}$ \\
\hline \multicolumn{5}{|l|}{ Annual mother' Income } \\
\hline $10,000-14,999$ & $\begin{array}{c}0.003 \\
(0.012)\end{array}$ & $\begin{array}{l}0.0005 \\
(0.015)\end{array}$ & i.v. & i.v. \\
\hline $15,000-19,999$ & $\begin{array}{c}0.018 \\
(0.013)\end{array}$ & $\begin{array}{c}0.017 \\
(0.015)\end{array}$ & i.v. & i.v. \\
\hline $20,000-29,999$ & $\begin{array}{l}0.024 * \\
(0.013)\end{array}$ & $\begin{array}{l}0.023 * \\
(0.014)\end{array}$ & i.v. & i.v. \\
\hline $30,000-39,999$ & $\begin{array}{c}0.047 * * * \\
(0.017) \\
\end{array}$ & $\begin{array}{c}0.044 * * * \\
(0.015) \\
\end{array}$ & i.v. & i.v. \\
\hline 40,000 or more & $\begin{array}{c}0.038^{* * *} \\
(0.012)\end{array}$ & $\begin{array}{c}0.035 * * * \\
(0.011)\end{array}$ & i.v. & i.v. \\
\hline \multicolumn{5}{|l|}{ Annual father's income } \\
\hline $10,000-14,999$ & $\begin{array}{c}-0.043 * * \\
(0.021)\end{array}$ & $\begin{array}{l}-0.043 * \\
(0.026)\end{array}$ & i.v. & i.v. \\
\hline $15,000-19,999$ & $\begin{array}{c}0.002 \\
(0.027) \\
\end{array}$ & $\begin{array}{r}0.007 \\
(0.026) \\
\end{array}$ & i.v. & i.v. \\
\hline 20,000-29,999 & $\begin{array}{l}-0.028 \\
(0.019)\end{array}$ & $\begin{array}{l}-0.029 \\
(0.020)\end{array}$ & i.v. & i.v. \\
\hline $30,000-39,999$ & $\begin{array}{l}-0.015 \\
(0.020)\end{array}$ & $\begin{array}{l}-0.015 \\
(0.021)\end{array}$ & i.v. & i.v. \\
\hline
\end{tabular}




\begin{tabular}{|l|c|c|c|c|}
\hline \multicolumn{1}{|c|}{40,000 or more } & $\begin{array}{c}0.003 \\
(0.018)\end{array}$ & $\begin{array}{c}0.004 \\
(0.018)\end{array}$ & i.v. \\
\hline $\begin{array}{l}\text { Receipt of social } \\
\text { assistance }\end{array}$ & $\begin{array}{c}-0.002 \\
(0.013)\end{array}$ & $\begin{array}{c}-0.002 \\
(0.016)\end{array}$ & i.v. & i.v. \\
\hline $\begin{array}{l}\text { Receipt of employment } \\
\text { insurance }\end{array}$ & $\begin{array}{c}-0.002 \\
(0.010)\end{array}$ & $\begin{array}{c}-0.002 \\
(0.011)\end{array}$ & i.v. & i.v. \\
\hline Intercept & $\begin{array}{c}0.006 \\
(0.025)\end{array}$ & & $-0.565^{* *}$ \\
$(0.229)$ & \\
\hline Sample Size & 12010 & 12010 & 3671 & 3671 \\
\hline $\begin{array}{l}\text { P value of the } \\
\text { endogenous test of the } \\
\text { reading score }\end{array}$ & & & 0.00 & \\
\hline $\begin{array}{l}\text { F value and p value of } \\
\text { the test of the quality of } \\
\text { the instruments }\end{array}$ & & & $\mathrm{F}=4.95$ & \\
\hline
\end{tabular}

Note:

1. Children in French language schools who are not in language immersion programs are excluded from the sample.

2. Controls for child's age, residence in a rural area, size of urban area of residence and region of residence are also included in the model. The hyperactivity score with higher values indicating more hyperactive of the child is also included in the regression in columns (1) and (2) of Table 24 , the estimates on the hyperactivity is close to zero and insignificantly different from zero at the conventional levels.

3. Standard errors are in round brackets. Statistical significance denoted by $* * *, * *$ and $*$ for the one, five and ten percent levels, respectively.

4. The mother tongue language is defined by the language first learned at home and still understood by the parent.

5. The default income variable is less than $\$ 10,000$ annually.

6. The receipt of social assistance and employment insurance variables respectively indicate whether the respondent received any social assistance and provincial income supplements, and employment insurance in the past 12 months.

\subsection{The attrition of French immersion programs}

In this section, we investigate attritions of French immersion participations by examining potential factors that could be related to decisions to transfer out of French immersion programs. In particular, we try to isolate the relationship between children's behavioral problems and their departure from French immersion programs. So far, we have shown some statistical evidence which indicates that children in French immersion programs have a significantly lower mean hyperactivity score, although the regression results do not show any significant relationship 
between children's behavioral problems and their enrollment in French immersion. However, as they advance to higher grades in these programs, children might develop some new types of behavioral problems, or reveal their original (subtle) ones. These behavioral problems could affect a French immersion attrition decision through two channels: 1) lower academic achievements that have resulted from a behavioral disorder will drive children to drop out of relatively competitive French immersion programs; and 2) the moral hazard hypothesis that speculates teachers in French immersion programs might tend to persuade "problem" students to transfer into normal English programs in order to keep the class easy to manage and thus reduce their corresponding workloads.

We also speculate that the gender of the teacher in French immersion might matter in affecting dropout decisions of children with behavioral problems. Hyperactive students might get along better with male teachers than female teachers. In this case, they might be more likely to stay in French immersion if they have male teachers in the program. Another case is that female teachers might be less tolerant to children with behavioral problems and thus tend to get "problem" students out of the programs. The investigation into effects of the interacted term of behavioral problems of students with the gender of teachers on the decision to leave French immersion programs is another step towards addressing speculation that French immersion teachers purposely drive these students out of the program in order to avoid heavy work efforts, regardless of children's academic outcomes.

We selected French immersion students aged four to 15 years old in Cycle 3 of the NLSCY and then tracked them every two years in subsequent cycles until Cycle 8 . However, the composition of our longitudinal sample is very complicated. Table 25 presents the sample dynamics from Cycle 3 to Cycle 4, broken down by children's ages. Column (1) of Table 25 
shows the proportion of French immersion children successfully tracked from Cycle 3 to Cycle 4. There are three sources leading to the longitudinal sample attritions from Cycle 3 to Cycle 4: 1) only four- year- old through 15-year-old children will be surveyed in each cycle. Due to the age restriction, those children who are older than 13 in Cycle 3 will not be eligible for the French immersion survey in Cycle 4 after two years; 2) the natural longitudinal attrition is around 20 percent in our sample due to no response and loss of contact; and 3) Cycle 3 of the NLSCY includes a cross-sectional sample of five-year-old children who were not planned to be longitudinally followed in later years. Correspondingly, the 5-year-old cross-sectional observations are dropped in our longitudinal analysis. We have noticed that the right censoring problem, which is caused by age restrictions on the survey and natural longitudinal attritions through time, is a challenge which needs to be properly addressed. Overall, the drop-out rate from French immersion programs from Cycle 3 to Cycle 4 is approximately 39 percent, with variations across ages ${ }^{82}$. It appears that children are more likely to transfer out of French immersion programs at ages seven, 10,13 and 14. There are also children who were not in French immersion in the previous cycle and then entered into the programs in one of later cycles. Column (3) of Table 25 shows that the new entrants account for around two percent of the original French immersion students from Cycle 3 to Cycle 4. We also include these children in our longitudinal analysis. In other words, we include every child who was in French immersion in one of the eight cycles and who was also tracked for at least two years in the data.

\footnotetext{
${ }^{82}$ According to the French immersion reports -Toronto district in 2011 (http://www.tdsb.on.ca/boardroom/bd_agenda/uploads/generalinfo/110603\%20FSL.PDF), the attrition rate from senior kindergarten through to grade eight from entry at 2003 is around $54 \%$. We are unable to find a national attrition rate for the French immersion program in the existing literature; however, the regional dropout rate does not deviate a lot from the attrition rate found in our sample.
} 
Table 25 - Dynamics of enrollment in French immersion programs from Cycle 3 to Cycle 4 broken down by ages

\begin{tabular}{|c|c|c|c|}
\hline Age in Cycle 3 & Merged sample (\%) & $\begin{array}{c}\text { In the merged sample, } \\
\text { out of F.I. (\%) }\end{array}$ & $\begin{array}{c}\text { In the merged sample, } \\
\text { new entrants to F.I. in } \\
\text { Cycle 4 }\end{array}$ \\
\hline & $(1)$ & $(2)$ & $(3)$ \\
\hline 4 & 76.4 & 25.7 & 8.6 \\
\hline 5 & $\mathbf{2 0 . 7}$ & 43.1 & 3.3 \\
\hline 6 & 81.9 & 33.7 & 1.7 \\
\hline 7 & 82 & 34.8 & 0.9 \\
\hline 8 & 81.5 & 43.4 & 2.0 \\
\hline 9 & 80.5 & 27.7 & 2.5 \\
\hline 10 & 76.8 & 30.5 & 3.3 \\
\hline 11 & 77.7 & 49.9 & 0.9 \\
\hline 12 & 78.6 & 50.3 & 1.8 \\
\hline 13 & 73.7 & 38.1 & 3.0 \\
\hline 14 & $\mathbf{1 0}$ & 37.2 & $\mathbf{0 . 0}$ \\
\hline 15 & n.a. & n.a. & n.a. \\
\hline 16 & n.a. & n.a. & n.a. \\
\hline Average & $\mathbf{6 7 . 2 5}$ & 38.7 & 2.4 \\
\hline
\end{tabular}

Notes.

1. Column (1) represents the proportion of children who were in Cycle 3 and were successfully tracked to Cycle 4 of the NLSCY.

2. Column (2) indicates the percentage of children who were enrolled in French immersion programs in Cycle 3 and were followed to Cycle 4 and were not in French immersion programs in Cycle 4.

3. Column (3) presents the proportion of children who were not in French immersion programs in Cycle 3 but entered in immersion programs in Cycle 4.

First, we employed a simple Logistic model to explore factors which might be attributable to decisions of transferring out of French immersion programs. If the latent variable $y_{i}^{*}=\boldsymbol{x}_{\boldsymbol{i}} \boldsymbol{\beta}+\varepsilon_{i} \geq 0, y=1$ implying that the child $i$ drops out of French immersion programs; if $y_{i}^{*}=\boldsymbol{x}_{\boldsymbol{i}} \boldsymbol{\beta}+\varepsilon_{i}<0, y=0$ implying that the child $i$ stays in French immersion programs within the longitudinal tracking window. The vector $\boldsymbol{x}_{i}$ contains a set of variables capturing the initial characteristics of children, their parents, and their teachers, which were taken at the time when children were firstly observed in French immersion programs in the survey. Following this setup, we assume 


$$
\operatorname{Pr}\left(y_{i}=1\right)=\frac{\exp \left(\boldsymbol{x}_{i} \boldsymbol{\beta}\right)}{1+\exp \left(\boldsymbol{x}_{i} \boldsymbol{\beta}\right)}
$$

By maximizing the log likelihood function, we got a vector of estimated coefficients $\widehat{\boldsymbol{\beta}}$, based on which we calculated the marginal effects and the results are listed in the first five columns of Table 26 with different choices of covariates in $\boldsymbol{x}$.

Overall, all the logit estimates show that female French immersion students are significantly less likely to drop out of the programs compared to their male classmates. The difference in the dropout rate between female and male French immersion students is around 11 percentage points. Without adding the interaction variable between the gender of teachers and the children's hyperactivity scores in the models, the estimates in the first three columns of Table 26 reveal a significant positive association between children's hyperactivity scores and their probabilities of transferring out of French immersion programs, implying that children with behavioral problems are more likely to drop out of the programs. In particular, a one standard deviation increase in the child's hyperactivity score is related to roughly eight percentage points $(0.024 * 3.30=0.08)$ increase in the propensity to leave French immersion programs. Although a significantly negative relationship is found between having a female teacher and the dropout probability of French immersion students as a whole, the story is different for children who have behavioral problems ${ }^{83}$. According to results in column (4) of Table 26, the propensity to transfer out of French immersion will increase by around 16 percentage points $(0.048 * 3.3=0.158)$ with one standard deviation increase in the hyperactivity score of children only when the children have female teachers. The equivalent effect does not exist for children who have male teachers.

\footnotetext{
${ }^{83}$ The teachers of children are identified through the education survey, which is answered by the teacher. We treat those teachers who responded to the survey as the ones who are mainly responsible for the children and are most likely to interact with children frequently.
} 
One might suspect that it is the academic performance that confounds the true connection between the behavioral issue of children and their likelihood of leaving French immersion programs. However, when we control for the mathematic score in our model, which could isolate the effect of academic performance of children from that of their behavioral issues ${ }^{84}$, we find from the results in column (5) of Table 26 that given a certain level of academic performance of children, the behavioral problem is still significantly positive related to the departure from French immersion if the children's teacher is female. This finding eliminates the possibility that children having behavioral problems drop out of French immersion programs because of their lower school performance caused by their behavioral problems. In sum, having trouble managing their behavior is a factor related to their departure from French immersion programs if they have a female teacher regardless of their school performance based on the logit regression results.

In order to address the right censoring problem existing in our sample, we use the semiparametric Cox proportional hazards model (Cox, 1972), and the conditional hazard is assumed to be

$$
h(t)=h_{0}(t) \exp (\boldsymbol{x} \boldsymbol{\beta})
$$

in which $\boldsymbol{x}$ contains the same set of variables as those in the logistic model (3). Estimating the model (4) will give us the estimated coefficients of $\boldsymbol{\beta} . h_{0}(t)$ is the baseline hazard which could not be directly identified by the Cox model and $t$ measures the duration time of children in the French immersion programs. Not only could the Cox model properly take the right censoring problem into account, it could also model the time contingency of hazard rate. However, it is worth pointing out that the French immersion variable employed in this analysis is not perfect for

\footnotetext{
${ }^{84}$ Since the reading test is only administered to children in Cycle 3 of NLSCY, we use the mathematics score rather than reading score to account for those children who enrolled in French immersion after Cycle 3.
} 
a duration model because we cannot obtain accurate information on when the child first enrolled in the French immersion programs. Therefore, we use the children's ages to approximate their duration in the programs by assuming that every immersion student entered the programs at four years old ${ }^{85}$. In the future, we hope to have a variable asking how long children have been in the French immersion programs in a national survey to measure the duration of French immersion.

The estimated hazard ratios of model (4) are reported in the last two columns of Table 26. The results are qualitatively similar to those from the logit estimations. In particular it shows that, at any duration, the risk of dropping out of French immersion programs decreases by around 25 percent for female students compared to male students, and decreases by roughly 50 percent for students having a female teacher relative to having a male teacher. In addition, female teachers tend to increase the hazard rate of transferring out of French immersion programs by around 33 percent for their students whose hyperactivity scores increase by one standard deviation. The effect still exists after we control for the mathematics score of the child.

Overall, both logit and Cox estimation results have implied that the gender of the teacher matters in terms of the decisions to drop out of French immersion if their students are more hyperactive. It is possible that female teachers might be more likely to transfer hyperactive students out of programs in order to reduce their workloads. The results also indicate that the decisions to leave French immersion programs depend on the children's behavior rather than their academic scores, which is against the traditional speculation that children who have trouble with their school work in the academically demanding French immersion programs might choose

\footnotetext{
${ }^{85}$ We could have treated the existence period of French immersion children observed in the longitudinal survey as their duration time in the programs; however, we think this method is not accurate considering that we have a large proportion of children who are above seven years old and who have probably been in the programs for a long time. Also, the biannual tracking frequency makes us unclear about when the children transferred out of French immersion programs from one cycle to another.
} 
to drop out. This could be because the children/parents have already self-selected them to the programs based on their academic ability at the program entry point. Combined with our early analysis on the program "streaming" effect, we can have a better understanding of who is actually in the French immersion programs. We conclude that children with higher academic ability, richer economic family backgrounds, one of parents having French as a mother-tongue language, and easy-to -manage behavior, are more likely to enter and complete the French immersion programs. Our findings serve as strong evidence on the "streaming" effect of French immersion programs. 
Table 26 - Estimation results of decisions of dropping out of French immersion programs

\begin{tabular}{|c|c|c|c|c|c|c|c|}
\hline & Logit & Logit & Logit & Logit & Logit & $\begin{array}{c}\text { Cox } \\
\text { (Hazard } \\
\text { ratios) } \\
\end{array}$ & $\begin{array}{c}\text { Cox } \\
\text { (Hazard } \\
\text { ratios) } \\
\end{array}$ \\
\hline & (1) & (2) & (3) & (4) & (5) & (6) & (7) \\
\hline $\begin{array}{l}\text { Female } \\
\text { children }\end{array}$ & $\begin{array}{c}-0.106^{* * *} \\
(0.041)\end{array}$ & $\begin{array}{c}-0.106^{* *} \\
(0.042)\end{array}$ & $\begin{array}{l}-0.106^{*} \\
(0.054)\end{array}$ & $\begin{array}{c}-0.109 * * \\
(0.053)\end{array}$ & $\begin{array}{c}-0.120 * * \\
(0.054)\end{array}$ & $\begin{array}{l}0.751^{*} \\
(0.127)\end{array}$ & $\begin{array}{c}0.756^{*} \\
(0.127)\end{array}$ \\
\hline $\begin{array}{c}\text { Hyperactivity } \\
\text { score }\end{array}$ & $\begin{array}{c}0.024 * * * \\
(0.006)\end{array}$ & $\begin{array}{c}0.021 * * * \\
(0.006)\end{array}$ & $\begin{array}{c}0.024 * * * \\
(0.008)\end{array}$ & $\begin{array}{l}-0.015 \\
(0.021)\end{array}$ & $\begin{array}{l}-0.019 \\
(0.021)\end{array}$ & $\begin{array}{l}1.019 \\
(0.047)\end{array}$ & $\begin{array}{c}1.008 \\
(0.049)\end{array}$ \\
\hline Math Score & No & $\begin{array}{l}-0.006 \\
(0.004)\end{array}$ & No & No & $\begin{array}{l}-0.005 \\
(0.006)\end{array}$ & No & $\begin{array}{c}0.984 \\
(0.018)\end{array}$ \\
\hline $\begin{array}{l}\text { Female } \\
\text { teachers }\end{array}$ & No & No & $\begin{array}{l}-0.125^{*} \\
(0.075)\end{array}$ & $\begin{array}{c}-0.309 * * * \\
(0.112)\end{array}$ & $\begin{array}{c}-0.301 * * * \\
(0.113)\end{array}$ & $\begin{array}{c}0.499 * * * \\
(0.130)\end{array}$ & $\begin{array}{c}0.486 * * * \\
(0.130)\end{array}$ \\
\hline $\begin{array}{c}\text { Female } \\
\text { teachers* } \\
\text { Hyperscore }\end{array}$ & No & No & No & $\begin{array}{c}0.048 * * \\
(0.023)\end{array}$ & $\begin{array}{c}0.050 * * \\
(0.023)\end{array}$ & $\begin{array}{l}1.094^{*} \\
(0.057)\end{array}$ & $\begin{array}{l}1.105^{*} \\
(0.059)\end{array}$ \\
\hline PMK income & Yes & Yes & Yes & Yes & Yes & Yes & Yes \\
\hline $\begin{array}{c}\text { PMK } \\
\text { education }\end{array}$ & Yes & Yes & Yes & Yes & Yes & Yes & Yes \\
\hline Constant & Yes & Yes & Yes & Yes & Yes & Yes & Yes \\
\hline $\mathrm{N}$ & 1124 & 1054 & 634 & 634 & 617 & 634 & 617 \\
\hline
\end{tabular}

\section{Notes.}

1. Children in French language schools who are not in language immersion programs are excluded from the sample.

2. Controls for the age of children, residence in a rural area, size of urban area of residence and province of residence are also included in all models.

3. The hyperactivity score ranges from 0 to 16 and was derived using a set of weighted items with higher value indicating the presence of hypoactive/inattentive behavior of the child.

4. Standard errors are in round brackets. Statistical significance denoted by $* * *, * *$ and $*$ for the one, five and ten percent levels, respectively. 


\subsection{Sensitivity analysis of the change of the teacher's gender}

Considering that the gender of the teacher could change across cycles of the NLSCY due to a change in the children's teacher, controlling for the initial gender of the teacher in our models might blur the real effects of the gender of the teacher on French immersion attrition. However, we are unable to capture the change of the gender of the teacher in our analysis because the gender of the teacher is only available in cycles three and four of the NLSCY while we track most French immersion children from cycle three through to cycle eight. Here, we conduct a sensitivity analysis to check whether our results are sensitive to the choice of the gender of the teacher taken from the initial year or from years closer to the time when the children make their dropout decisions.

In the first case, we only track French immersion students from cycle three through to cycle five; in the second case, we track them from cycle three through to cycle six; in the third case, we track them from cycle three through to cycle seven; and in the last case, we track them from cycle three through to cycle eight. In addition, in each case, the teacher's gender variable is taken from cycle four rather than cycle three for those children who are still in French immersion programs after cycle three. In the first two cases, since we only track children until cycles five and six, we assure that the gender of the teacher from cycle four are near the time when the decision of leaving French immersion is made. The cox model with the same model specification as that in column (7) of Table 26 is estimated for each above case and the results are respectively reported in Table 27.

The results listed in Table 27 are fairly consistent to those reported in column (7) of Table 26 with only one exception of the insignificance of all estimates in the first case, which could be due to the lack of variations from the short tracking period. Overall, the results do not 
alter much and are insensitive to whether the gender of the teacher is taken from years closer to when the children decide to leave the French immersion programs. Thus, there is no evidence to suggest that our conclusions that the hyperactive children are more likely to drop out of French immersion programs when they have female teachers are biased by controlling for the gender of the earlier teacher.

Table 27 - Sensitivity analysis of the cox duration estimates to the choice of the gender of the teacher

\begin{tabular}{|c|c|c|c|c|}
\hline & $\begin{array}{c}\text { Cox } \\
\text { (Hazard ratios) } \\
\text { Cycles 3-5 }\end{array}$ & $\begin{array}{c}\text { Cox } \\
\text { (Hazard ratios) } \\
\text { Cycles 3-6 }\end{array}$ & $\begin{array}{c}\text { Cox } \\
\text { (Hazard ratios) } \\
\text { Cycles 3-7 }\end{array}$ & $\begin{array}{c}\text { Cox } \\
\text { (Hazard ratios) } \\
\text { Cycles 3-8 }\end{array}$ \\
\hline & $(1)$ & $(2)$ & $(3)$ & $(4)$ \\
\hline Female children & 1.298 & 0.830 & $0.754^{*}$ & $0.758^{*}$ \\
& $(0.302)$ & $(0.153)$ & $(0.130)$ & $(0.127)$ \\
\hline $\begin{array}{c}\text { Hyperactivity } \\
\text { score }\end{array}$ & 1.019 & 0.984 & 0.980 & 0.992 \\
\hline Math Score & $(0.084)$ & $(0.052)$ & $(0.050)$ & $(0.048)$ \\
\hline Female teachers & 0.962 & 0.977 & 0.982 & 0.983 \\
& $(0.030)$ & $(0.021)$ & $(0.018)$ & $(0.018)$ \\
\hline Female teachers* & 0.676 & $0.474^{* * *}$ & $0.434^{* * *}$ & $0.449^{* * *}$ \\
Hyper score & $(0.290)$ & $(0.132)$ & $(0.114)$ & $(0.116)$ \\
\hline PMK income & Yes & $0.125^{*}$ & $1.143^{* *}$ & $1.130^{* *}$ \\
& Yes & $(0.066)$ & $(0.065)$ & $(0.061)$ \\
\hline PMK education & Yes & Yes & Yes \\
\hline Constant & Yes & Yes & Yes & Yes \\
\hline N & 542 & 589 & 617 & 617 \\
\hline
\end{tabular}

Notes.

1. Children in French language schools who are not in language immersion programs are excluded from the sample.

2. Controls for the age of children, residence in a rural area, size of urban area of residence and province of residence are also included in all models.

3. The hyperactivity score ranges from 0 to 16 and was derived using a set of weighted items with higher value indicating the presence of hypoactive/inattentive behavior of the child.

4. The variable of the teacher's gender is from the cycle four for children who are still in French immersion programs after cycle three. 
5. Standard errors are in round brackets. Statistical significance denoted by ***,** and * for the one, five and ten percent levels, respectively.

\subsection{Conclusions}

The debate over the existence and expansion of school choice in the Canadian Education system has raised many important questions related to the efficiency and equity of public education. This paper has analyzed one aspect of school choice using the case of French Immersion programs in Canada. Empirical evidence has been presented on the issue of "streaming" or the selection of children with high ability and from high socio-economic families into French Immersion programs. Additionally, the selection continues through French immersion attrition which is based on children's behavior.

Estimates from a structural model of French Immersion enrollment indicate that both family preferences (proxied by the parents' having French as a mother tongue) as well as the child's performance in reading are important determinants of the decision to enroll a child in French Immersion. In particular, a one standard deviation increase in a child's reading score is associated with an increase in the probability of French Immersion enrollment by 25 to 34 percentage points.

Estimations of logistic and Cox duration models have shown that children's behavioral issues (measured by hyperactivity scores) play a significant part in influencing whether children are able to complete the programs, while the academic performance seems irrelevant in French immersion dropout decisions due to the possibility that the selection based on the academic ability of children may have occurred at the program entry point by parents. Interestingly, the gender of the teacher matters in determining the existence of a significant negative relationship between the hyperactivity scores of children and their probability of transferring out of French immersion. The equivalent relationship does not exist if the children have a male teacher. It 
raises the question of whether female teachers try to reduce their workloads by transferring hyperactive students out of the French Immersion Program.

The results indicate that "streaming" of children by academic ability, socio-economic status and behavioral problems has occurred with respect to Canada's French Immersion Program. There are two sources for "streaming": 1) initial self-selection into the programs based on academic ability; and 2) French immersion attrition based on children's behavior. The first source might not be bad considering that French immersion is an academically competitive program, while the second source is a problem which needs to be recognized and properly addressed by policy makers. Overall, this paper lends support to the argument that school program choice within the public school system may create privileged enclaves within the public school system, leading to different types of education with differing levels of quality. 


\subsection{References}

Allen, Mary (2004) "Reading achievement of students in French immersion programs." Educational Quarterly Review, Volume 9, number 4, pages 25-30. Catalogue 81-003XIE.

Christofides, L. N. and Swidinsky, Robert (2010) "The Economic Returns to the Knowledge and Use of a Second Official Language: English in Quebec and French in the Rest-ofCanada." Canadian Public Policy, 36 (2), pg. 137-158.

Cox, D. R. (1972) "Regression models and life-tables (with discussion)." Journal of the Royal Statistical Society, Series B 34: 187-220.

Epple, D. and R.E. Romano (1998) 'Competition Between Private and Public Schools, Vouchers, and Peer-Group Effects,' American Economic Review, 88(1): 33-62.

Gallant, A. R. (1987) Nonlinear Statistical Models. New York: Wiley.

Gardner, R., Masgoret, A.-M., and Tremblay, Paul (1999) "Home Background Characteristics and Second Language Learning.” Journal of Language and Social Psychology, 18 (4), pg. 419-437.

Heckman, James J. and Thomas E. MaCurdy (1985) "A Simultaneous Equations Linear Probability Model," Canadian Journal of Economics, 18(1):28-37.

Hoxby, Caroline M. (2000) "Does Competition among Public Schools Benefit Students and Taxpayers?" American Economic Review, 90(5): 1209-38.

Hoxby, Caroline M. (1999) 'The productivity of Schools and other Local Public Goods Producers,' Journal of Public Economics, 74: 1-30.

Lawton, Stephen B. (2001) "Educational Finance and School Choice in the United States and Canada," Occasional Paper No. 17, National Center for the Study of Privatization in Education, Teachers College, Columbia University, March.

Lazaruk, Wally (2007) "Linguistic, Academic, and Cognitive Benefits of French Immersion." Canadian Modern Language Review, 63 (5), pg. 605-627.

MaCurdy, Thomas E. (1981) “An Empirical Model of Labor Supply in a Life-Cycle Setting," Journal of Political Economy, 89(6): 1059-85.

Makropoulos, J. (2009) "Gaining Access to Late French-Immersion Programs: Class-Based Perspectives of Canadian Students in an Ottawa High School." Bilingual Research Journal, 32 (3), pg. 317-330. 
Muircheartaigh, Jonathan Ó and Hickey, Tina (2008) "Academic Outcome, Anxiety and Attitudes in Early and Late Immersion in Ireland." International Journal of Bilingual Education and Bilingualism, 11 (5), pg. 558-576.

Newey, W. K. (1987) "Efficient estimation of limited dependent variable models with endogenous explanatory variables." Journal of Econometrics 36: 231-250.

Rehner, Katherine (2011) "The sociolinguistic competence of former immersion students at the post-secondary level: the case of lexical variation." International Journal of Bilingual Education and Bilingualism, 14 (3), pg. 243-259

Stock, J.H., Wright, J.H. and Yogo, M. (2002) “A survey of weak instruments and weak identification in generalized method of moments." Journal of Business and Economic Statistics 20: 518-529.

Swain, Merrill (2000) "French Immersion Research in Canada: Recent Contributions to SLA and Applied Linguistics," Annual Review of Applied Linguistics, volume 20, 199-212.

Yoon, Ee-Seul and Gulson, K.N. (2010) "School choice in the stratilingual city of Vancouver." British Journal of Sociology of Education, 31 (6), pg. 703-718. 


\section{Conclusions}

Due to the availability of the rich longitudinal Canadian dataset of children and youth, many useful conclusions have been drawn from a series of empirical analyses on school performance, bullying behaviour, and language immersion of children in Canada. Next, I will list the main conclusions from each chapter of this Ph.D. thesis.

From the first chapter, we find that while children with an immigrant parent whose mother tongue is neither English nor French (NEF) have much lower vocabulary scores before elementary school, adolescent NEF children have similar scores with children of native-born parents in all tests. Children with an immigrant parent whose first language is either English or French have much higher test scores than those of NEF children before elementary school, but lower numeracy scores later at ages 20 to 21 .

In the second chapter, the empirical results support the predictions of the model: not only does the tougher parental response to child bullying lead to lower probability of bullying, but also different parenting styles/strategies are associated with different likelihoods of child bullying. One of the major gender differences is that a girl's bullying behavior is easier to inhibit through stricter parenting than that of a boy.

Consistent with our proposed bullying habit formation hypothesis, the empirical results in the third chapter show that early bullying detection and intervention contributes to a positive suppression effect on it of around 5 to 8 percent for all children based on different empirical identification strategies.

In the last chapter, evidence is found that children in French Immersion have higher scores in reading tests, that their parents are more likely to have the French language as their mother tongue and that they are generally from families with higher incomes. The results further 
indicate that a one standard deviation improvement in a child's reading score is associated with 25 to 34 percentage points increase in the child's probability of being enrolled in French Immersion. Furthermore, children with behavioral problems that have higher hyperactivity scores are found to be more likely to drop out of the programs only if they have a female teacher in the program. In particular, having female teachers in the French immersion program is associated with a higher propensity to drop out of the programs by 33 percent for students whose hyperactivity scores increase by one standard deviation according to the Cox regression results. This relationship still exists after the academic performance of the children is controlled for in the model, implying that being hyperactive is a problem which leads to decisions to drop out of French immersion. 